
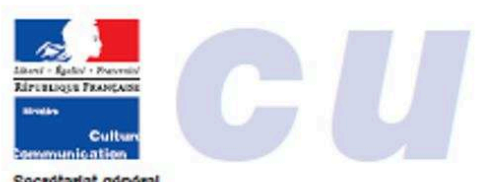

Secretarlat genera

Service de la

polltiques cultureites

et de rinnovation

Departement

des etardes,

de la prospective

et des statstiques

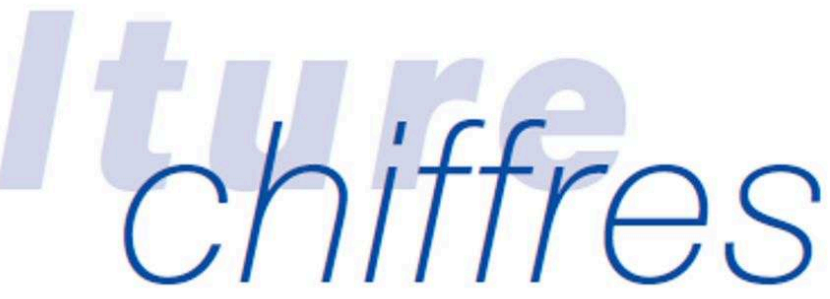

182, rue Saint-Honoré, 75033 Paris cedex 01

\& $0140157917-$ - 0140157999

\title{
Les dépenses culturelles des collectivités territoriales en 2010 : 7,6 milliards d'euros pour la culture
}

\author{
Jean-Cédric Delvainquière*, François Tugores ${ }^{*}$, Nicolas LAROCHE**, Benoît JouRdan**
}

Local and regional authority cultural expenditure in 2010:

$€ 7.6$ bn going to culture

En 2010, les dépenses culturelles des collectivités territoriales (régions, départements, communes de plus de 10000 habitants et leurs groupements, Dom compris) se sont élevées à 7,6 milliards d'euros soit 118 euros par habitant. Les communes et leurs groupements assument près des trois quarts $(73 \%)$ de ces dépenses (respectivement 4,6 milliards et 1 milliard d'euros), les départements $18 \%$ (soit 1,4 milliard) et les régions $9 \%(0,7$ milliard). Ces dépenses représentent en moyenne une part plus élevée des dépenses totales des communes et de leurs groupements $(8,0 \%$ et $7,0 \%)$ que de celles des régions $(2,7 \%)$ et des départements $(2,1 \%)$

Par rapport à 2006, année de la précédente édition de l'enquête, les dépenses culturelles territoriales ont progressé de près de $10 \%$ soit $+2,3 \%$ par an en France métropolitaine. Progressant quasiment au même rythme que l'inflation $(+1,4 \%$ par an), les dépenses culturelles des communes ont plutôt stagné en volume, mais le nombre de groupements de communes actifs dans le domaine culturel a progressé et leurs dépenses culturelles ont augmenté de $6 \%$ par an. L'évolution des dépenses culturelles des départements et des régions est légèrement supérieure à l'inflation pour les départements (+ $1,8 \%$ par an), plus significative pour les régions ( $+4,5 \%$ par an) et tient surtout à une forte progression en début de période. L'effort culturel des départements et des régions s'est ensuite contracté en raison d'une plus forte progression des dépenses totales, liée aux transferts de compétences.

Le soutien à l'expression artistique et aux activités culturelles regroupe près de $60 \%$ des dépenses des communes et de leurs groupements (4,3 milliards d'euros), en grande partie des dépenses de fonctionnement $(85 \%)$. Départements et régions se sont investis de manière croissante dans le patrimoine, qui représente $59 \%$ des dépenses culturelles départementales et $23 \%$ des dépenses culturelles régionales en 2010.

Plus impliqué dans la gestion souvent directe de services et d'équipements culturels de proximité (bibliothèques, conservatoires et écoles d'art, musées, etc. ), le bloc communal consacre plus de la moitié de ses dépenses culturelles de fonctionnement à la rémunération des personnels, pour près de 2,5 milliards d'euros. Ce sont toutefois les subventions culturelles de fonctionnement qui ont le plus progressé ( $+5 \%$ par an pour les communes métropolitaines entre 2006 et 2010), en particulier au bénéfice des théâtres et des arts plastiques.

A l'inverse, les subventions représentent plus de $80 \%$ des dépenses culturelles des régions. Elles soutiennent, pour leur fonctionnement, des bénéficiaires de droit privé, notamment associatifs, et l'effort d'investissement culturel des communes et de leurs groupements.

${ }^{\star}$ DePS, ${ }^{\star x}$ SII/Forum pour la gestion des villes et des collectivités territoriales. 


\section{Les dépenses culturelles des collectivités territoriales en $2010:$ 7,6 milliards d'euros pour la culture}

Local and regional authority cultural expenditure in 2010 : $€ 7.6 \mathrm{bn}$ going to culture

Jean-Cédric Delvainquière, François Tugores, Nicolas Laroche et Benoit Jourdan

Éditeur : Département des études, de la prospective et des statistiques

Lieu d'édition : Paris

Année d'édition : 2014

Date de mise en ligne : 21 septembre 2015

Collection : Culture chiffres

ISBN électronique : 9782111398177

\section{Soneratition}

http://books.openedition.org

\section{Édition imprimée}

Date de publication : 1 mars 2014

Nombre de pages : 32

\section{Référence électronique}

DELVAINQUIĖRE, Jean-Cédric ; et al. Les dépenses culturelles des collectivités territoriales en 2010 : 7,6 milliards d'euros pour la culture. Nouvelle édition [en ligne]. Paris : Département des études, de la prospective et des statistiques, 2014 (généré le 25 avril 2021). Disponible sur Internet : <http:// books.openedition.org/deps/474>. ISBN : 9782111398177. 

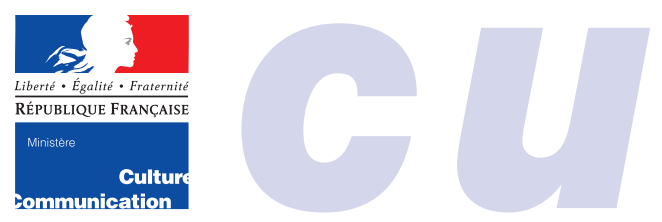

Secrétariat général

Service de la

coordination des

politiques culturelles

et de l'innovation

Département

des études,

de la prospective

et des statistiques

\title{
Les dépenses culturelles des collectivités territoriales en 2010 : 7,6 milliards d'euros pour la culture
}

\author{
Jean-Cédric Delvainquière*, François Tugores", Nicolas LaRoCHE**, Benoît Jourdan***

\section{Local and regional authority cultural expenditure in 2010: $€ 7.6 \mathrm{bn}$ going to culture}

En 2010, les dépenses culturelles des collectivités territoriales (régions, départements, communes de plus de 10000 habitants et leurs groupements, DOM compris) se sont élevées à 7,6 milliards d'euros soit 118 euros par habitant. Les communes et leurs groupements assument près des trois quarts $(73 \%)$ de ces dépenses (respectivement 4,6 milliards et 1 milliard d'euros), les départements $18 \%$ (soit 1,4 milliard) et les régions $9 \%$ (0,7 milliard). Ces dépenses représentent en moyenne une part plus élevée des dépenses totales des communes et de leurs groupements $(8,0 \%$ et $7,0 \%)$ que de celles des régions $(2,7 \%)$ et des départements $(2,1 \%)$.

Par rapport à 2006, année de la précédente édition de l'enquête, les dépenses culturelles territoriales ont progressé de près de $10 \%$ soit $+2,3 \%$ par an en France métropolitaine. Progressant quasiment au même rythme que l'inflation (+ 1,4 \% par an), les dépenses culturelles des communes ont plutôt stagné en volume, mais le nombre de groupements de communes actifs dans le domaine culturel a progressé et leurs dépenses culturelles ont augmenté de $6 \%$ par an. L'évolution des dépenses culturelles des départements et des régions est légèrement supérieure à l'inflation pour les départements (+ 1,8\% par an), plus significative pour les régions (+ 4,5\% par an) et tient surtout à une forte progression en début de période. L'effort culturel des départements et des régions s'est ensuite contracté en raison d'une plus forte progression des dépenses totales, liée aux transferts de compétences.

Le soutien à l'expression artistique et aux activités culturelles regroupe près de $60 \%$ des dépenses des communes et de leurs groupements (4,3 milliards d'euros), en grande partie des dépenses de fonctionnement (85\%). Départements et régions se sont investis de manière croissante dans le patrimoine, qui représente $59 \%$ des dépenses culturelles départementales et $23 \%$ des dépenses culturelles régionales en 2010.

Plus impliqué dans la gestion souvent directe de services et d'équipements culturels de proximité (bibliothèques, conservatoires et écoles d'art, musées, etc. ), le bloc communal consacre plus de la moitié de ses dépenses culturelles de fonctionnement à la rémunération des personnels, pour près de 2,5 milliards d'euros. Ce sont toutefois les subventions culturelles de fonctionnement qui ont le plus progressé (+ $5 \%$ par an pour les communes métropolitaines entre 2006 et 2010), en particulier au bénéfice des théâtres et des arts plastiques.

À l'inverse, les subventions représentent plus de $80 \%$ des dépenses culturelles des régions. Elles soutiennent, pour leur fonctionnement, des bénéficiaires de droit privé, notamment associatifs, et l'effort d'investissement culturel des communes et de leurs groupements.

* DEPS, ** SFL/Forum pour la gestion des villes et des collectivités territoriales. 


\section{LES DÉPENSES CULTURELLES CONSOLIDÉES DES COLLECTIVITÉS TERRITORIALES}

\section{7,5 milliards d'euros de dépenses culturelles des collectivités territoriales métropolitaines}

Les dépenses et les recettes culturelles des collectivités territoriales sont ventilées selon les nomenclatures comptables en vigueur pour chaque type de collectivité ; l'enquête menée régulièrement par le ministère de la Culture auprès des régions, des départements, des groupements de communes et des communes de plus de 10000 habitants permet de collecter, redresser et agréger ces données pour estimer les dépenses au niveau national (voir annexe méthodologique, p. 23).

La dépense culturelle consolidée des collectivités territoriales métropolitaines en 2010 est estimée à 7,47 milliards d'euros (tableau 1), soit 119 euros par habitant si l'on rapporte cette somme à la population nationale. Ce montant est dit « consolidé » car il déduit du total des dépenses les transferts allant d'une collectivité à une autre, afin de ne pas les compter deux fois (encadré 1). Par rapport à 2006, cette dépense consolidée a augmenté de 9,6\% (graphique 1), soit 2,3\% par an en moyenne. Une fois prise en compte l'inflation, la dépense en volume a augmenté de $0,8 \%$ par an. Rapportée au nombre d'habitants, cette dépense en volume par habitant a augmenté de 0,3\% par an en moyenne depuis 2006.

\section{Grande stabilité de la répartition des dépenses par type de collectivités}

Cette évolution a très peu affecté les grands agrégats. Ainsi, les dépenses consolidées des régions ont augmenté plus vite que celles des autres collectivités, mais elles étaient limitées en 2006, et le restent en 2010 (8,8\% des dépenses consolidées de l'ensemble des collectivités). Le bloc des communes et des groupements de communes reste celui qui finance le plus largement les dépenses culturelles, malgré une légère baisse de son importance $(72,8 \%$ des dépenses contre 73,0 \% en 2006). Au sein de ce bloc, le mouvement le plus marqué est en fait le transfert de la part des communes $(59,6 \%$ en 2010 , soit 1,7 point de moins qu'en 2006) au profit des groupements $(13,2 \%$, soit 1,5 point de plus). L'analyse de l'évolution des dépenses de ces collectivités «communales» est, de ce fait, moins lisible que pour les autres collectivités. Pris ensemble, les dépenses consolidées de ces deux types de collectivités ont augmenté de 2,2\% par an, plutôt à destination de l'expression artistique et des activités culturelles $(+4,9 \%$ par an entre 2006 et 2010) et moins vers la conservation et la diffusion des patrimoines $(+1,3 \%)$. Enfin, la part des départements dans le financement de la culture se contracte très légèrement.

Tableau 1 - Dépenses culturelles consolidées des collectivités territoriales, 2010 (France métropolitaine)

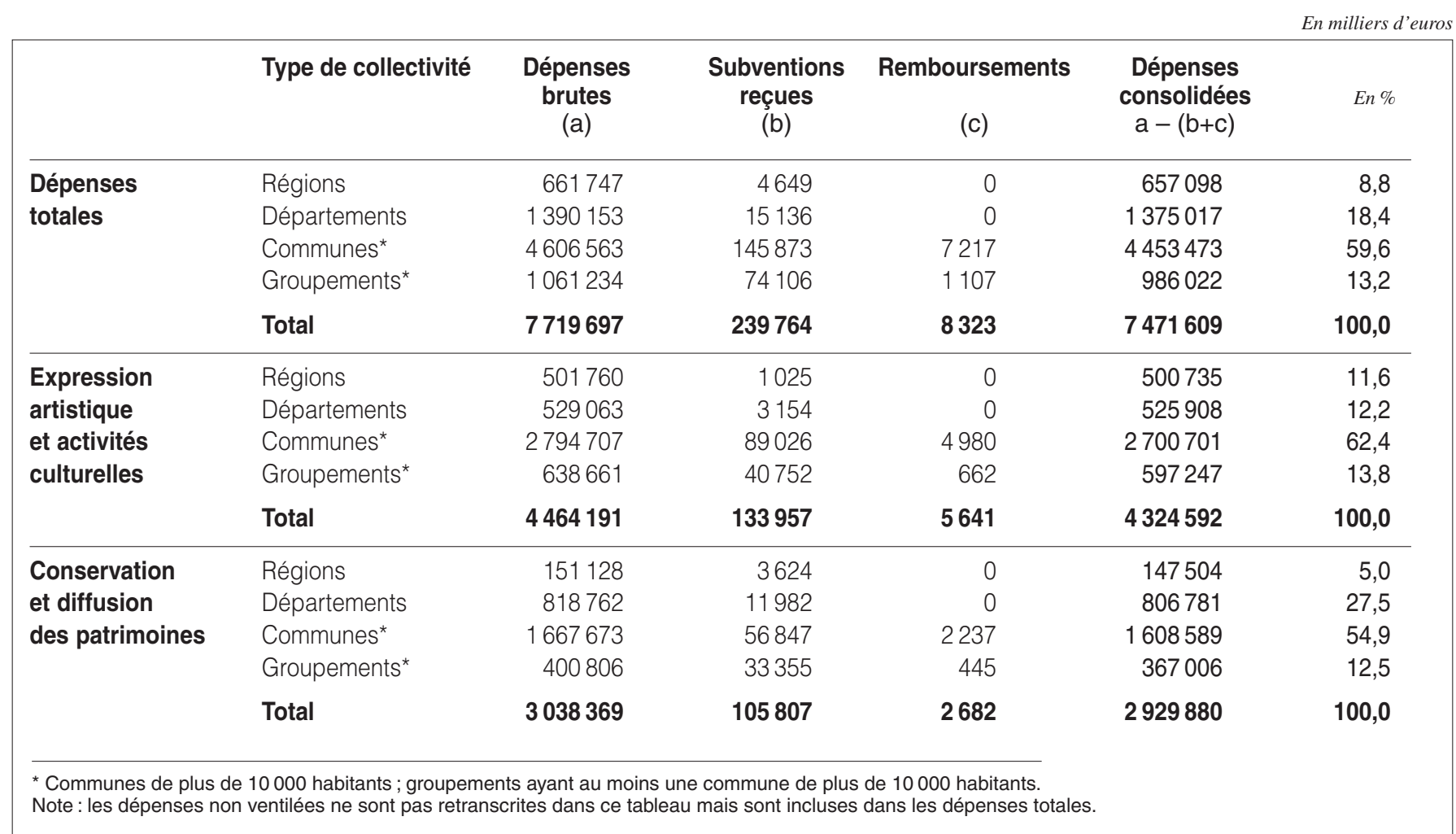


Graphique 1 - Répartition et évolution des dépenses culturelles consolidées entre 2006 et 2010 (France métropolitaine)

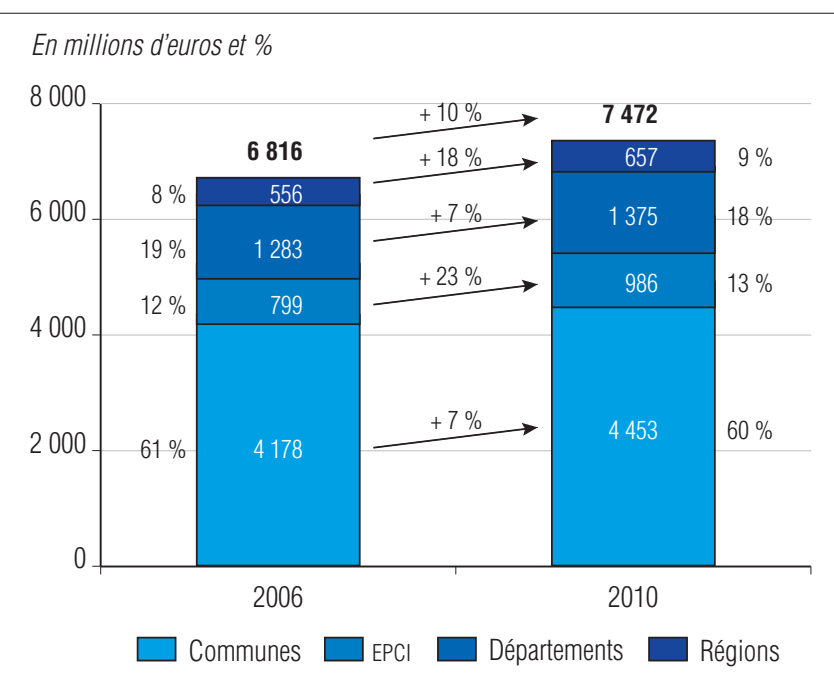

Lecture : en 2010, les dépenses consolidées des communes s'élèvent à 4453 millions d'euros. Elles représentent $60 \%$ des dépenses consolidées de l'ensemble des collectivités locales. Elles ont augmenté de $7 \%$ par rapport à 2006, où elles représentaient $61 \%$ des dépenses.

Source: Observatoire SFL-Forum/DEPS, Ministère de la Culture et de la Communication, 2014
Graphique 2 - Dépenses culturelles consolidées par domaine des collectivités territoriales, 2010 (France métropolitaine)

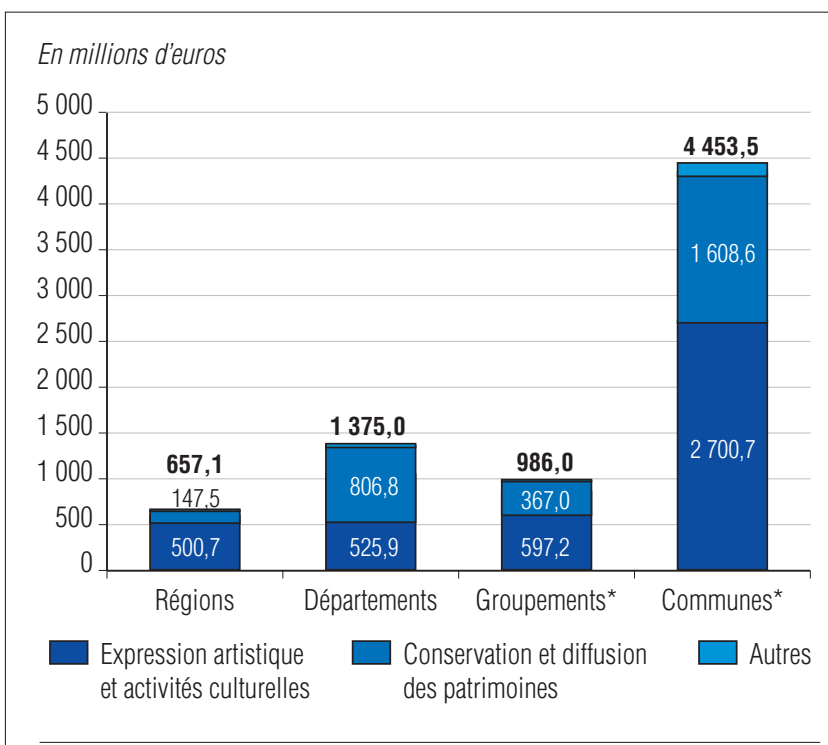

* Communes de plus de 10000 habitants ; groupements ayant au moins une commune de plus de 10000 habitants.

Source : Observatoire SFL-Forum/DEPS, Ministère de la Culture et de la Communication, 2014

\section{Compétences culturelles propres et interventions croisées des collectivités territoriales}

Ces dépenses et leurs évolutions sont à relier aux compétences propres à chacune des collectivités territoriales. Les lois de décentralisation encadrent en effet les domaines où elles peuvent agir. Tous les niveaux de collectivités territoriales sont ainsi soumis à l'obligation de consacrer $1 \%$ du montant des investissements dans la plupart des constructions publiques à l'insertion d'œuvres d'art et doivent assurer la garde et la conservation des objets mobiliers classés au titre des monuments historiques dont elles sont propriétaires, affectataires ou dépositaires. Tous les niveaux de collectivités territoriales sont compétents en matière d'enseignement public de la musique, de la danse et de l'art dramatique, et soutiennent également les écoles d'art (plus particulièrement les communes et intercommunalités mais sans exclusivité). Toutes les collectivités ont également reçu la compétence en matière d'archives, d'organisation et de financement de leurs musées ainsi que de leurs services archéologiques, le cas échéant. Elles ont en outre, depuis la loi du 13 août 2004, la possibilité de demander le transfert de la propriété de monuments classés ou inscrits, et des objets qu'ils renferment, appartenant à l'État ou au Centre des monuments nationaux et figurant sur une liste établie par décret en Conseil d'État. Sur les 176 monuments et sites transférables, le transfert de 65 monuments a été engagé. Sur les 65 monuments, 43 transferts ont été effectués au bénéfice des communes, 16 à celui des départements et 6 à celui des régions.

Les communes sont par ailleurs dotées d'une compétence spécifique en matière de lecture publique, pour l'or- ganisation et le financement des bibliothèques municipales ; elles peuvent également soutenir les salles de cinéma, et ont l'obligation d'entretenir les églises et chapelles construites avant 1907.

Les départements ont la charge particulière des bibliothèques départementales de prêts, qui assurent l'offre de livres dans les communes de moins de 10000 habitants. Ils assument également, au travers des archives départementales, la conservation des archives des services déconcentrés de l'État ou d'autres archives publiques et peuvent recevoir les archives municipales et régionales. La loi du 13 août 2004 leur a également confié la conservation du patrimoine rural non protégé et leur permet, à défaut des régions, et pour ceux qui le souhaitaient (ce fut le cas pour un département), d'expérimenter la gestion des crédits d'entretien et de restauration du patrimoine classé ou inscrit n'appartenant pas à l'État ou à ses établissements publics.

Les régions ont une responsabilité en matière de développement culturel et ont reçu la mission de l'inventaire général des monuments et richesses artistiques de la France, transférée par la loi du 13 août 2004.

Même si chaque collectivité territoriale a des compétences spécifiques, un même projet culturel peut être financé par plusieurs collectivités de types différents (communes, département, région). De plus, en vertu de la clause générale de compétence, chaque collectivité peut intervenir dans tous les domaines qui ne relèvent pas de la compétence exclusive d'une autre collectivité, ce qui, comme l'étude le confirme à nouveau, est largement le cas dans le champ culturel. Dans ce cadre, de nombreux projets et équipements culturels bénéficient de financements conjoints des différentes collectivités. 


\section{Augmentation des dépenses en faveur de l'expression artistique et des activités culturelles}

Si l'on considère maintenant la ventilation principale de la hausse des dépenses consolidées non plus par type de collectivité mais par grands domaines de dépense, l'augmentation est particulièrement forte pour l'expression artistique et les activités culturelles (création et diffusion des œuvres artistiques, enseignement des différentes disciplines, animation culturelle). Ce sont les communes et les groupements de communes qui contribuent le plus à cette augmentation. En contrepartie, les dépenses de conservation et de diffusion des patrimoines (entretien, protection et fonctionnement des musées, archives, bibliothèques, médiathèques) augmentent moins vite. Régions et départements s'investissent de manière croissante dans ces domaines.

Là encore, la répartition des dépenses par domaine d'intervention est malgré tout assez peu affectée par les évolutions constatées entre 2006 et 2010. Le domaine de l'expression artistique et des activités culturelles regroupe $58 \%$ des dépenses (4,32 milliards d'euros), en grande partie (85\%) des dépenses de fonctionnement. De leur côté les dépenses de conservation et de diffusion des patrimoines s'élèvent à 2,93 milliards d'euros; la part des dépenses de fonctionnement y est plus faible que pour celles orientées vers les activités culturelles, mais elle reste majoritaire (68\%). Enfin, une partie des dépenses culturelles (217 millions d'euros, soit $3 \%$ des dépenses culturelles consolidées) ne peut pas être classée dans un des deux domaines, soit par manque d'information, soit parce qu'elles leur sont transversales. Il s'agit essentiellement de dépenses de fonctionnement $(69 \%)$.

\section{Dépenses d'investissement : l'incidence du calendrier électoral}

Les dépenses d'investissement (1,66 milliard d'euros) représentent $22 \%$ des dépenses culturelles consolidées en métropole en 2010, et celles de fonctionnement $78 \%$ (5,81 milliards d'euros).

En 2010, les dépenses d'investissement sont légèrement inférieures à celles de 2006 (1,70 milliard d'euros). Alors que l'année 2006 correspond, pour le bloc communal (communes et groupements), à la sixième année du mandat municipal 2001-2008, l'année 2010 correspondait à la troisième année du mandat 2008-2014. Or, les premières années de mandat sont traditionnellement marquées par un niveau d'investissement inférieur à celui des dernières années de mandat. De plus, la mise en place, en 2009, du mécanisme de remboursement anticipé du fonds de compensation de la TVA, dans le cadre du plan de relance de l'économie, a pu conduire à une hausse des investissements culturels des collectivités locales en 2009 plus soutenue que celle qui aurait été enregistrée sans ce mécanisme. En effet, les collectivités qui s'engageaient, par convention, à accroître leurs investissements en 2009 par rapport à la moyenne de leurs investissements 2004-2007, bénéficiaient d'une avance du fonds de compensation leur permettant d'accroître leur capacité de financement : elles étaient donc fortement incitées à anticiper la réalisation de certains de leurs investissements sur l'année 2009. En 2010, les investissements des communes, et particulièrement des groupements de communes, en ont subi le contrecoup et se situent certainement en deçà de ce qu'ils auraient été s'ils avaient suivi une évolution tendancielle. De leur côté, les dépenses d'investissement des départements et des régions ont atteint, en 2010, un niveau supérieur à celui de 2006.

Les évolutions des dépenses d'investissement sont de ce fait assez délicates à commenter, et on privilégiera les commentaires sur les dépenses de fonctionnement, moins dépendantes du choix de l'année d'enquête.

\section{Encadré 1 - Traiter les flux croisés de subventions pour calculer les dépenses consolidées}

La simple addition des dépenses culturelles de chaque niveau de collectivité ne permet pas de donner une vision consolidée de l'engagement culturel de l'ensemble des collectivités. En effet, certaines interventions culturelles locales peuvent faire l'objet de financements croisés de la part de plusieurs collectivités et entraîner ainsi des doubles comptes. Aussi convient-il de prendre en compte, dans les comptes administratifs et dans l'enquête, les transferts ou subventions entre les différents niveaux de collectivités territoriales au titre de leur intervention en matière culturelle, et de neutraliser les doubles comptes.

\section{Les subventions}

Le premier type de flux croisé, le plus important, est lié au versement de subventions (qui intègrent ici également les fonds de concours). À titre d'exemple, si une région verse une subvention à une commune pour financer la construction d'une bibliothèque, cette subvention est enregistrée comme une dépense de la région et comme une recette de la commune. La construction de la bibliothèque figure également dans les dépenses de la commune pour son montant total alors qu'une partie du financement, en fait assurée par la région, est déjà comptabilisée au titre des dépenses de la région.

Le montant des subventions versées n'est pas égal à celui des subventions reçues. En effet, une partie des subventions versées peut bénéficier à des collectivités locales qui n'entrent pas dans le champ de l'enquête, comme les villes de moins de 10000 habitants et leurs EPCI à fiscalité propre. Ce sont donc les subventions reçues par les collectivités analysées qui ont été retenues pour réaliser le travail de consolidation. À cet égard:

- les collectivités du champ de l'étude peuvent bénéficier de subventions en provenance de villes et de groupements qui n'entrent pas dans le champ. Le biais est cependant faible puisque, à titre d'exemple, les subventions reçues par les villes et les EPCI en provenance d'autres collectivités du bloc communal, pour lesquelles il n'est pas possible de préciser si elles font partie ou non du champ de l'enquête (i.e. s'il s'agit de communes de plus de 10000 habitants, et pour les groupements, s'il s'agit ou non de groupements comportant au moins une commune membre de plus de 10000 habitants), ne représentent que $4,6 \%$ du total des subventions reçues par les villes et EPCI du champ;

- de manière plus significative, il peut exister des décalages temporels entre l'inscription d'une subvention dans le compte de la collectivité qui la verse et dans celui de la collectivité qui en bénéficie. Ainsi, à titre d'exemple, les subventions versées par les régions aux départements sont estimées à 8,7 millions d'euros en 2010 quand les subventions reçues par les départements en provenance des régions s'établissent à 12,9 millions d'euros. 
Le versement d'une subvention n'est pas le seul type de flux croisé qui peut exister entre deux collectivités. Ainsi, dans le cadre de la mutualisation de plus en plus forte des services et des moyens entre villes et EPCI, il peut exister des flux liés à la mise à disposition de personnel ou à des remboursements de frais. À titre d'exemple, si une ville met du personnel à la disposition de son groupement en vue de l'organisation d'un événement culturel, la charge de personnel figure en dépense dans le compte de la ville, mais une facturation est effectuée au groupement : cette dernière correspond alors à une dépense pour l'EPCI et à une recette pour la ville. Le financement de la dépense est donc en réalité porté par le groupement.

La nomenclature M14 permettant désormais d'identifier de tels montants, leur chiffrage a été tenté lors de l'exploitation de l'enquête. Les montants ainsi identifiés sont en fait très limités: ainsi, les groupements ont remboursé 7,2 millions d'euros (France métropolitaine) à leurs villes membres au titre de frais de personnel ou de frais pris en charge par ces dernières pour le compte de l'EPCI. À l'inverse, les villes ont remboursé 1,1 million d'euros (France métropolitaine) à leur EPCI au titre de frais de personnel ou de frais qu'ils ont eux-mêmes pris en charge. Au total, les dépenses culturelles de chaque type de collectivité ont été diminuées des subventions et des remboursements qu'elles ont perçus au titre de la culture. II en ressort que les doubles comptes entre collectivités ne représentent que 239,8 millions d'euros de subventions en 2010 pour la France métropolitaine (tableau A) et 8,3 millions d'euros pour les remboursements, soit au total $3,3 \%$ des dépenses culturelles consolidées, cette part s'élevant autour de $10 \%$ pour les seules dépenses d'investissement. Pour la métropole et les DOM, ces doubles comptes, subventions et remboursements, s'élevent à 257 millions d'euros.

\section{Tableau A - Subventions culturelles reçues par les} collectivités territoriales métropolitaines, 2010

\begin{tabular}{|l|cccc|}
\multicolumn{1}{c|}{} & \multicolumn{4}{c|}{ En millions d'euros } \\
\hline Subventions reçues & régions & départements villes et & Total \\
par les... & & \multicolumn{3}{c}{ groupements } \\
$\quad$ régions & - & 0,2 & 4,4 & $\mathbf{4 , 6}$ \\
départements & 12,9 & 0,1 & 2,2 & $\mathbf{1 5 , 1}$ \\
communes & 61,5 & 63,0 & 21,4 & $\mathbf{1 4 5 , 9}$ \\
groupements & 34,9 & 32,2 & 7,1 & $\mathbf{7 4 , 1}$ \\
Total & $\mathbf{1 0 9 , 2}$ & $\mathbf{9 5 , 5}$ & $\mathbf{3 5 , 1}$ & $\mathbf{2 3 9 , 8}$ \\
\hline
\end{tabular}

* Les nomenclatures budgétaires et comptables ne permettent pas de distinguer si une subvention reçue est versée par une commune ou par un groupement,les subventions en provenance de ces deux types de collectivité étant enregistrées dans un même article.

Source : Observatoire SFL-Forum/DEPS, Ministère de la Culture et de la Communication, 2014

\section{Les subventions culturelles entre collectivités territoriales sont stables par rapport à 2006 mais se distribuent différemment entre les niveaux}

En 2010, les subventions reçues par les collectivités métropolitaines en provenance d'autres collectivités s'établissent à 239,8 millions d'euros contre 230,8 millions d'euros en 2006. Les subventions reçues en 2010 sont donc en très faible augmentation sur quatre ans, mais la répartition des flux s'est quelque peu modifiée :

- les subventions proviennent bien davantage qu'en $2006 \mathrm{du}$ bloc communal (communes et groupements). Ce sont en effet maintenant $15 \%$ des subventions qui proviennent de ces collectivités locales, contre seulement $4 \%$ en 2006 . Les subventions versées aux régions par les communes et leurs groupements, quasi nulles en 2006, atteignent 4,4 millions d'euros en 2010. La progression est significative mais le montant reste malgré tout marginal. Ces subventions communales perçues par les régions sont concentrées sur un nombre très limité de régions et proviennent surtout des grandes villes;

- l'augmentation des subventions en provenance des collectivités communales s'est en fait orientée essentiellement vers les villes elles-mêmes : elles passent de 3,2 millions d'euros en 2006 à 21,4 millions en 2010. Cela semble en bonne partie lié au développement de l'intercommunalité culturelle pouvant conduire à des versements de subventions aux communes qui assurent le financement d'équipements ou d'événements culturels "d'intérêt communautaire" par exemple. Mais ce mouvement s'est fait en compensation des subventions versées par les départements, moins fortes en 2010 qu'en 2006 ;

- le montant des subventions versées par les régions aux autres collectivités territoriales reste stable : 109 millions d'euros. En revanche, la répartition des bénéficiaires a radicalement changé : la part des départements parmi les bénéficiaires des subventions régionales a doublé; celle des groupements de communes a augmenté de $50 \%$. Les subventions régionales aux communes sont en revanche passées de 81,6 millions d'euros en 2006 à 61,5 millions en 2010.

De façon assez logique compte tenu du développement de l'intercommunalité, au total, et toutes provenances confondues, les subventions croisées des collectivités territoriales ont surtout bénéficié aux groupements de communes et, dans une moindre mesure, aux départements, et ont baissé pour les villes.

\section{Graphique A - Subventions culturelles reçues par les collectivités territoriales métropolitaines, 2010}

En millions d'euros

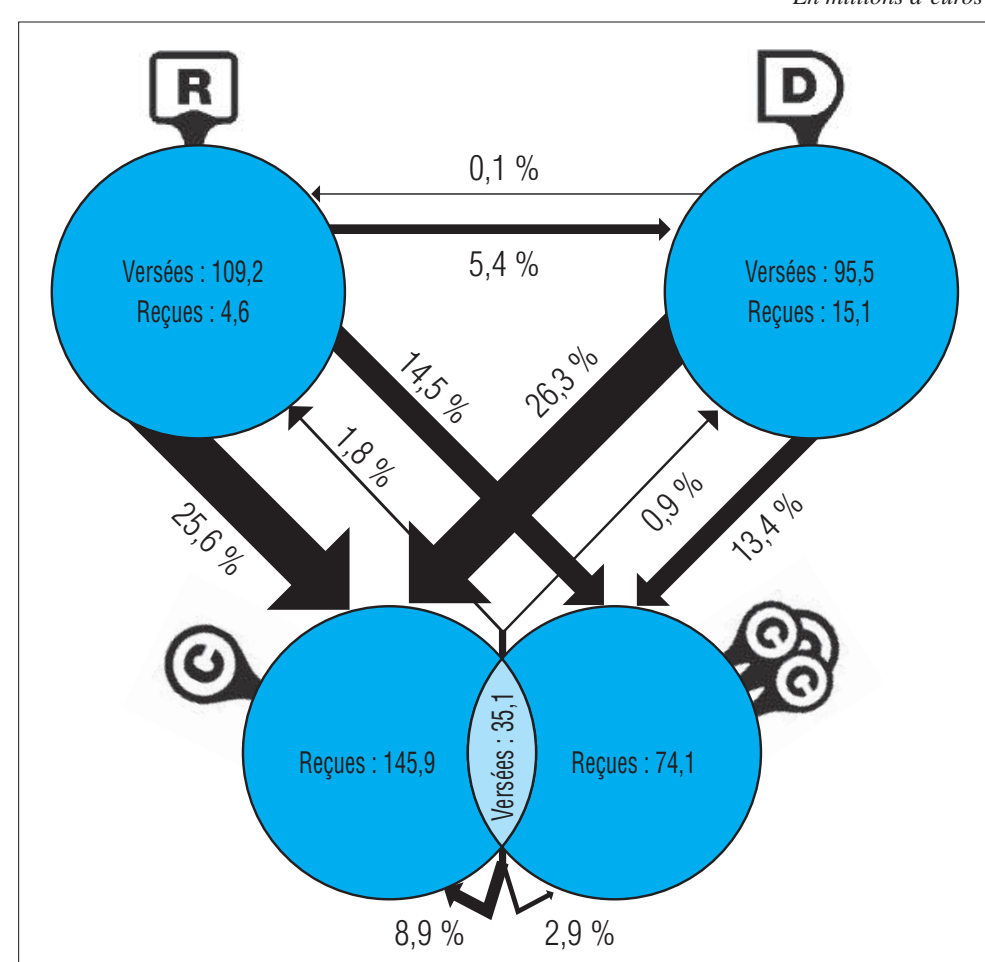

Note de lecture : les 61,5 millions d'euros versés par les régions aux communes représentent $25,63 \%$ du montant total des subventions entre collectivités ( 239,8 millions d'euros). 


\section{Dépenses culturelles consolidées} en métropole et dans les DOM :

\section{7,64 milliards d'euros}

Pour la première fois, l'édition 2010 de l'enquête sur les dépenses et les recettes culturelles des collectivités territoriales couvre les départements d'outre-mer (DOM). Leurs dépenses culturelles consolidées sont de 172 millions d'euros, l'essentiel en fonctionnement (140 millions d'euros, soit plus de $80 \%$ c'est-à-dire plus qu'en métropole) et le reste en investissement (32 millions d'euros). Au total, les dépenses culturelles consolidées des collectivités territoriales en métropole et dans les DOM sont estimées en 2010 à 7,64 milliards d'euros.

L'intercommunalité culturelle étant encore très limitée dans les territoires d'outre-mer, la part des dépenses cultu- relles assumées par les groupements y est très faible $(1 \%$ en fonctionnement, $3 \%$ en investissement). A contrario, celle des régions et des départements est plus élevée qu'en métropole : respectivement $18 \%$ et $22 \%$ en fonctionnement.

La conservation et la diffusion des patrimoines totalisent une part plus importante des dépenses culturelles qu'en métropole : $41 \%$ des dépenses de fonctionnement (contre $34 \%$ en métropole).

L'analyse des évolutions n'étant possible que sur le champ métropolitain, on privilégiera ce contour dans le reste de l'étude, y compris pour les résultats portant sur 2010. Les résultats des collectivités d'outre-mer et la comparaison avec ceux de métropole seront décrits dans des encadrés spécifiques.

\section{Encadré 2 - Dépense nette des collectivités : le poids des recettes spécifiquement culturelles}

Les subventions versées entre collectivités ont été neutralisées pour calculer une dépense de l'ensemble des collectivités, c'est la dépense dite «consolidée ». Une autre approche prend également en compte les recettes spécifiquement culturelles et en mesure l'importance par rapport aux dépenses spécifiquement culturelles, pour établir une dépense «nette ". Il s'agit là de mesurer le montant des recettes que les collectivités reçoivent de l'État et de l'Union européenne au titre de la culture, et aussi celles, appelées « produits des services », qui proviennent

\section{Graphique B - Recettes spécifiquement culturelles enregistrées dans les comptes}

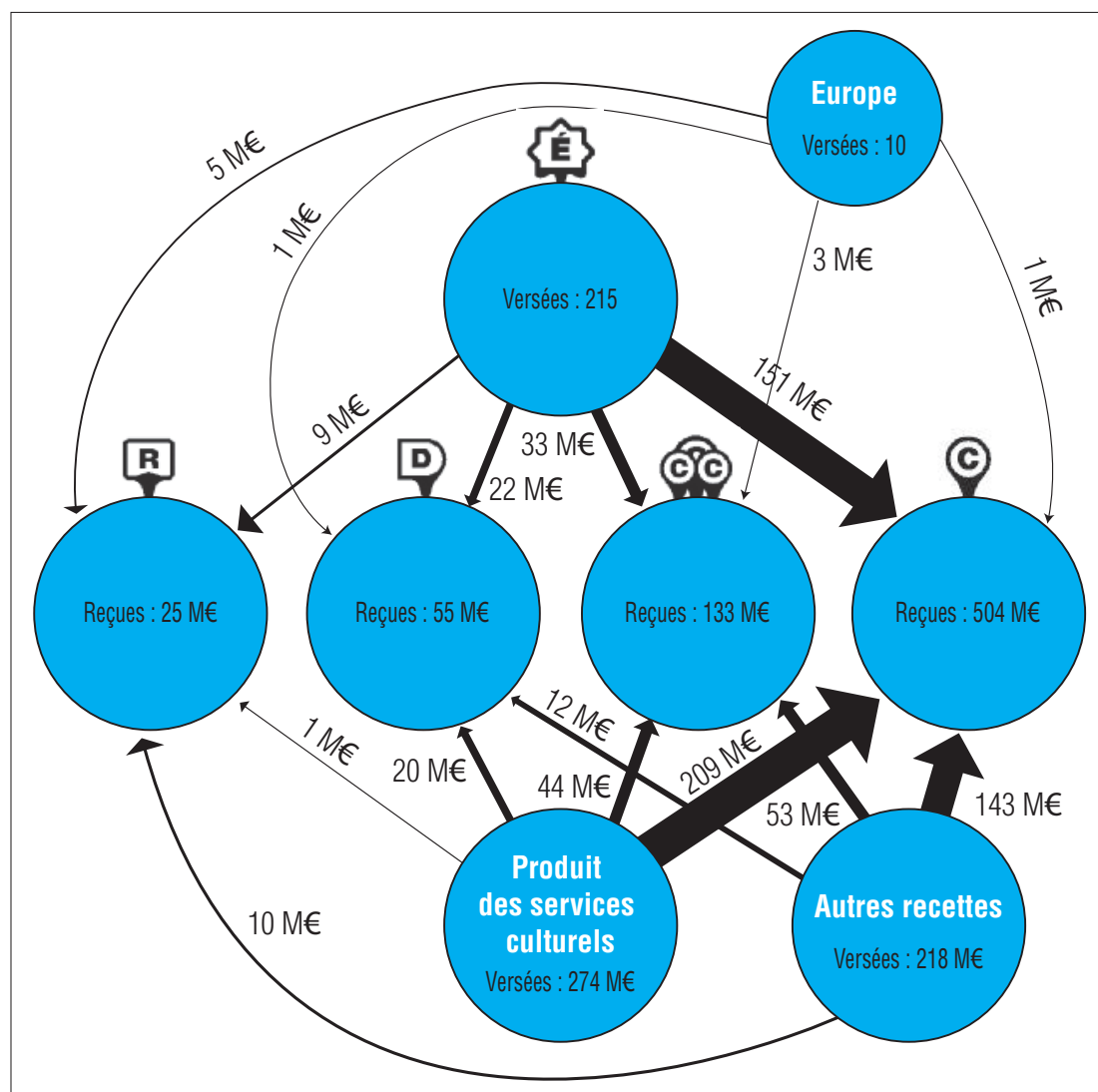

Rappel (précaution de lecture) : le chiffrage des recettes spécifiquement culturelles, y compris des subventions de l'État aux collectivités territoriales, est établi à partir des montants inscrits en recettes dans les chapitres comptables culturels (fonctions, sous-fonctions et rubriques culturelles) des comptes administratifs des collectivités enquêtées (hors communes de moins de 10000 habitants donc) et consiste, pour les communes, en un montant extrapolé à partir de l'échantillon. de la participation des usagers des services culturels : frais d'inscription dans les conservatoires, droit d'entrée dans un établissement géré directement par une collectivité, par exemple.

Toutes les recettes «culturelles» ne sont pas comptées puisque, par exemple, la billetterie d'un théâtre subventionné, mais qui n'est pas géré directement par une commune, ne sera pas enregistrée dans les comptes de la commune. C'est pourtant une recette qu'on peut identifier comme spécifiquement culturelle, mais ce n'est pas une recette d'une collectivité locale. On mesure donc ici seulement les recettes, spécifiquement culturelles, enregistrées dans les comptes des collectivités. Elles totalisent 717 millions d'euros en France métropolitaine et dans les DOM (hors subventions et remboursements entre collectivités territoriales : 257 millions d'euros). Au sein de ces recettes spécifiques, les subventions reçues de l'État, au titre de la culture, se sont élevées à près de 215 millions d'euros (dont plus de 150 millions d'euros au bénéfice des seules communes, 33 millions d'euros à celui des groupements, 22 millions d'euros pour les départements et 9 millions d'euros pour les régions) et celles en provenance de l'Union européenne, 10 millions d'euros ; l'ensemble des autres recettes spécifiquement culturelles se chiffrent ainsi à 492 millions d'euros, dont 274 millions d'euros pour les produits des services culturels (209 millions d'euros au bénéfice des communes et 44 millions d'euros à celui des groupements).

La dépense «nette » est donc de 6,9 milliards d'euros. Les recettes spécifiquement culturelles enregistrées dans les comptes des collectivités territoriales représentent ainsi $9,4 \%$ des dépenses culturelles consolidées $(7,9 \%$ en fonctionnement et $14,7 \%$ en investissement). 


\section{LES DÉPENSES CULTURELLES}

\section{DES COMMUNES}

\section{DE PLUS DE 10000 HABITANTS EN 2010}

Communes de plus de 10000 habitants : 4,6 milliards d'euros en 2010, soit $8,2 \%$ de leur budget en métropole

En 2010, l'effort financier des communes de métropole de plus de 10000 habitants dans le domaine culturel est de 4,61 milliards d'euros. Cela représente $8,2 \%$ de leur budget et 152 euros par habitant.

Les villes centres (encadré 3, Typologie des communes) s'engagent de manière plus soutenue dans le domaine culturel $(9,5 \%$ de leur budget) que les villes périphériques ou les villes isolées $(6,8 \%)$. De même, l'effort culturel des grandes villes (9,6\% pour les villes de plus de 100000 habitants) est plus important que la moyenne : la dépense culturelle par habitant s'y élève en effet à 181 euros. D'une grande ville à l'autre, la dépense par habitant varie de 1 à 8 .

Ces fortes disparités peuvent en partie trouver leur origine dans le degré d'intégration intercommunale des villes, dans la mesure où elles peuvent avoir transféré une partie de l'intervention culturelle au niveau intercommunal. Si elles n'en assument directement plus qu'une part réduite, l'effort budgétaire culturel, qui rapporte la dépense culturelle à la somme des dépenses qui restent à leur charge, apparaîtra alors faible. À l'inverse, si des communes transfèrent plutôt des compétences autres que culturelles vers des groupements intercommunaux, l'effort budgétaire culturel sera élevé.

En comptant les dépenses des communes des départements d'outre-mer (104 millions d'euros, encadré 4), les dépenses culturelles des communes sont de 4,71 milliards d'euros en 2010.

\section{Tableau 2 - Dépenses culturelles des communes} de plus de 10000 habitants, 2010

\begin{tabular}{|c|c|c|c|}
\hline & $\begin{array}{l}\text { Communes } \\
\text { de métropole }\end{array}$ & $\begin{array}{l}\text { Communes } \\
\text { d'outre-mer* }\end{array}$ & $\begin{array}{r}\text { Ensemble } \\
\text { des communes }\end{array}$ \\
\hline \multicolumn{4}{|l|}{ Dépenses culturelles } \\
\hline En milliers d'euros & 4606563 & 103886 & 4710448 \\
\hline dont fonctionnement & 3691774 & 86139 & 3777914 \\
\hline dont investissement & 914788 & 17746 & 932535 \\
\hline En euros/habitant $(€ /$ int & 152,4 & 67,1 & 148,2 \\
\hline dont fonctionnement & 122,1 & 55,7 & 118,9 \\
\hline dont investissement & 30,3 & 11,5 & 29,3 \\
\hline En \% du budget & 8,2 & 4,1 & 8,0 \\
\hline dont fonctionnement & 9,0 & 4,4 & 8,8 \\
\hline dont investissement & 6,0 & 3,0 & 5,9 \\
\hline
\end{tabular}

\section{Les dépenses culturelles des villes ont stagné en volume entre 2006 et 2010}

Entre 2006 et 2010, les dépenses culturelles des villes de métropole de plus de 10000 habitants ont progressé quasiment au même rythme que l'inflation: $+1,4 \%$ par an. Elles ont donc stagné en volume, c'est-à-dire compte tenu de l'inflation (tableau 3).

La précédente période d'analyse (2002-2006) correspondait aux premières années d'application de la loi du 12 juillet 1999 relative au renforcement et à la simplification de la coopération intercommunale, dite loi Chevènement, qui a dynamisé le phénomène intercommunal. Les transferts de compétence des communes aux établissements publics de coopération intercommunale (EPCI) expliquaient alors la baisse en volume des dépenses culturelles communales de fonctionnement sur la période 2002-2006 (+ 0,6\% par an en

\section{Tableau 3 - Évolution moyenne annuelle des dépenses culturelles des communes de plus de 10000 habitants de métropole, 2002-2010}

\begin{tabular}{|lcc|}
\hline & & En \% \\
Évolution annuelle en valeur & $\mathbf{2 0 0 2 - 2 0 0 6}$ & $\mathbf{2 0 0 6 - 2 0 1 0}$ \\
$\begin{array}{l}\text { Dépenses culturelles totales } \\
\text { dont fonctionnement }\end{array}$ & $+1,7$ & $+1,4$ \\
dont investissement & $+0,6$ & $+2,2$ \\
Évolution annuelle en volume & $+6,5$ & $-1,4$ \\
$\begin{array}{l}\text { Dépenses culturelles totales } \\
\text { dont fonctionnement } \\
\text { dont investissement }\end{array}$ & $-0,2$ & $-0,1$ \\
& $-1,3$ & $+0,7$ \\
& $+4,5$ & $-2,8$ \\
\hline
\end{tabular}
Source : Observatoire SFL-Forum/DEPS,
Ministère de la Culture et de la Communication, 2014

\section{Graphique 3 - Dépense culturelle par habitant des communes de plus de 10000 habitants et de leurs groupements, 1978-2010 (en volume)}

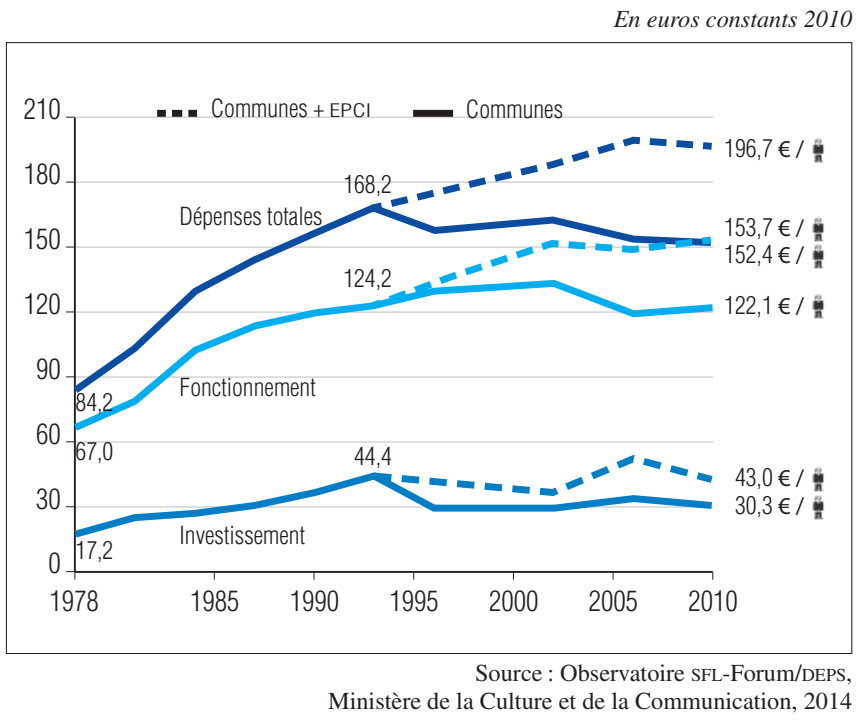


valeur, avec une inflation de $+1,9 \%$ par an, soit $-1,3 \%$ par an). Ensuite, entre 2006 et 2010, l'ampleur des transferts a été moindre et les dépenses communales de fonctionnement n'ont pas baissé. Pour des raisons qui tiennent au calendrier électoral, les dépenses d'investissement de 2010 sont par ailleurs plus faibles que celles de 2006 .

L'effort budgétaire culturel, c'est-à-dire le poids des dépenses culturelles dans le budget des communes, a légèrement régressé, passant de 8,6\% du budget total en 2006 à $8,2 \%$ en 2010 . La progression des dépenses culturelles a donc été plus lente que la progression des autres dépenses des communes.

Rapportée au nombre de leurs habitants, la dépense culturelle des communes de plus de 10000 habitants a augmenté moins vite que l'inflation. En tenant compte de l'inflation, elle a donc baissé entre 2006 et 2010 (graphique 3). Cette baisse prolonge celle observée depuis le milieu des années 1990. Les transferts de compétences vers les EPCI expliquent largement cette baisse de moyen terme. Ajoutées aux dépenses des EPCI, les dépenses totales par habitant du bloc communal avaient nettement augmenté jusqu'en 2006. Leur baisse récente en volume entre 2006 et 2010 vient rompre cette tendance. Si l'on s'en tient aux seules dépenses de fonctionnement, les dépenses culturelles par habitant en volume ont cependant très légèrement progressé (graphique 3).

\section{$54 \%$ des dépenses de fonctionnement sont des dépenses de personnel et $21 \%$ sont des subventions}

Les villes s'occupent du fonctionnement des services culturels de proximité (bibliothèques, enseignement musical et chorégraphique...). Assez naturellement, les 3,7 milliards d'euros de dépenses de fonctionnement qu'elles consacrent à la culture sont en grande partie des dépenses directes : 2 milliards d'euros de charges de personnel et 0,7 milliard de charges à caractère général (tableau 4). Les transferts effectués vers d'autres partenaires culturels des villes, comme les associations par exemple, représentent la quasi-totalité (0,9 milliard d'euros) du dernier quart des dépenses culturelles de fonctionnement.

Les dépenses de personnel couvrent à elles seules $54 \%$ des dépenses de fonctionnement (tableau 4). Elles concernent surtout les équipements culturels des communes, comme les archives, les bibliothèques et médiathèques - respectivement $88 \%$ et $80 \%$ des dépenses de fonctionnement -, ainsi que les musées et les actions menées en faveur de l'expression musicale, lyrique et chorégraphique, où l'on trouve les dépenses relatives aux établissements d'enseignement (conservatoires, écoles d'art et de musique...) - autour de $69 \%$ des dépenses de fonctionnement. D'autres secteurs sont moins concernés par les dépenses de personnel, qui ne représentent par exemple que $35 \%$ des dépenses de fonctionnement destinées aux cinémas et autres salles de spectacle, $26 \%$ dans l'action culturelle ou $23 \%$ des dépenses

Tableau 4 - Dépenses culturelles des communes de plus de 10000 habitants par nature comptable et secteur d'intervention, 2010 (France métropolitaine)

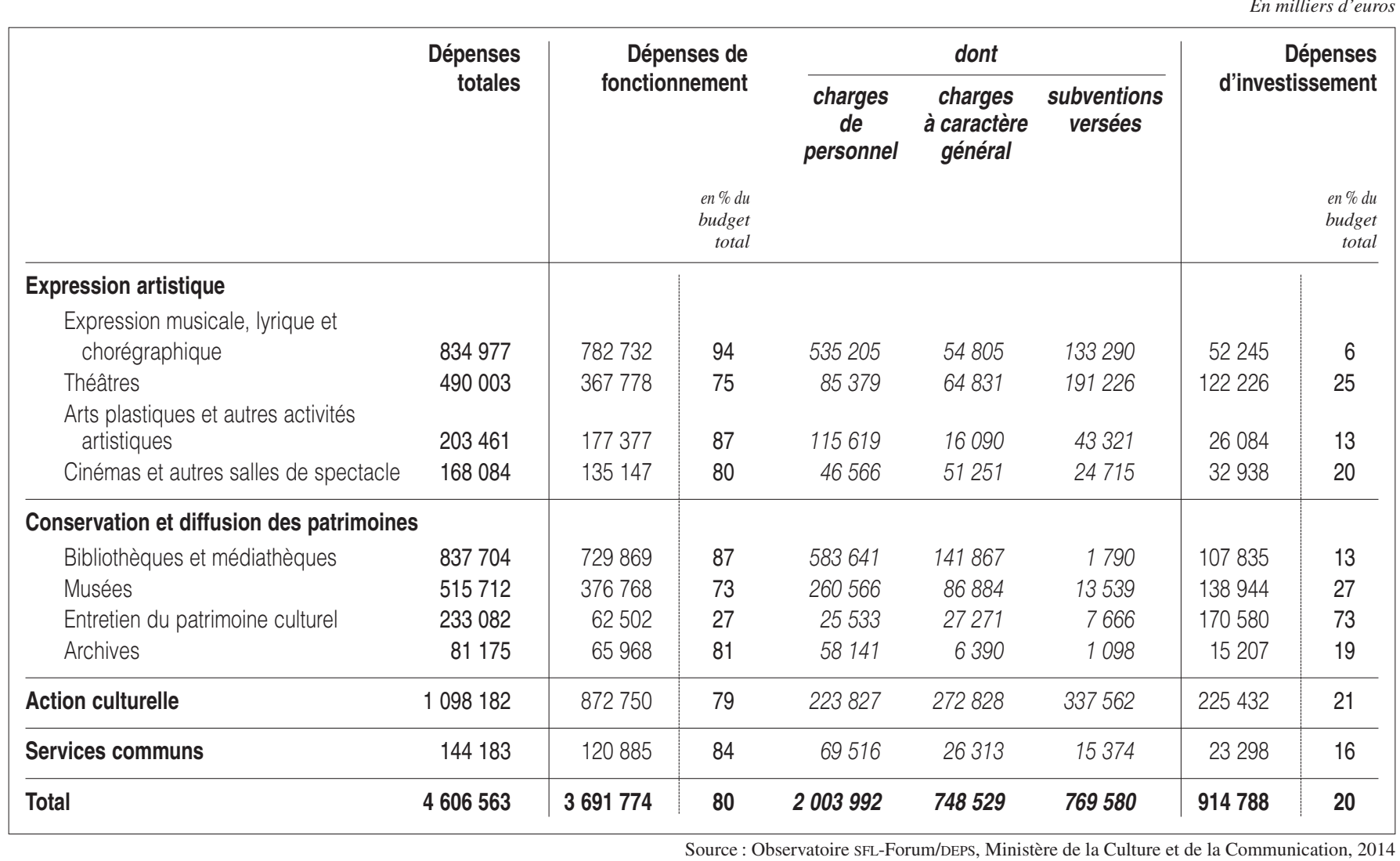


dans le domaine des théâtres. La délégation de la gestion de ces actions à des tiers (associations...) peut expliquer cette faible part des frais de personnel. L'appréciation des dépenses destinées aux théâtres est par ailleurs perturbée par les budgets annexes, qui ne sont pas pris en compte dans l'étude. Ces budgets annexes bénéficient de subventions du budget principal et la nature des dépenses du budget principal prises en compte (subvention) masque donc la nature réelle (personnel, charges générales, etc.) des dépenses engagées par les communes pour les théâtres.

\section{Baisse du poids des dépenses de personnel, surtout dans les arts plastiques et les activités artistiques}

La part des dépenses de personnel dans l'ensemble des dépenses de fonctionnement a baissé de quatre points depuis 2006. Cette contraction des dépenses est très significative pour les arts plastiques et autres activités artistiques (- 10 points), ou encore l'expression musicale, lyrique et chorégraphique ( -6 points), domaines où la part des charges de personnel est relativement élevée, du fait de l'importance de personnel fonctionnaire. Elle a en revanche augmenté dans des domaines où ces charges sont faibles, comme par exemple le cinéma et les salles de spectacle (+ 10 points). Elle est stable pour les bibliothèques.

\section{0 millions d'euros de subventions culturelles de fonctionnement en 2010}

$90 \%$ des autres charges de gestion courante correspondent à des subventions versées par les communes : 770 millions d'euros, soit $21 \%$ des dépenses de fonctionnement (tableau 4). La part des subventions versées est plus importante dans les villes centres que dans les autres villes; les dépenses de fonctionnement des villes isolées et des villes périphériques sont en revanche plutôt des dépenses de personnel et des charges générales.
Les subventions bénéficient surtout au(x) théâtre(s). La part des subventions dans leurs dépenses de fonctionnement est en effet très forte $(52 \%)$, et elle a augmenté de 10 points entre 2006 et 2010. De même pour les arts plastiques et autres activités artistiques: hausse de 11 points, ce qui amène la part des subventions dans leurs dépenses de fonctionnement à $24 \%$ en 2010. Les subventions représentent aussi une forte part des dépenses de fonctionnement pour l'action culturelle (39\%), mais cette part est en revanche en baisse (de 6 points). Ces secteurs sont aussi ceux où la délégation de service public et le conventionnement des associations sont fréquents.

$80 \%$ des subventions communales sont destinées à des organismes de droit privé, comme des associations. Dans les théâtres et pour l'expression musicale, lyrique et chorégraphique, ces organismes privés ne représentent cependant que les deux tiers des bénéficiaires.

\section{Dépenses d'investissement : $47 \%$ pour la conservation et la diffusion des patrimoines}

$20 \%$ des dépenses des communes de plus de 10000 habitants sont des dépenses d'investissement. Cela représente pour elles 0,9 milliard d'euros en 2010. La quasi-totalité porte sur les équipements propres des communes et $95 \%$ de ces dépenses correspondent à des dépenses d'équipement brut, le reste étant des subventions d'équipement. 2,6\% de ces dépenses d'équipement correspondent à l'achat d'œuvres d'art (23 millions d'euros en 2010).

La part des dépenses d'investissement dans les dépenses culturelles totales des communes de plus de 10000 habitants est particulièrement importante dans l'entretien du patrimoine $(73 \%)$. Celles des musées et des théâtres lui sont très inférieures (autour de $25 \%$ des dépenses culturelles totales) mais sont supérieures à la moyenne. La part des investissements dans les dépenses culturelles est en revanche très faible dans les dépenses affectées à l'expression lyrique et chorégraphique (graphique 4).

\section{Graphique 4 - Dépenses culturelles des villes de plus de 10000 habitants de métropole par secteur d'intervention et nature comptable, 2010 (France métropolitaine)}

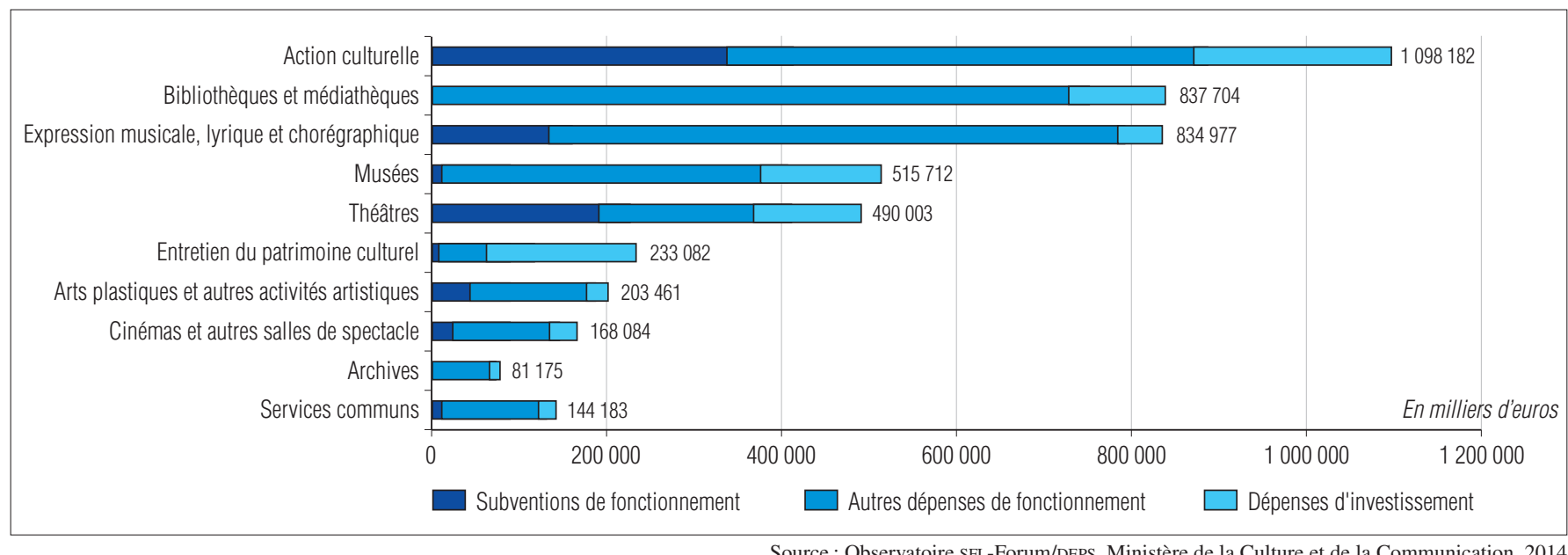


Baisse des dépenses pour l'expression lyrique et chorégraphique et pour les bibliothèques, malgré un soutien par les subventions

Entre 2006 et 2010, les dépenses culturelles des villes de plus de 10000 habitants de métropole ont augmenté de $1,4 \%$ par an en valeur. Cette hausse a été portée par celle des subventions: elles représentent une faible part des dépenses totales (16,7\% en 2010) mais elles ont augmenté de $5 \%$ par an. Par comparaison, les charges de personnel n'ont augmenté que de 0,6\% par an, et les dépenses d'investissement ont baissé de 1,4\% par an.

Les plus fortes hausses des dépenses communales ont été orientées vers l'action culturelle, les théâtres et vers les arts plastiques. Pour les théâtres et les arts plastiques, elles ont été largement portées par les subventions, tandis que celles pour l'action culturelle l'ont été par les charges de personnel.

Les baisses concernent le cinéma et autres salles de spectacle et, dans une moindre mesure, l'expression lyrique et chorégraphique et les bibliothèques, qui ont pourtant bénéficié d'un soutien par les subventions très important. En revanche, les subventions vers les cinémas et les salles de spectacle ont baissé de presque $20 \%$ par an entre 2006 et 2010.

Les dépenses d'investissement ont aussi baissé pour les cinémas et les salles de spectacle. Les seules hausses de dépenses communales orientées vers ce secteur sont en fait les charges de personnel.

\section{Encadré 3 - Typologie des communes (Insee)}

Unité urbaine : la notion d'unité urbaine repose sur la continuité du bâti et le nombre d'habitants. On appelle unité urbaine une commune ou un ensemble de communes présentant une zone de bâti continu (pas de coupure de plus de 200 mètres entre deux constructions) qui compte au moins 2000 habitants.

Si l'unité urbaine se situe sur une seule commune, elle est dénommée ville isolée.

Si l'unité urbaine s'étend sur plusieurs communes, et si chacune de ces communes concentre plus de la moitié de sa population dans la zone de bâti continu, elle est dénommée agglomération multicommunale. Si une commune représente plus de $50 \%$ de la population de l'agglomération multicommunale, elle est seule ville centre. Sinon, toutes les communes qui ont une population supérieure à $50 \%$ de celle de la commune la plus peuplée, ainsi que cette dernière, sont villes centres. Les communes urbaines qui ne sont pas villes centres constituent la banlieue de l'agglomération multicommunale.

Les unités urbaines sont redéfinies périodiquement. L'actuel zonage, daté de 2010, a été établi en référence à la population connue au recensement de 2007 et sur la géographie du territoire au $1^{\mathrm{er}}$ janvier 2010.

\section{Encadré 4 - Les villes d'outre-mer réalisent un effort culturel moitié moindre que celui des communes métropolitaines}

Toutes les communes de plus de 10000 habitants des quatre territoires d'outre-mer ont été enquêtées. L'ensemble de leurs dépenses culturelles se chiffre à 104 millions d'euros en 2010 , dont 86 millions en fonctionnement (tableau 2). L'effort culturel moyen de ces communes est deux fois moindre que celui des communes de métropole (4,1\% contre $8,2 \%$ pour les dépenses totales). En fonctionnement, les communes ultra-marines ont dépensé près de 56 euros par habitant au titre de la culture, contre plus du double pour les communes métropolitaines. En investissement, les dépenses ont été presque trois fois moindres.

Le faible nombre de grandes villes dans ces territoires est à prendre en compte ; ainsi, deux communes seulement sur les 48 de plus de 10000 habitants des DOM atteignent ou dépassent les 100000 habitants, toutes deux situées à La Réunion. Dans chacun des trois autres territoires, une seule ville atteint ou dépasse les 50000 habitants (deux villes, les 30000 habitants), la plus peuplée en Martinique en comptant moins de 90000 .

D'un DOM à l'autre, les dépenses par habitant sont assez similaires, tout au moins en fonctionnement. En Martinique toutefois, les investissements culturels de trois villes ont représenté en 2010 plus du tiers des investissements culturels des quatre départements et, de ce fait, les dépenses culturelles d'investissement des communes de plus de 10000 habitants y apparaissent deux fois plus élevées que pour l'ensemble des départements d'outre-mer, et représentent une part deux fois plus élevée des investissements totaux des communes (6,2\%). A contrario, ces indicateurs sont significativement inférieurs aux moyennes des quatre départements pour les communes concernées de La Réunion et, plus encore, de Guyane.

Considérées globalement, les communes des Dom présentent un profil de leurs dépenses culturelles sensiblement différent de celui des communes métropolitaines : si l'action culturelle et les bibliothèques-médiathèques arrivent en tête des domaines d'intervention, comme en métropole, ceux de l'expression musicale, lyrique et chorégraphique et plus encore, des musées, des théâtres et des arts plastiques et autres activités culturelles ne représentent qu'une bien moindre proportion des dépenses totales. A contrario, on observe une plus grande part des dépenses ventilées dans la rubrique des services communs, ce qui peut aussi tenir à une ventilation au sein des autres domaines plus difficile à obtenir. Les dépenses en faveur de l'entretien du patrimoine culturel ainsi que des archives (essentiellement de l'investissement) de même qu'en matière de cinémas et autres salles de spectacle (essentiellement des dépenses directes de fonctionnement) se situent dans des proportions comparables à celles des communes métropolitaines. 
LES DÉPENSES CULTURELLES

\section{DES GROUPEMENTS DE COMMUNES EN 2010}

\section{Dépenses culturelles des groupements de communes de plus de 10000 habitants : 1,1 milliard d'euros en 2010}

Les groupements des villes de plus de 10000 habitants en métropole, et compétents dans le domaine culturel, ont dépensé à ce titre 1,1 milliard d'euros en 2010. Cela représente $7,1 \%$ de leur budget et 44,3 euros par habitant (tableau 5). Pour les groupements des DOM, les dépenses culturelles se sont élevées à près de 4,8 millions d'euros (encadré 5).

Chaque type de groupements (communauté d'agglomération, communauté de communes, communauté urbaine, syndicat d'agglomération nouvelle) présente des caractéristiques spécifiques (population regroupée, compétences obligatoires...) et leurs dépenses doivent donc être analysées séparément.

Les communautés d'agglomération (CA) constituent plus de la moitié des EPCI du champ de l'enquête et près des deux tiers de leur population (tableau 5). Leurs dépenses culturelles représentent en 2010 plus des trois quarts des dépenses culturelles de l'ensemble des EPCI. La dépense par habitant des communautés d'agglomération (54,2 euros par habitant) est de ce fait la plus forte des EPCI (à l'exception des trois syndicats d'agglomération nouvelle). Leur budget culturel représente $10 \%$ de leur budget total.
Les communautés de communes (CC) enquêtées, dont l'effectif se rapproche de celui des CA, regroupent une population inférieure à celle des $\mathrm{CU}$; elles ont mobilisé un volume de crédits culturels 1,7 fois plus élevé que les CU. Leur effort culturel est comparable à celui des CA même si, rapportées à la population regroupée, leurs dépenses culturelles sont moindres.

Les communautés urbaines (CU), type d'intercommunalité très intégré et le plus densément peuplé, sont dotées de nombreuses compétences obligatoires, qui se traduisent par des budgets totaux très conséquents. Dotées en moyenne d'un budget de 6 à 7 fois plus important que les CA, les CU apparaissent pourtant mobiliser des volumes de crédits culturels comparables à ceux des $\mathrm{CA}$ (autour de 6 millions d'euros en moyenne). Leur effort culturel est de ce fait particulièrement bas $(1,5 \%$ de leur budget et 14,7 euros par habitant) même si la masse de crédits gérés par chaque $\mathrm{CU}$ peut être importante. De fortes disparités existent cependant entre les CU : pour plusieurs d'entre elles, les villes centres assument encore la plus grande partie du financement des interventions culturelles sur le territoire communautaire.

Les syndicats d'agglomération nouvelle (SAN) ont le taux d'effort culturel le plus élevé (121,9 euros par habitant et $11,5 \%$ du budget global).

\section{Fortes disparités des taux d'effort budgétaire culturel}

Si certains groupements ne disposent que de compétences spécifiques dans le domaine culturel, d'autres peuvent avoir en charge l'intégralité des actions menées dans

Tableau 5 - Dépenses culturelles des EPCI à fiscalité propre et comportant au moins une commune de plus de 10000 habitants, 2010

\begin{tabular}{|c|c|c|c|c|c|c|c|}
\hline & \multirow{2}{*}{$\begin{array}{c}\text { Ensemble des EPCI } \\
\text { de métropole }\end{array}$} & \multicolumn{4}{|c|}{ dont } & \multirow{2}{*}{$\begin{array}{c}\text { EPCI } \\
\text { d'outre-mer }\end{array}$} & \multirow{2}{*}{$\begin{array}{l}\text { Ensemble } \\
\text { des EPCl }\end{array}$} \\
\hline & & CA & $\mathrm{CC}$ & CU & SAN & & \\
\hline Nombre d'EPCI* & 242 (sur 416) & 124 (sur 178) & 102 (sur 217) & 13 (sur 16) & 3 (sur 5) & 3 (sur 8) & 245 (sur 424) \\
\hline Population & $\begin{array}{c}23,9 \\
\text { (sur } 36,4 \text { millions) }\end{array}$ & $\begin{array}{c}15,1 \\
\text { (sur 21,5 millions) }\end{array}$ & $\begin{array}{c}3,3 \\
\text { (sur 7,1 millions) }\end{array}$ & $\begin{array}{c}5,2 \\
\text { (sur } 7,5 \text { millions) }\end{array}$ & $\begin{array}{c}0,3 \\
\text { (sur } 0,3 \text { million) }\end{array}$ & $\begin{array}{c}0,6 \\
\text { (sur } 1,0 \text { million) }\end{array}$ & $\begin{array}{c}24,5 \\
\text { (sur 37,4 millions) }\end{array}$ \\
\hline \multicolumn{8}{|l|}{ En milliers d'euros } \\
\hline $\begin{array}{l}\text { Dépenses culturelles } \\
\text { dont fonctionnement } \\
\text { dont investissement }\end{array}$ & $\begin{array}{r}1061234 \\
757681 \\
303553\end{array}$ & $\begin{array}{l}816579 \\
573330 \\
243250\end{array}$ & $\begin{array}{r}133491 \\
92332 \\
41159\end{array}$ & $\begin{array}{l}76968 \\
63770 \\
13198\end{array}$ & $\begin{array}{r}34196 \\
28250 \\
5946\end{array}$ & $\begin{array}{l}4762 \\
2302 \\
2460\end{array}$ & $\begin{array}{r}1065997 \\
759983 \\
306013\end{array}$ \\
\hline \multicolumn{8}{|l|}{ En euros/habitant $(€ / / \hat{n})$} \\
\hline $\begin{array}{l}\text { Dépenses culturelles } \\
\text { dont fonctionnement } \\
\text { dont investissement }\end{array}$ & $\begin{array}{l}44,3 \\
31,6 \\
12,7\end{array}$ & $\begin{array}{l}\mathbf{5 4 , 2} \\
38,1 \\
16,1\end{array}$ & $\begin{array}{l}39,8 \\
27,5 \\
12,3\end{array}$ & $\begin{array}{r}14,7 \\
12,2 \\
2,5\end{array}$ & $\begin{array}{r}121,9 \\
100,7 \\
21,2\end{array}$ & $\begin{array}{l}9,3 \\
4,5 \\
4,8\end{array}$ & $\begin{array}{l}43,6 \\
31,1 \\
12,5\end{array}$ \\
\hline \multicolumn{8}{|l|}{ En \% du budget } \\
\hline Dépenses culturelles & 7,1 & 10,0 & 10,1 & 1,5 & 11,5 & 2,0 & 7,0 \\
\hline dont fonctionnement & 7,8 & 10,8 & 9,5 & 2,0 & 15,5 & 1,2 & 7,7 \\
\hline dont investissement & 5,8 & 8,5 & 11,8 & 0,7 & 5,2 & 4,9 & 5,8 \\
\hline
\end{tabular}


ce domaine sur leur territoire. Il en résulte des situations très contrastées. Pour les 245 groupements compétents et ayant engagé des dépenses en 2010, les dépenses par habitant varient ainsi de moins de 1 euro à 307 euros et le poids des dépenses culturelles dans le budget s'échelonne entre moins de $1 \%$ et $56 \%$. Ainsi, les valeurs médianes, c'est-à-dire la valeur des variables qui permet de scinder les groupements d'une catégorie en deux groupes de même taille, sont plus faibles que les valeurs moyennes. Les dépenses médianes par habitant s'établissent ainsi à 40 euros pour les communautés d'agglomération (contre 54 euros en moyenne), 35 euros pour les communautés de communes (contre 40 euros en moyenne) du fait des très nombreux groupements qui ont de très faibles dépenses par habitant.

\section{Stagnation de la dépense par habitant}

Entre 2006 et 2010, les dépenses des EPCI de métropole ont augmenté de $6 \%$ par an. Cette très forte progression s'explique par l'augmentation du nombre d'EPCI de plus de 10000 habitants à fiscalité propre et à compétence culturelle, qui est passé de 194 à 242. En 2010, près de $60 \%$ des EPCI interviennent en effet dans le domaine culturel, contre la moitié en 2006 et seulement un tiers en 2002. Cette extension traduit la poursuite du développement de l'intercommunalité culturelle et doit à cet égard être mise en relation avec la faible croissance des dépenses des communes de plus de 10000 habitants. Mais elle traduit vraisemblablement aussi l'achèvement de ce développement, la croissance des dépenses étant malgré tout bien inférieure à celle qui avait été observée au cours de la précédente période d'enquête (tableau 6).

Rapportée au nombre d'habitants, la dépense budgétaire culturelle a en fait quasiment stagné en valeur, autour de 44 euros par habitant, et donc légèrement régressé en euros constants (graphique 3).

Pour les mêmes raisons liées au calendrier municipal que pour les communes, les dépenses d'investissement des EPCI ont baissé. Celles de fonctionnement ont en revanche augmenté de presque $10 \%$ par an.

\section{Tableau 6 - Évolution moyenne annuelle des dépenses culturelles des EPCI de métropole, 2002-2010}

\begin{tabular}{|lcc|}
\hline & & En \% \\
Évolution annuelle en valeur & $\mathbf{2 0 0 2 - 2 0 0 6}$ & $\mathbf{2 0 0 6 - 2 0 1 0}$ \\
$\begin{array}{l}\text { Dépenses culturelles totales } \\
\text { dont fonctionnement }\end{array}$ & $+46,1$ & $+6,0$ \\
dont investissement & $+43,4$ & $+9,8$ \\
Évolution annuelle en volume & $+51,0$ & $-1,3$ \\
Dépenses culturelles totales & & \\
dont fonctionnement & $+43,3$ & $+4,4$ \\
dont investissement & $+40,8$ & $+8,2$ \\
& $+48,2$ & $-2,7$ \\
\hline
\end{tabular}

Source : Observatoire SFL-Forum/DEPS, Ministère de la Culture et de la Communication, 2014

\section{Une structure des dépenses proche de celle des communes}

La structure des dépenses de fonctionnement des groupements est assez similaire à celle des villes. Elle est caractéristique d'acteurs de proximité: les dépenses directes (charges de personnel et charges à caractère général) représentent un peu plus des trois quarts $(77 \%)$ des dépenses de fonctionnement (tableau 7). Les autres charges de gestion courante, qui correspondent quasi exclusivement au versement de subventions de fonctionnement, en constituent moins d'un quart (22\%).

Les dépenses de personnel représentent 445 millions d'euros, soit $59 \%$ des dépenses de fonctionnement des EPCI (tableau 7). Comme pour les communes, ces frais sont particulièrement importants dans les dépenses orientées vers les archives (84\%), les bibliothèques-médiathèques $(73 \%)$ et vers l'expression musicale, lyrique et chorégraphique $(80 \%)$. Les charges générales sont en revanche proportionnellement plus importantes pour les musées $(30 \%$ des dépenses de fonctionnement, contre $19 \%$ pour l'ensemble des EPCI).

Les subventions représentent $19 \%$ des frais de fonctionnement, et sont versées principalement aux théâtres (61\% des dépenses de fonctionnement) et aux cinémas et autres salles de spectacle ( $58 \%)$.

Comme pour les communes, ce sont des personnes de droit privé, notamment des associations, qui bénéficient le plus des subventions de fonctionnement. Sauf dans deux domaines: les bibliothèques et l'expression musicale, lyrique et chorégraphique, où les organismes publics en captent la majorité (respectivement $85 \%$ et $54 \%$ ). Pour ces deux derniers domaines, cela s'explique par l'importance des équipements municipaux, les bibliothèques et les établissements d'enseignement (conservatoires et écoles), que peuvent soutenir les intercommunalités.

L'importance des frais de personnel et des charges générales dans le budget des EPCI est propre aux dépenses à caractère culturel. Les dépenses directes sont moins importantes dans leurs dépenses destinées aux autres secteurs économiques, et les subventions prennent plus de place. Cela peut être relié à la prise en charge de la gestion directe d'équipements qui leur ont été transférés en lien avec les compétences dont ils ont été dotés dans le champ culturel, ainsi qu'aux créations de nouvelles structures culturelles d'emblée intercommunales. L'intervention directe, par le biais des frais de personnel et des charges générales et la faible part des subventions, s'est accrue entre 2006 et 2010.

\section{Grandes disparités des domaines d'action culturelle entre types d'EPCI}

L'action culturelle représente une part deux fois moins importante du budget des EPCI (13\%) que de celui des communes $(24 \%)$. L'essentiel de l'intervention en matière culturelle se porte vers l'expression musicale, lyrique et chorégraphique (29\% des dépenses, plutôt des dépenses de fonctionnement) et vers les bibliothèques et médiathèques ( $23 \%$ des dépenses). Les dépenses d'investissement sont 
proportionnellement plus élevées pour les actions de conservation et diffusion des patrimoines (graphique 5).

Les domaines d'intervention sont en fait assez différents d'un type d'EPCI à un autre (graphique 6).

Pour les communautés urbaines, les dépenses liées aux bibliothèques, aux médiathèques et aux théâtres présentent un poids relativement faible, au bénéfice des musées et des cinémas et autres salles de spectacle. C'est l'inverse pour les communautés de communes: le poids des dépenses de fonctionnement consacrées aux bibliothèques et médiathèques est plus fort que pour l'ensemble des EPCI, et aussi, bien que dans une moindre mesure, pour les dépenses consacrées à l'expression musicale, lyrique et chorégraphique. Pour ces mêmes communautés, les dépenses de fonctionnement relatives aux théâtres et aux musées y sont moins marquées.

Les SAN privilégient l'action culturelle (40\% des dépenses culturelles de fonctionnement) et les bibliothèques et médiathèques. Les communautés d'agglomération ont en revanche une structure de dépense par domaine culturel logiquement proche de la moyenne, étant donné leur poids dans le total des dépenses.

Tableau 7 - Dépenses culturelles des EPCI par nature comptable et secteur d'intervention, 2010 (France métropolitaine)

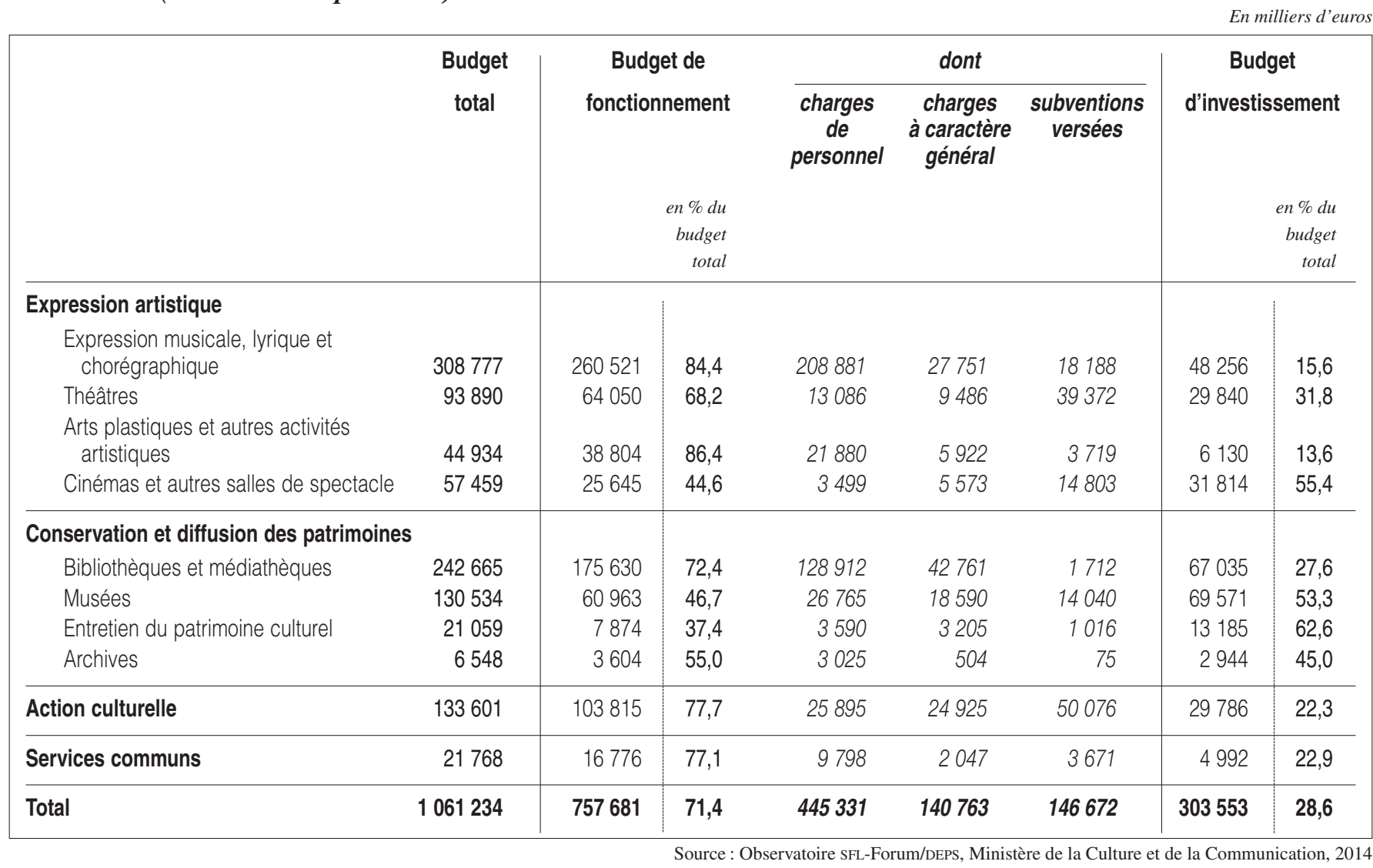

Graphique 5 - Dépenses culturelles des EPCI par secteur d'intervention et nature comptable, 2010 (France métropolitaine)

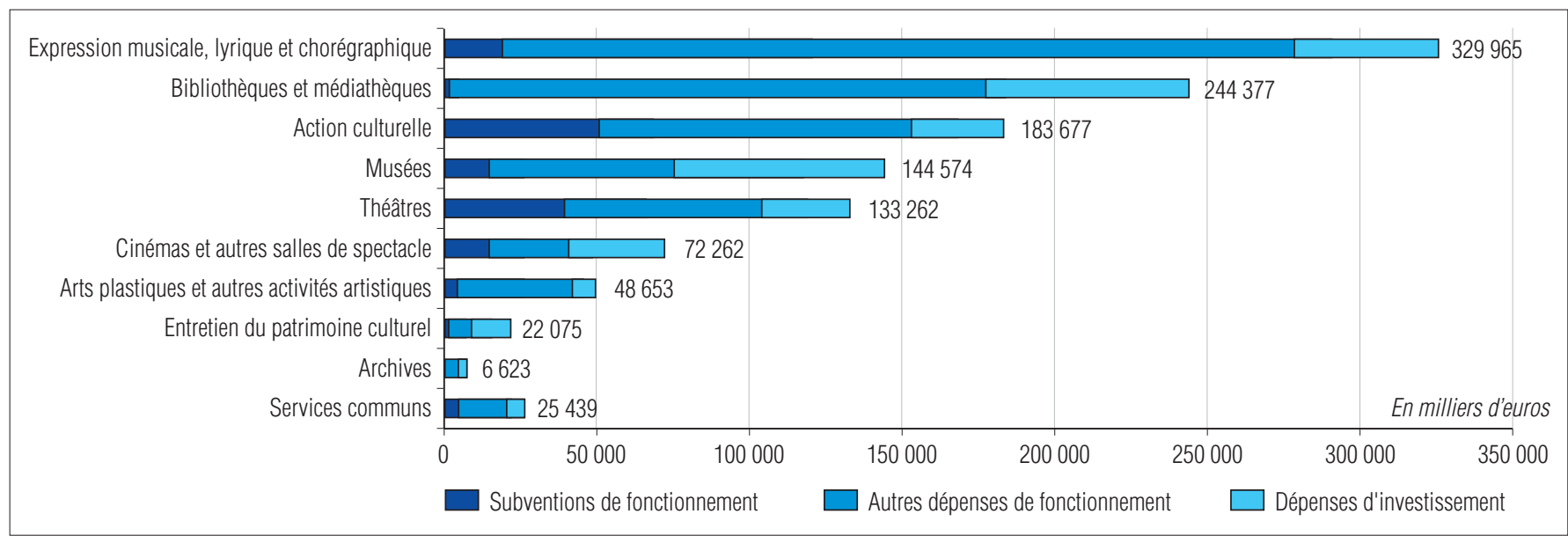

Source : Observatoire SFL-Forum/DEPS, Ministère de la Culture et de la Communication, 2014 
Au-delà de ces disparités entre type de groupements, ceux-ci étant eux-mêmes de taille très variable au sein de chaque type et ayant reçu des compétences d'ampleur et de nature différentes, selon le type d'équipements ou de ser- vices culturels qu'ils peuvent être amenés à gérer par exemple, il n'est pas pertinent de conclure à certaines spécialisations par secteur des différents types de groupements.

\section{Graphique 6 - Répartition des dépenses culturelles des EPCI en fonctionnement par secteur, 2010}

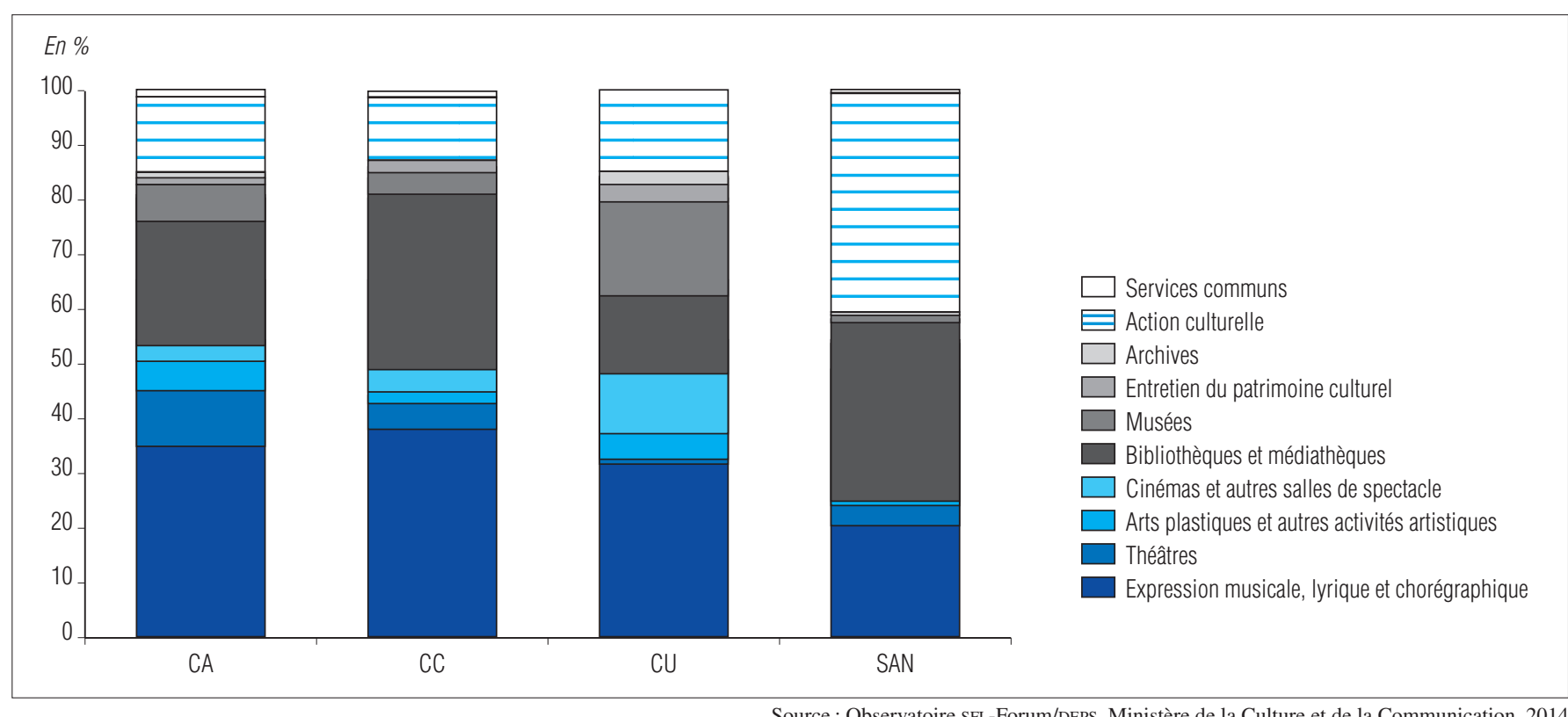

\section{Encadré 5 - Territoires d'outre-mer : l'intercommunalité culturelle limitée à La Réunion, en 2010}

Les territoires d'outre-mer comportaient en tout 16 groupements de communes à fiscalité propre au $1^{\text {er }}$ janvier $2010: 8$ communautés d'agglomération et 8 communautés de communes. Huit de ces groupements étaient concernés par l'enquête au titre de leur compétence culturelle mais quatre d'entre eux n'ont engagé aucune dépense en 2010 , et seules quatre communautés d'agglomération sont finalement concernées, toutes situées à La Réunion.

Regroupant près de $60 \%$ des communes de La Réunion et plus de $50 \%$ de sa population, ces groupements de communes réalisent un effort culturel très sensiblement moindre qu'en métropole, plus particulièrement en ce qui concerne les dépenses culturelles de fonctionnement ( $1,2 \%$ contre 10,8\% pour l'ensemble des communautés d'agglomération de métropole).

En 2010, le montant global engagé au titre de la culture est légèrement supérieur en investissement qu'en fonctionnement (2,5 millions d'euros pour 2,3 millions d'euros). Mais quelle que soit la nature des dépenses, rapportées au nombre d'habitants, elles se situent toujours à un niveau significativement plus bas que pour les communautés d'agglomération de métropole : 4,5 euros par habitant en fonctionnement et 4,8 euros en investissement, contre 38 euros et 16,1 euros par habitant en métropole.

Considérées globalement, les dépenses culturelles de ces groupements sont très fortement concentrées sur le poste bibliothèques-médiathèques (70\% des dépenses, les trois quarts en investissement) ; les charges de personnel au titre de la culture se répartissent presque à parité entre ce poste (bibliothèques-médiathèques) et les services communs et constituent près des trois quarts des dépenses culturelles de fonctionnement. Le dernier quart est constitué de subventions, classées en totalité en «action culturelle » (12\% des dépenses totales). 


\section{LES DÉPENSES CULTURELLES DES DÉPARTEMENTS EN 2010}

\section{1,4 milliard d'euros, soit 2,1\% du budget des départements, est consacré aux dépenses culturelles en métropole}

Les départements métropolitains ont consacré 1,4 milliard d'euros à la culture en 2010, soit 2,1 \% de leur budget et 22,1 euros par habitant (tableau 8). Le fonctionnement (dépenses de personnel, charges générales, subventions de fonctionnement) couvre $69 \%$ de ces dépenses soit 1 milliard d'euros. Les investissements culturels sont de 0,4 milliard d'euros et représentent 3,1\% des dépenses d'investissement des départements.

L'intervention du département de Paris dans le champ culturel est limitée au financement des archives départementales. Le reste relève des dépenses de la ville de Paris, de la région Île-de-France ou de l'État. L'effort culturel du département n'est de ce fait que de $0,2 \%$. Hors Paris, l'effort culturel des départements varie de $0,7 \%$ à $4,8 \%$, soit un rapport de 1 à 7 entre le plus faible et le plus élevé. En euros par habitant, l'écart est de 1 à 9, de 7,2 à 64,3 euros (cartes). Les départements d'outre-mer en 2010 (donc hors Mayotte) ont dépensé 38,3 millions d'euros (tableau 8 et encadré 6).

\section{Forte augmentation des dépenses culturelles en 2007 et 2008, suivie d'un net recul}

Les dépenses culturelles des départements ont augmenté de 1,8\% par an en moyenne en métropole entre 2006 et 2010. Cela marque un ralentissement par rapport à la période d'enquête précédente (2002-2006), en particulier pour les dépenses d'investissement (tableau 9).

En termes d'effort budgétaire, c'est-à-dire rapportées au budget total des départements, les dépenses culturelles ont un peu régressé : elles représentent $2,1 \%$ du budget en 2010, contre $2,4 \%$ en 2006. L'interprétation de cette baisse

\section{Tableau 8 - Dépenses culturelles des départements, 2010}

\begin{tabular}{|lrrr|}
\hline & $\begin{array}{r}\text { Départements } \\
\text { de métropole }\end{array}$ & $\begin{array}{r}\text { Départements } \\
\text { d'outre-mer* }\end{array}$ & $\begin{array}{r}\text { Ensemble des } \\
\text { départements }\end{array}$ \\
Dépenses culturelles & & & \\
En milliers d'euros & 1390153 & 38267 & $\mathbf{1 4 2 8} \mathbf{4 2 0}$ \\
dont fonctionnement & 957481 & 31586 & 989066 \\
dont investissement & 432672 & 6681 & 439353 \\
En euros/habitant $(€ /$ i⿱n- & 22,1 & 20,7 & $\mathbf{2 2 , 1}$ \\
dont fonctionnement & 15,3 & 17,1 & 15,3 \\
dont investissement & 6,9 & 3,6 & 6,8 \\
En \% du budget & 2,1 & 1,3 & $\mathbf{2 , 1}$ \\
dont fonctionnement & 1,9 & 1,3 & 1,9 \\
dont investissement & 3,1 & 1,4 & 3,0 \\
\hline * Guadeloupe, Guyane, Martinique et La Réunion & & \\
\hline
\end{tabular}

\section{Cartes - Dépenses culturelles en euros par habitant} et en pourcentage du budget, 2010

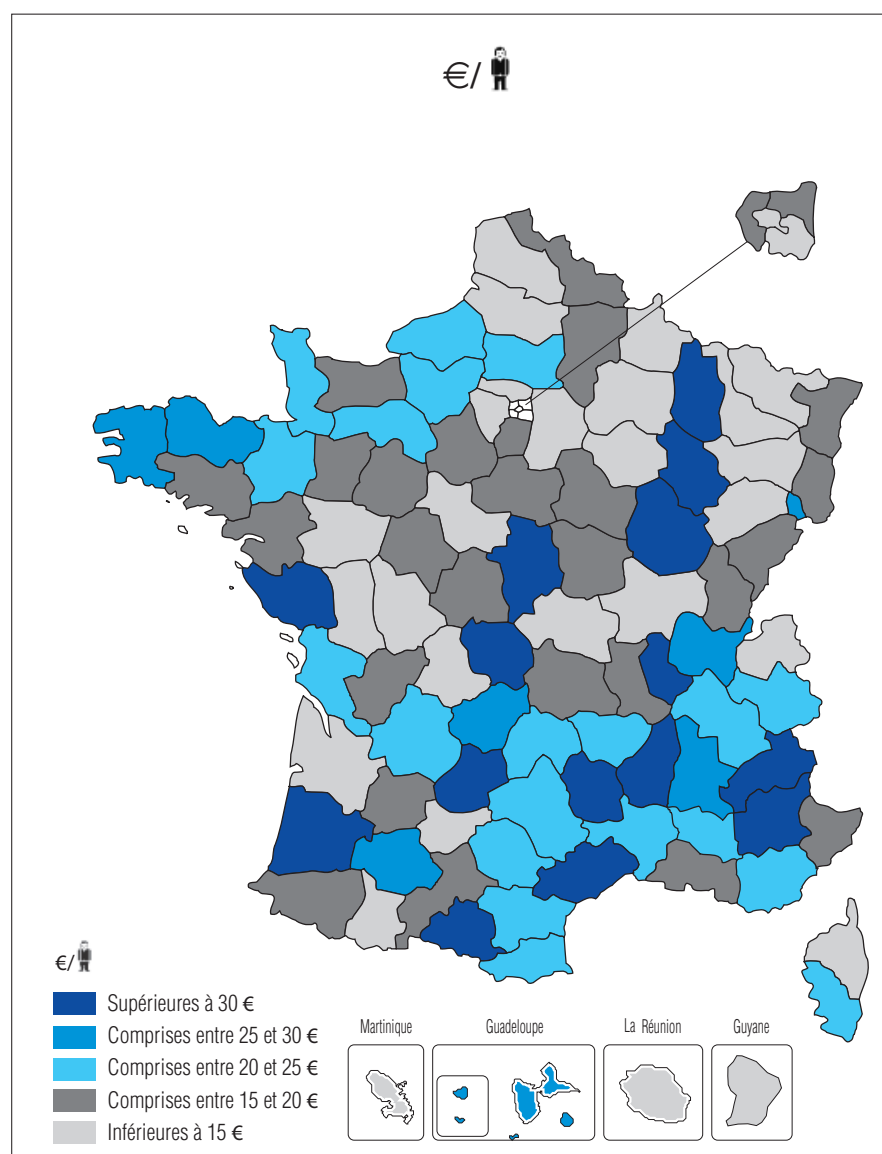

En $\%$ des dépenses totales

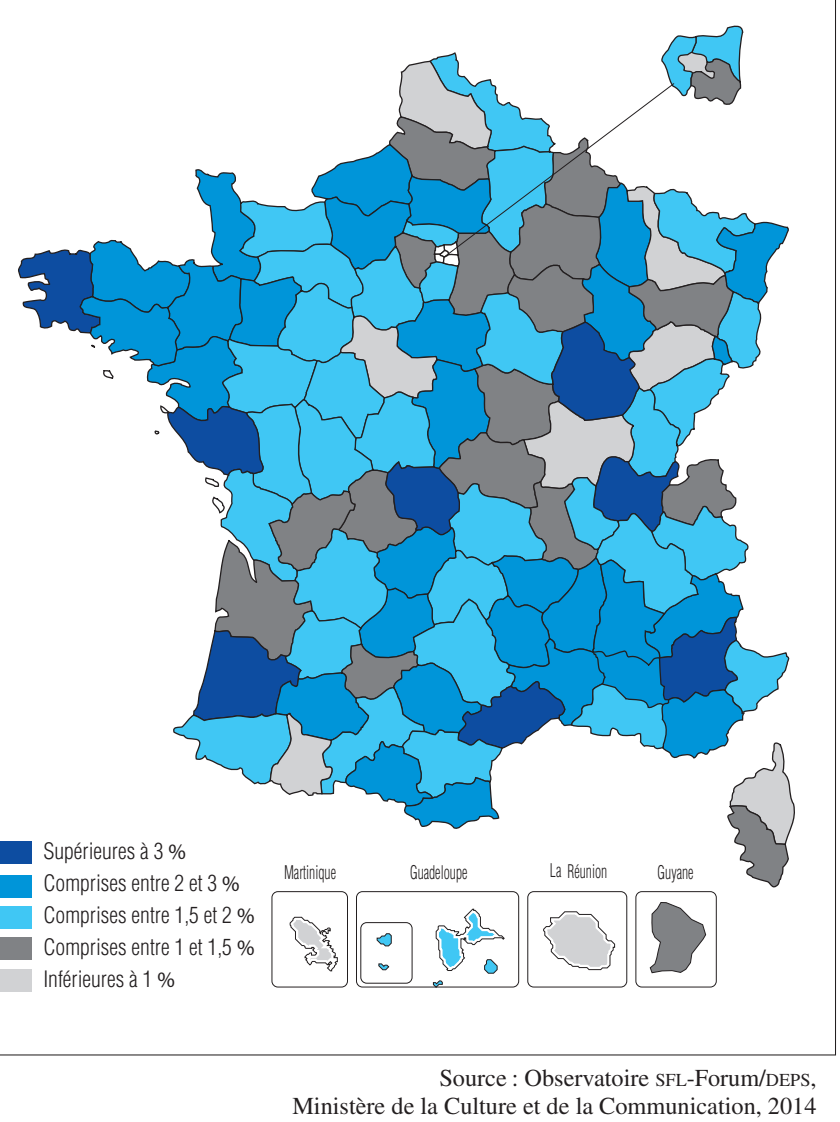




\section{Tableau 9 - Évolution moyenne annuelle des dépenses culturelles des départements de métropole, 2002-2010}

\begin{tabular}{|lcc|}
\hline & & En $\%$ \\
Évolution annuelle en valeur & $\mathbf{2 0 0 2 - 2 0 0 6}$ & $\mathbf{2 0 0 6 - 2 0 1 0}$ \\
Dépenses culturelles totales & & \\
dont fonctionnement & $+3,3$ & $+1,8$ \\
dont investissement & $+0,6$ & $+2,0$ \\
Évolution annuelle en volume & $+10,7$ & $+1,5$ \\
Dépenses culturelles totales & & \\
dont fonctionnement & $+1,3$ & $+0,4$ \\
dont investissement & $-1,3$ & $+0,5$ \\
& $+8,6$ & $+0,1$ \\
\hline
\end{tabular}

Source : Observatoire SFL-Forum/DEPS, Ministère de la Culture et de la Communication, 2014

doit être relativisée. Les dépenses totales des départements ont en effet augmenté rapidement du fait des transferts de compétences et de moyens en provenance de l'État, dans les domaines des collèges et de la voirie notamment, et de la forte progression des dépenses d'action sociale (voir Annexe méthodologique, p. 23). Cela prolonge les transferts de compétences antérieurs, dans le contexte de la création de l'allocation personnalisée d'autonomie (APA) en 2002 et des transferts de gestion de l'intégralité du dispositif revenu minimum d'insertion (RMI) en 2004, période où l'on avait observé une baisse consécutive de plus d'un point de l'effort budgétaire culturel. Rapportées à un budget en forte augmentation du fait d'un contour en évolution, les dépenses culturelles en représentent une part moindre, même si elles progressent.

\section{Hausse des subventions de fonctionnement...}

En euros courants, les dépenses totales de fonctionnement ont apparemment progressé plus rapidement qu'entre 2002 et 2006 ( $2 \%$ par an entre 2006 et 2010 contre $0,6 \%$ avant). Mais les données brutes des comptes administratifs,

\section{Graphique 7 -Évolution des dépenses culturelles des départements en fonctionnement, 2006-2013}

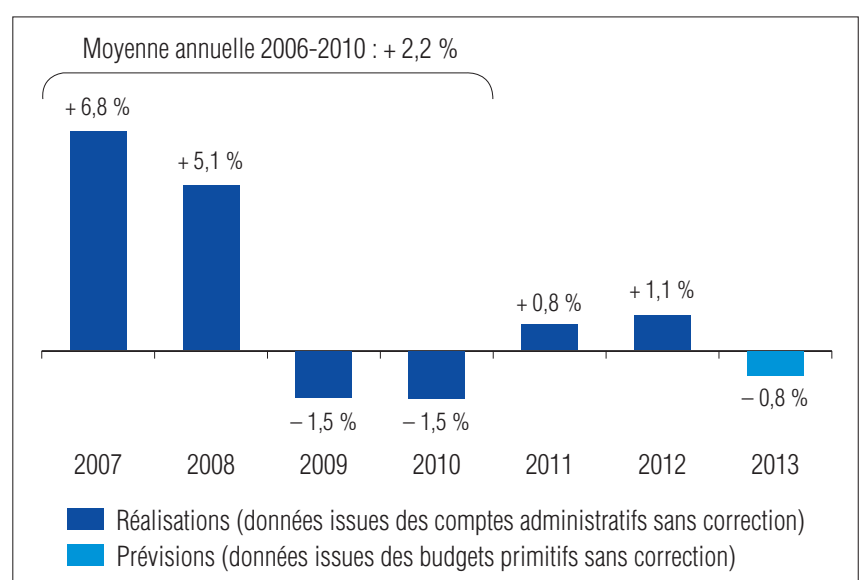

c'est-à-dire non corrigées et non redressées, permettent de suivre année après année le profil de l'évolution des dépenses globales culturelles de fonctionnement des départements (graphique 7). Elles n'ont été très fortes qu'en début de période (2007 et 2008). Elles ont ensuite reculé ou peu augmenté, moins vite que l'inflation; on ne peut plus parler d'augmentation des dépenses culturelles des départements depuis 2008.

Parmi les dépenses de fonctionnement, les charges générales ont été tenues à peu près au même rythme que l'inflation (+ 1,5\% par an environ) et les charges de personnel ont augmenté de 2,1\% par an. Les subventions, et particulièrement celles versées aux communes ou à leurs groupements, ont en revanche augmenté plus vite : $+3,4 \%$ par an.

\section{... baisse des subventions d'investissement}

De leur côté, les dépenses d'investissement ont augmenté de 1,5\% par an, soit beaucoup moins qu'entre 2002 et 2006 (tableau 9). Ici, les subventions baissent, en particulier celles orientées vers les communes et leurs groupements $(-4,4 \%$ par an) et vers les personnes et organismes de droit privé $(-3,8 \%)$; elles contribuent donc fortement au ralentissement des dépenses d'investissement. Les achats de collections et d'œuvres d'art aussi (-6,5\% par an). Les dépenses d'équipement augmentent en revanche de $+5,5 \%$ par an entre 2006 et 2010 ; ce sont elles qui font l'essentiel de la progression des dépenses d'investissement. La mesure des variations des dépenses d'investissement peut toutefois être influencée par le cycle municipal, quoique de façon indirecte. Son ralentissement ne peut donc pas être considéré à coup sûr comme représentatif d'une tendance réelle.

\section{Recul en volume des dépenses par habitant}

L'engagement culturel des départements peut aussi se mesurer par la dépense moyenne par habitant: elle est de 22,1 euros par habitant en 2010 en métropole, en hausse de

\section{Graphique 8 - Dépenses culturelles par habitant des départements en volume, 1975-2010}

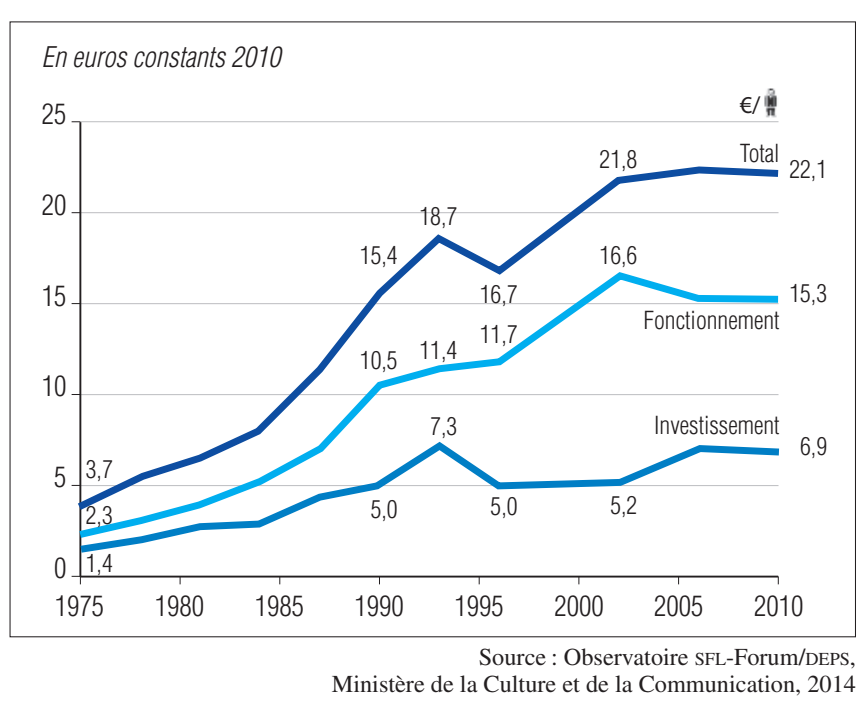


$5 \%$ par rapport à 2006 (21 euros si on rapporte les dépenses d'alors à la population recensée en 2006). Une fois prise en compte l'évolution de l'inflation, elle a très légèrement régressé en volume (graphique 8). La tendance au ralentissement des dépenses que l'on observait déjà entre 2002 et 2006 se prolonge donc, pour les dépenses de fonctionnement comme pour celles d'investissement.

\section{$36 \%$ des dépenses départementales de fonctionnement sont des dépenses de personnel et $41 \%$ sont des subventions}

Du fait de leurs compétences différentes (voir « Les dépenses consolidées »), la structure des dépenses culturelles des départements est très différente de celle des communes. D'abord, les dépenses d'investissement y sont proportionnellement plus importantes : $31 \%$ des dépenses culturelles départementales sont des dépenses d'investissement, contre $20 \%$ seulement pour celles des villes de plus de 10000 habitants. Ensuite, les dépenses des départements sont beaucoup plus orientées vers le patrimoine, en particulier vers les services d'archives et l'entretien du patrimoine, alors que celles des communes sont avant tout destinées à soutenir l'action culturelle et l'expression artistique. De fait, les dépenses d'investissement se dirigent généralement en priorité vers le patrimoine. Enfin, les dépenses de fonctionnement ne sont pas structurées de la même façon: moins de dépenses de personnel (36\% des dépenses de fonctionnement) et plus de subventions (41\%) dans les départements que dans les communes.

\section{Subventions départementales : surtout pour l'activité artistique et l'action culturelle}

Les dépenses de personnel prennent une place particulièrement importante dans les dépenses départementales destinées aux services d'archives (80\% des dépenses de fonctionnement) et aux bibliothèques et médiathèques (70 \%), qui relèvent tous deux de la compétence explicite des départements (tableau 10). Elles entrent en revanche très peu dans la composition des dépenses départementales des activités artistiques $(11 \%)$.

La part des subventions dans les dépenses de fonctionnement est de son côté la plus élevée pour les activités artistiques et l'action culturelle ( $72 \%$ ). Cette fonction culturelle absorbe d'ailleurs la quasi-totalité des subventions départementales.

Tableau 10 - Dépenses culturelles des départements par nature comptable et secteur d'intervention, 2010 (France métropolitaine)

\begin{tabular}{|c|c|c|c|c|c|c|c|}
\hline & \multirow{2}{*}{$\begin{array}{l}\text { Budget } \\
\text { total }\end{array}$} & \multicolumn{2}{|c|}{$\begin{array}{c}\text { Budget de } \\
\text { fonctionnement }\end{array}$} & \multicolumn{2}{|r|}{ dont } & \multicolumn{2}{|c|}{$\begin{array}{c}\text { Budget } \\
\text { d'investissement }\end{array}$} \\
\hline & & fonctio & $\begin{array}{r}\text { en \% du } \\
\text { budget } \\
\text { total }\end{array}$ & $\begin{array}{l}\text { charges } \\
\text { de } \\
\text { personnel }\end{array}$ & $\begin{array}{c}\text { subventions } \\
\text { aux collectivités locales } \\
\text { et aux personnes } \\
\text { de droit privé }\end{array}$ & & $\begin{array}{r}\text { en \% du } \\
\text { budget } \\
\text { total }\end{array}$ \\
\hline Activités artistiques et action culturelle & 529063 & 480147 & 90,8 & 50805 & 347026 & 48916 & 9,2 \\
\hline Bibliothèques et médiathèques & 193609 & 164439 & 84,9 & 114467 & 12573 & 29171 & 15,1 \\
\hline Musées & 192045 & 82776 & 43,1 & 32694 & 8021 & 109269 & 56,9 \\
\hline Patrimoine & 259923 & 105322 & 40,5 & 47135 & 25153 & 154602 & 59,5 \\
\hline Services d'archives & 173185 & 121522 & 70,2 & 96883 & 647 & 51663 & 29,8 \\
\hline Autres & 42328 & 3276 & 7,7 & 3233 & 0 & 39052 & 92,3 \\
\hline Total & 1390153 & 957481 & 68,9 & 345218 & 393421 & 432672 & 31,1 \\
\hline
\end{tabular}

Graphique 9 - Dépenses culturelles des départements par secteur d'intervention et nature comptable, 2010 (France métropolitaine)

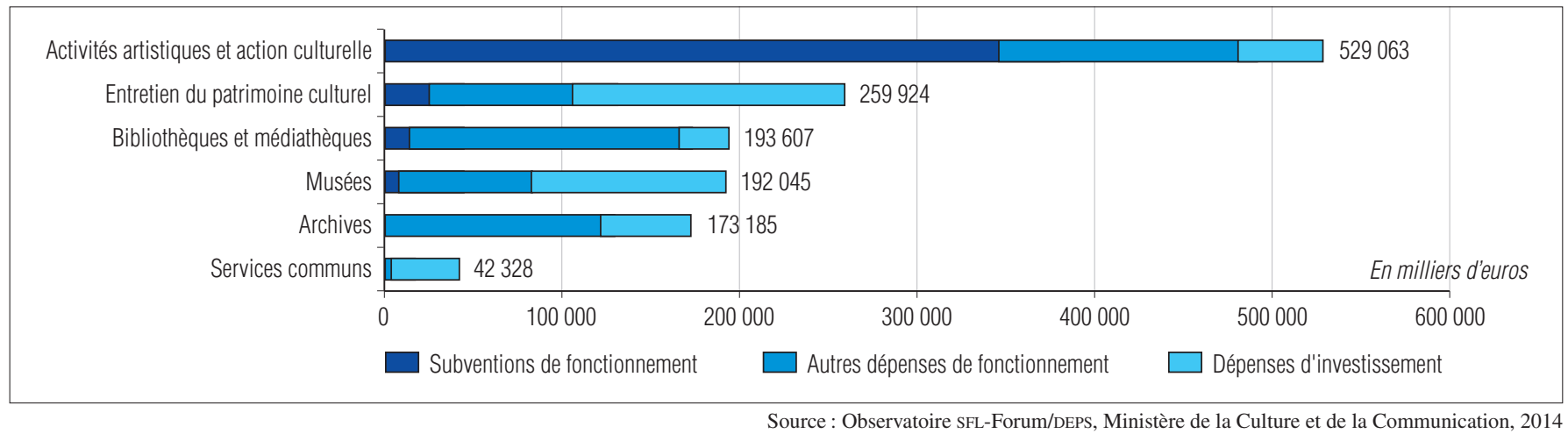


De leur côté, les dépenses d'investissement sont proportionnellement plus importantes pour l'entretien du patrimoine et les musées (graphique 9).

On retrouve donc là les grandes constantes liées à la nature des dépenses et à leur fonction culturelle de destination que l'on observe aussi dans les dépenses communales. Si les proportions sont différentes, la hiérarchie est quasi identique. Petite différence tout de même: les subventions départementales sont moins versées à des personnes ou organismes privés (71\% des subventions) que celles des communes $(80 \%)$, surtout lorsqu'elles sont destinées à la conservation et à la diffusion du patrimoine (52\%).

\section{Les musées constituent l'un des principaux facteurs de différenciation du profil des dépenses culturelles des départements}

Soixante-quinze des quatre-vingt-quinze départements de métropole (hors Paris) financent des actions dans l'ensemble des secteurs culturels. Tous les départements interviennent au titre des activités artistiques et des actions culturelles, des bibliothèques et médiathèques et des archives. Pour ces deux derniers domaines, cela est bien entendu lié aux compétences spécifiques transférées de longue date aux départements concernant les bibliothèques départementales de prêt ainsi que les services d'archives départementales. Ils sont 94 départements à avoir agi également au titre du patrimoine. Les interventions concernant les musées constituent alors un important facteur de disparité dans les interventions départementales: 19 départements n'ont, selon leurs comptes et leurs réponses à l'enquête, pas engagé de dépenses à ce titre en 2010. La disparité observée à cet égard s'amplifie si l'on considère la nature des dépenses engagées par les 76 autres départements : seulement 65 ont enregistré des dépenses en fonctionnement et en investissement ; les 11 autres n'ont engagé que des dépenses d'investissement (2) ou des dépenses de fonctionnement (9).

Pour les trois domaines dans lesquels tous les départements interviennent (activités artistiques et action culturelle, bibliothèques et médiathèques et archives), la quasi-totalité des départements (94) ont engagé des dépenses de fonctionnement. Les disparités sont plus marquées en investissement : si tous les départements sont intervenus au titre des archives, ils sont 88 dans ce cas dans le domaine des bibliothèques et médiathèques et seulement 81 pour des opérations liées aux activités artistiques et culturelles.

Concernant le patrimoine, à l'inverse, tous les départements concernés ou presque (94) interviennent en investissement mais ils sont légèrement moins nombreux en fonctionnement (89).

\section{Encadré 6 - Les dépenses des départements d'outre-mer}

Pour trois Dom sur quatre, les dépenses culturelles de fonctionnement sont inférieures à la moyenne métropolitaine.

Les DOM affichent des niveaux de dépenses culturelles un peu inférieurs à ceux des départements métropolitains, surtout en raison d'un niveau d'investissement culturel significativement plus faible (3,6 euros par habitant contre 6,9 euros en métropole). En fonctionnement, leurs dépenses culturelles par habitant sont en revanche un peu supérieures (17,1 euros contre 15,3 euros en métropole).

Le département de la Martinique affiche un budget culturel de fonctionnement comparable à celui de La Réunion, presque deux fois plus peuplée, et le ratio de ces dépenses rapportées au nombre d'habitants est, logiquement, deux fois plus élevé pour la Martinique. Les dépenses culturelles de fonctionnement de ce département le placent même dans le groupe de tête de la douzaine de départements affichant plus de 25 euros par habitant pour leurs dépenses culturelles de fonctionnement, alors que les trois autres DOM se situent un peu en deçà de la moyenne nationale. La Martinique réalise un effort budgétaire autour de $2 \%$ en fonctionnement, légèrement supérieur à la moyenne nationale (1,9\%) et supérieur donc à celui des autres Dom, un peu au-dessus de $1 \%$.

En matière d'investissement culturel, seul le département de la Guadeloupe échappe à un niveau nettement inférieur à la moyenne de l'ensemble des départements, en lui consacrant en 2010 près de $4 \%$ de ses investissements totaux (contre 3,1\% en métropole et 1,4\% pour les Dom). Le budget culturel de ce département se répartit d'ailleurs presque à parts égales (55\% et $45 \%$ ) entre dépenses de fonctionnement et d'investissement, contre 2/3 et 1/3 en moyenne.

Finalement, le département le plus peuplé et celui le moins peuplé, respectivement La Réunion et la Guyane, se rapprochent en matière de dépenses culturelles, tant en euros par habitant qu'en pourcentage des dépenses générales; ils ont tous deux réalisé en 2010 un très faible effort d'investissement culturel.

Les bibliothèques-médiathèques et les services d'archives mobilisent une grande part des dépenses culturelles de fonctionnement des départements d'outre-mer

Par rapport à la métropole, les DOM mobilisent proportionnellement un peu plus de crédits au titre des bibliothèques et médiathèques (et plus encore en fonctionnement, en lien avec une part plus importante relevant des dépenses de personnel pour ce secteur) ainsi que des archives, et un peu moins en direction des musées (en particulier en investissement) ou des activités culturelles et de l'action culturelle (en fonctionnement).

Le département de La Réunion est celui qui se rapproche le plus du profil moyen des départements de métropole, en consacrant plus de la moitié de ses dépenses culturelles de fonctionnement aux activités artistiques et à l'action culturelle et, respectivement, $15 \%$ aux bibliothèques-médiathèques (contre $17 \%$ en métropole) et $12 \%$ aux services d'archives (contre $13 \%$ ).

En revanche, les trois autres Dom s'en distinguent, en mobilisant par exemple une part relativement plus grande de leurs crédits de fonctionnement destinés à la culture en faveur des bibliothèques-médiathèques, en particulier le conseil général de Guyane ( $52 \%$ de ses dépenses culturelles de fonctionnement vont à ce seul secteur) ou en direction de leurs services d'archives, en particulier pour le département de la Guadeloupe (24\% en fonctionnement). Le département de la Martinique, enfin, se différencie également en faveur des musées, auxquels sont dévolus $12 \%$ des crédits culturels de fonctionnement (contre $9 \%$ en métropole), alors qu'a contrario, ce secteur ne pèse que $2 \%$ dans le budget culturel de la Guadeloupe. Ce dernier département affiche cependant le pourcentage de ses crédits de fonctionnement consacré au patrimoine le plus élevé des DoM (22\% contre $10 \%$ en moyenne) et de même en investissement: $42 \%$, très au-dessus de la moyenne métropolitaine (36\%).

Les dépenses d'investissement du département de la Guadeloupe représentaient globalement plus de $70 \%$ de l'ensemble des investissements culturels des DOM en 2010: $85 \%$ des investissements dans le secteur du patrimoine, $75 \%$ dans celui des archives (comme pour les activités artistiques), ou encore $60 \%$ dans le secteur des musées. 


\section{LES DÉPENSES CULTURELLES DES RÉGIONS EN 2010}

\section{2 millions d'euros, soit 2,6\% du budget des régions, sont consacrés aux dépenses culturelles en métropole}

Les régions métropolitaines ont consacré 662 millions d'euros à la culture en 2010, soit 2,6\% de leur budget et 10,5 euros par habitant. Le fonctionnement (dépenses de personnel, charges générales, subventions de fonctionnement) couvre $73 \%$ de ces dépenses soit 480 millions d'euros (tableau 11); c'est 3,1\% du budget de fonctionnement des régions. De leur côté, les investissements culturels sont de 182 millions d'euros et représentent $2 \%$ des dépenses d'investissement des régions.

L'effort culturel, qui rapporte le budget culturel au budget total, varie de 1 à 3 d'une région à une autre (de $1,7 \%$ à 4,6\%). La dépense par habitant varie entre 6,4 euros et 18,3 euros (hors Corse, 56 euros : la collectivité territoriale de Corse a, seule, bénéficié d'importants transferts de compétence culturelle, dans le domaine du patrimoine en particulier, par les lois du 13 mai 1991 - dite loi Joxe - et du 22 janvier 2002 ; elle est de plus la région métropolitaine la moins peuplée, 2,4 fois moins que le Limousin) (cartes).

Les régions d'outre-mer ont dépensé 34 millions d'euros au titre de la culture en 2010 (tableau 11 et encadré 7). La dépense culturelle par habitant des régions d'outre-mer est pratiquement deux fois plus élevée qu'en métropole, mais c'est aussi le cas de l'ensemble des dépenses : leur effort budgétaire culturel est donc assez semblable à celui des régions métropolitaines.

Tableau 11 - Dépenses culturelles des régions, 2010

\begin{tabular}{|lrrr|}
\hline Dépenses culturelles & $\begin{array}{r}\text { Régions } \\
\text { de métropole }\end{array}$ & $\begin{array}{r}\text { Régions } \\
\text { d'outre-mer* }\end{array}$ & $\begin{array}{r}\text { Ensemble des } \\
\text { régions }\end{array}$ \\
En milliers d'euros & 661747 & 34055 & $\mathbf{6 9 5} \mathbf{8 0 2}$ \\
dont fonctionnement & 479781 & 25879 & 505660 \\
dont investissement & 181966 & 8175 & 190142 \\
En euros/habitant $(€ /$ i. & 10,5 & 18,4 & 10,8 \\
dont fonctionnement & 7,6 & 14,0 & 7,8 \\
dont investissement & 2,9 & 4,4 & 2,9 \\
En \% du budget & 2,6 & 2,8 & $\mathbf{2 , 7}$ \\
dont fonctionnement & 3,1 & 3,9 & 3,1 \\
dont investissement & 2,0 & 1,5 & 1,9 \\
* Guadeloupe, Guyane, Martinique et La Réunion & & \\
\hline
\end{tabular}

Source : Observatoire SFL-Forum/DEPS, Ministère de la Culture et de la Communication, 2014

\section{Cartes - Dépenses culturelles en euros par habitant} et en pourcentage du budget, 2010

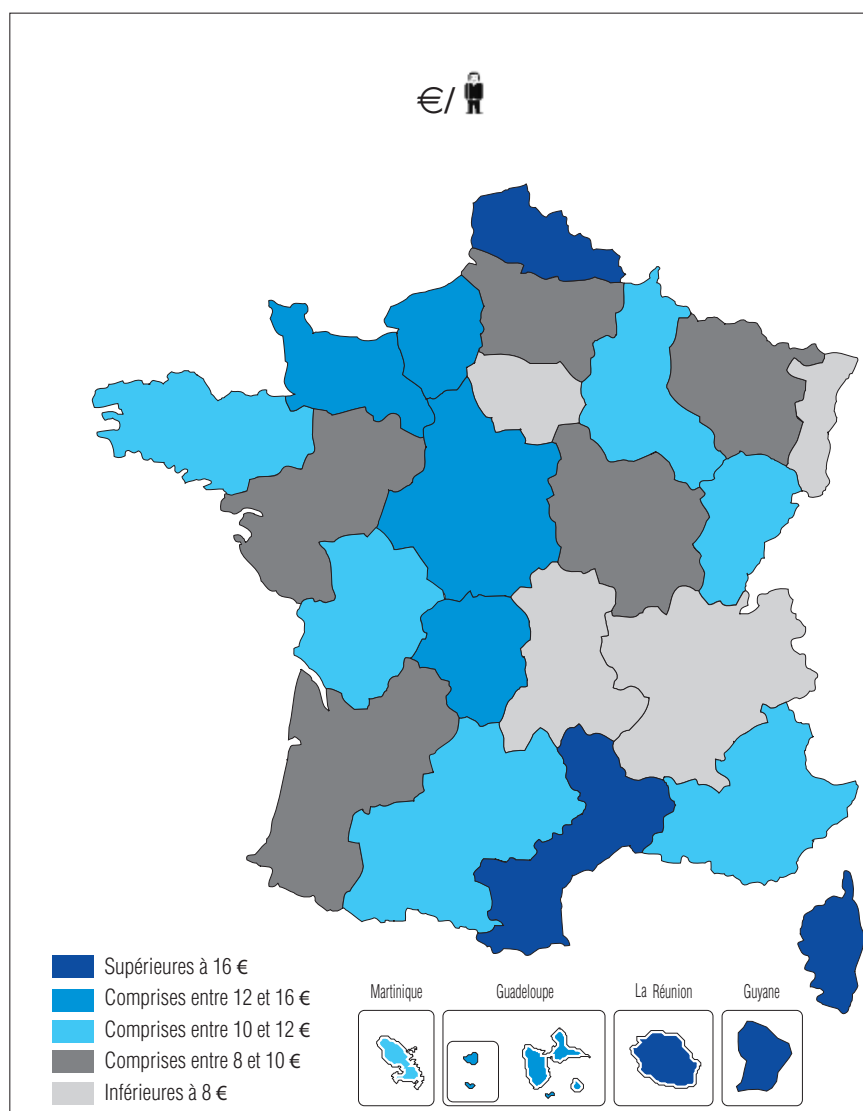

En \% des dépenses totales

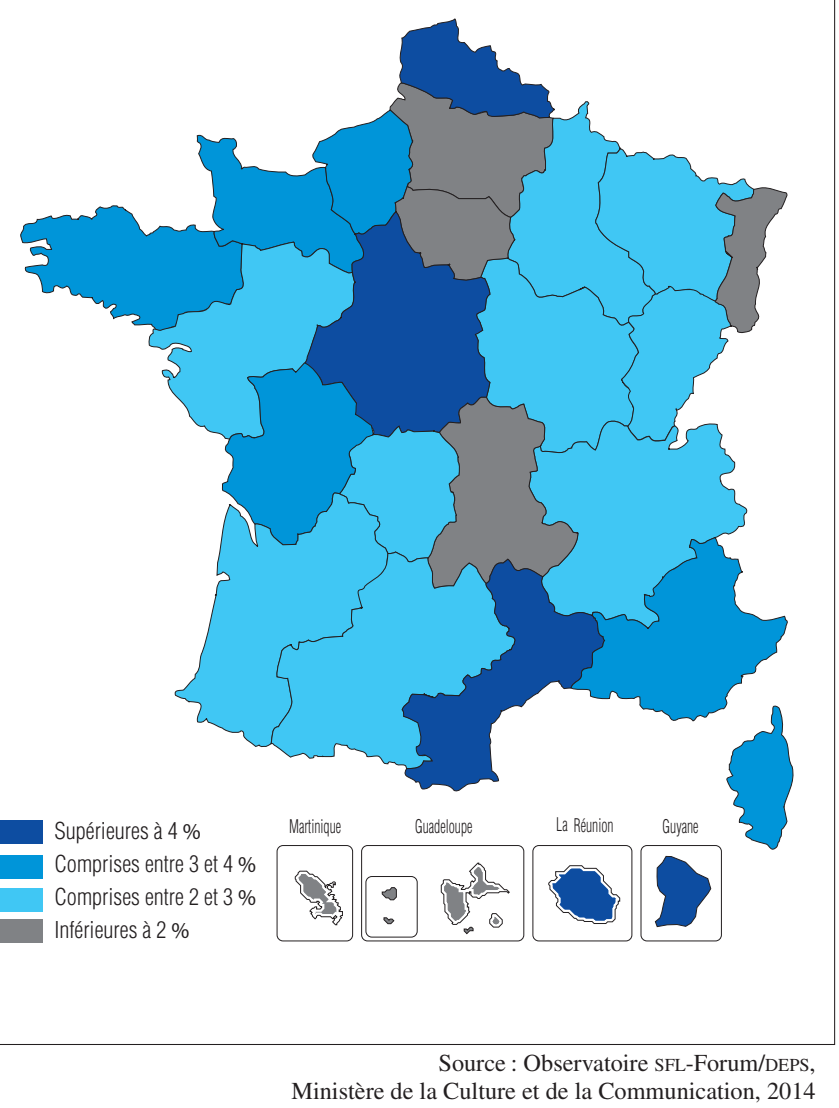




\section{Ralentissement des dépenses régionales}

Les dépenses culturelles des régions ont augmenté de 4,5\% par an en moyenne en métropole entre 2006 et 2010 (tableau 12). Ce dynamisme est surtout porté par les dépenses de fonctionnement (+ 5,5\% par an), l'investissement connaissant une progression plus modérée $(+2 \%)$. L'analyse de l'évolution en investissement est, ici aussi, rendue délicate sur la base de deux années de référence seulement, étant donné sa grande variabilité potentielle. Les crédits de fonctionnement consacrés à la culture ont augmenté pour 20 régions sur 22 . Par contraste, seulement 13 régions ont connu un accroissement des crédits d'investissement consacrés à la culture.

La progression des dépenses culturelles des régions enregistrée entre 2006 et 2010 a nettement décéléré par rapport à celle qui avait été observée à partir des précédentes enquêtes. Ainsi, l'évolution moyenne annuelle des dépenses de fonctionnement a été divisée par deux (tableau 12). Le tassement est plus sensible encore en investissement : alors que les dépenses culturelles avaient progressé de $12,1 \%$ par an en volume entre 2002 et 2006, elles sont quasiment stables entre 2006 et $2010(+0,6 \%)$.

\section{Baisse de l'effort budgétaire culturel par rapport à 2006}

En termes d'effort budgétaire, c'est-à-dire rapportées au budget total des régions, les dépenses culturelles se sont légèrement tassées : elles représentent $2,6 \%$ du budget en 2010 , contre $2,8 \%$ en 2006. Sur la période 2006-2010, la hausse des budgets globaux des régions $(+5,9 \%$ par an) a de fait été plus soutenue que celle des dépenses culturelles $(+4,5 \%)$. La progression des dépenses culturelles s'est en effet inscrite dans un contexte de poursuite de l'élargissement des budgets régionaux lié aux différents transferts de compétences dont elles ont fait l'objet, depuis 2002, dans les domaines de l'apprentissage et de la formation professionnelle, de l'enseignement secondaire et des transports. Le

\section{Tableau 12 - Évolution moyenne annuelle des dépenses culturelles des régions de métropole, 2002-2010}

\begin{tabular}{|c|c|c|}
\hline & 2002-2006 & 2006-2010 \\
\hline \multicolumn{3}{|l|}{ Évolution annuelle en valeur } \\
\hline Dépenses culturelles totales & $+11,6$ & $+4,5$ \\
\hline dont fonctionnement & $+10,5$ & $+5,5$ \\
\hline dont investissement & $+14,3$ & $+2,0$ \\
\hline \multicolumn{3}{|l|}{ Évolution annuelle en volume } \\
\hline Dépenses culturelles totales & $+9,5$ & $+3,0$ \\
\hline dont fonctionnement & $+8,4$ & $+3,9$ \\
\hline dont investissement & $+12,1$ & $+0,6$ \\
\hline
\end{tabular}

poids des dépenses culturelles dans les dépenses de fonctionnement a donc régressé, passant de $3,4 \%$ en 2006 à $3,1 \%$ en 2010. La majorité des transferts de compétences dont ont bénéficié les régions depuis 2002 a en effet touché la section de fonctionnement. Les données brutes des comptes administratifs, c'est-à-dire non corrigées et non redressées, permettent de suivre année après année le profil de l'évolution des dépenses globales culturelles de fonctionnement des régions (graphique 10). Elles ont en fait été très fortes en début de période (2007 et 2009) mais ont ensuite très peu augmenté, ou reculé comme en 2011 et en 2013 (concernant, pour cette dernière année, les données des budgets primitifs). La progression de 5,5\% par an des dépenses de fonctionnement doit donc être relativisée.

De son côté, le poids des dépenses d'investissement culturelles dans l'ensemble des dépenses d'investissement est resté stable entre 2006 et 2010, à $2 \%$.

\section{Ralentissement des dépenses par habitant en volume}

L'engagement culturel des régions peut aussi se mesurer par la dépense moyenne par habitant: elle est de 10,5 euros en 2010 en métropole, plus élevée qu'en 2006 même une fois corrigée de l'inflation (graphique 11). La progression est plus faible qu'entre 2002 et 2006, années de forte accélération des dépenses régionales. Elle est essentiellement portée par les dépenses de fonctionnement, celles d'investissement étant en léger retrait en volume.

\section{$84 \%$ des dépenses culturelles sont des subventions}

Du fait du partage de compétence entre niveaux de collectivité, contrairement aux autres collectivités territoriales, l'essentiel des dépenses culturelles des régions est constitué de subventions, qu'elles soient de fonctionnement ou d'investissement : 553 millions d'euros au total en métropole, soit $84 \%$ des dépenses culturelles.

En fonctionnement, les subventions versées par les régions au titre de la culture représentent 5,9\% de l'ensemble des subventions de fonctionnement versées par les régions. Elles bénéficient essentiellement aux personnes de droit privé ( $85 \%$ des subventions) : associations, individus (bourses, etc.) ou entreprises.

Contrairement aux subventions de fonctionnement, l'essentiel $(60 \%)$ des subventions d'investissement est versé aux communes et groupements de communes, illustrant l'importance des financements croisés, et seulement $24 \%$ aux bénéficiaires de droit privé.

La grande majorité des régions n'est en revanche pas en mesure d'identifier avec précision les dépenses relatives au personnel régional intervenant dans le domaine culturel (voir Annexe méthodologique, p. 23). 
Graphique 10 - Évolution des dépenses culturelles des régions en fonctionnement, 2006-2013

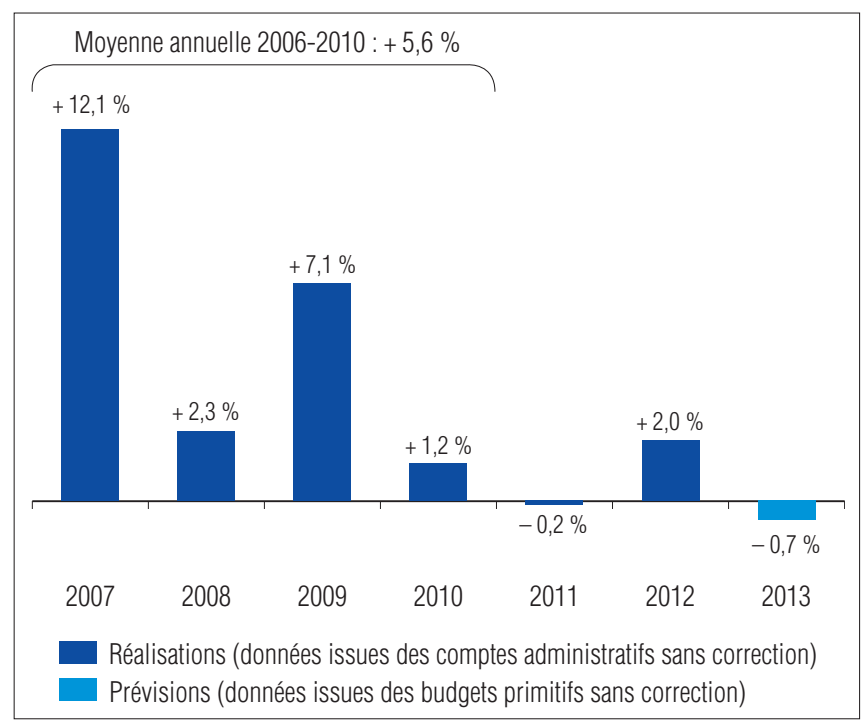

Source : Observatoire SFL-Forum/DEPS,

Ministère de la Culture et de la Communication, 2014

\section{Les trois quarts des dépenses des régions sont orientées vers les activités culturelles et artistiques, principalement sous forme de subventions}

La nomenclature fonctionnelle des comptes administratifs des régions est beaucoup plus agrégée que pour les autres types de collectivités, et constitue une limite forte pour l'appréciation de leurs dépenses culturelles. Les activités culturelles et artistiques, qui regroupent les actions en faveur de la création et de la diffusion des œuvres artistiques (voir Annexe méthodologique, pour les nomenclatures utilisées), représentent les trois quarts des dépenses culturelles régionales (graphique 12). Les régions métropolitaines y ont consacré 491 millions d'euros en 2010, dont 422 millions en fonctionnement. Il s'agit essentiellement de subventions ( $86 \%$ en fonctionnement) en direction de bénéfi-

\section{Graphique 11 - Dépenses culturelles par habitant des régions en volume, 1984-2010}

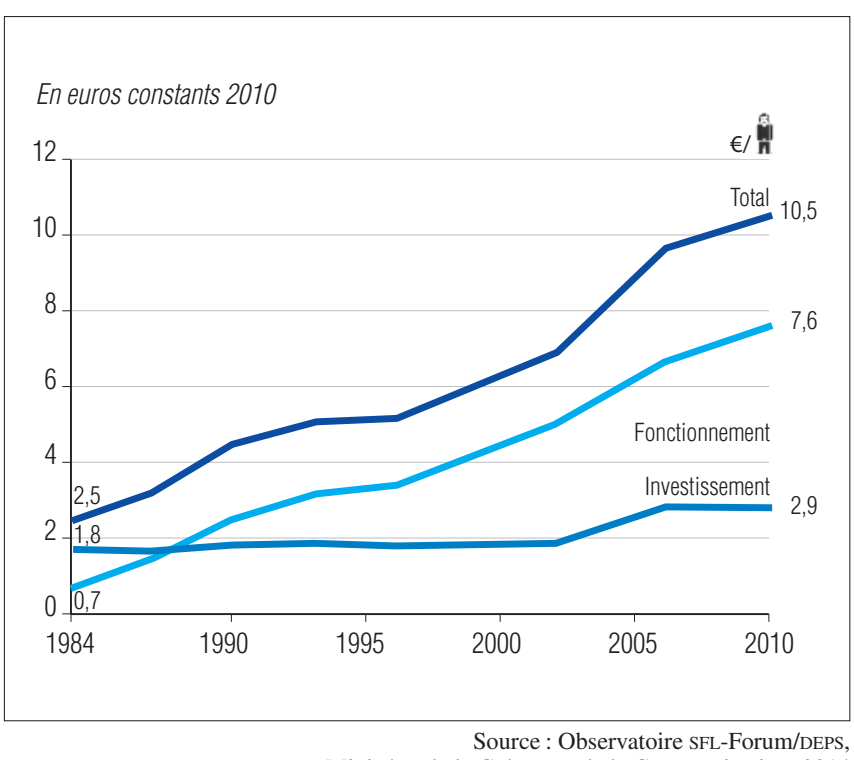

Ministère de la Culture et de la Communication, 2014

ciaires privés (327 millions d'euros en fonctionnement). Ces dépenses comprennent en particulier le soutien aux formations dites permanentes (orchestres, chorales, troupes de théâtre...), aux scènes nationales et autres salles de spectacle ainsi qu'aux festivals, ou encore les aides aux associations des différentes disciplines artistiques, y compris en matière de pratique amateur.

Les subventions d'équipement (investissement) versées dans ce domaine (64 millions d'euros) le sont plutôt au bénéfice des communes et de leurs groupements (à hauteur de 38 millions d'euros, soit $60 \%$ de ces subventions). Ce domaine, les activités culturelles et artistiques, où toutes les régions interviennent, totalise $88 \%$ des dépenses culturelles de fonctionnement des régions de métropole ; il a progressé de $+4,2 \%$ par an en moyenne entre 2006 et 2010.

La conservation et la diffusion des patrimoines, c'est-àdire les actions d'entretien, de protection et d'ouverture au public du patrimoine culturel (monuments, archives, biblio-

Graphique 12 - Dépenses culturelles des régions par secteur d'intervention et nature comptable, 2010 (France métropolitaine)

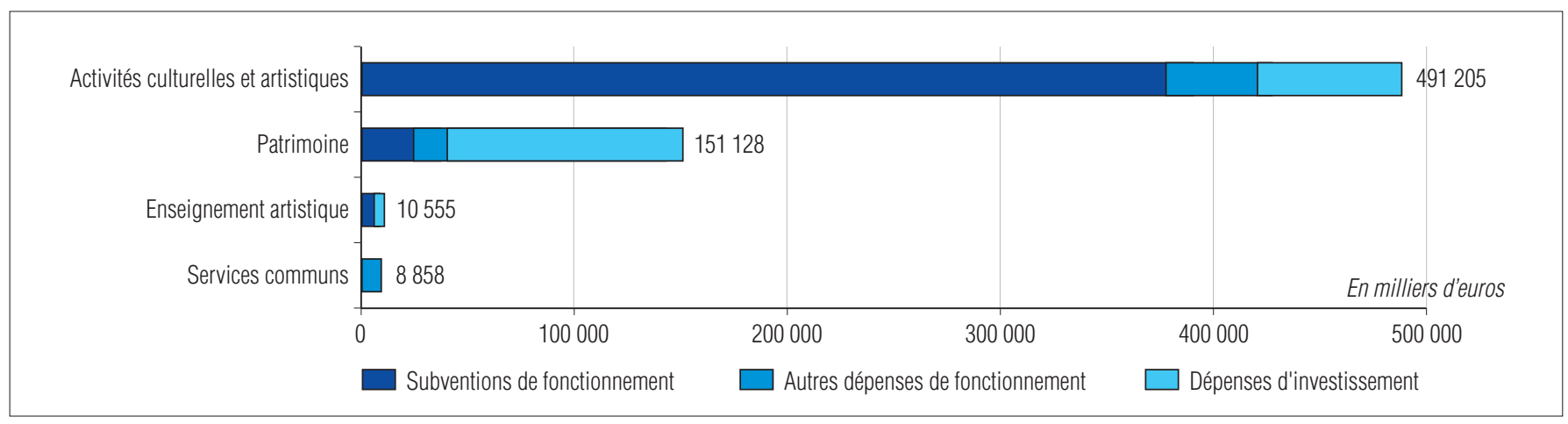


thèques, musées...), ont bénéficié de 151 millions d'euros, soit $23 \%$ des dépenses culturelles globales des régions métropolitaines. Ces dépenses correspondent essentiellement à des dépenses d'investissement et représentent de fait plus de $60 \%$ de toutes les dépenses culturelles en investissement; elles se composent aux deux tiers de subventions d'investissement. En investissement, les subventions bénéficiant aux communes et à leurs groupements dans ce domaine du patrimoine (44 millions d'euros) représentent le double des subventions régionales de fonctionnement en direction des acteurs privés (20 millions d'euros).

Comme les dépenses consacrées aux activités culturelles et artistiques, celles consacrées au patrimoine ont été dynamiques entre 2006 et 2010 (+ 7,6\% par an).

\section{Enseignement artistique : légère baisse des dépenses régionales entre 2006 et 2010}

La moitié seulement des régions métropolitaines (dix) présentent des dépenses dans le domaine de l'enseignement artistique, auquel elles ont consacré 11 millions d'euros en 2010 (1,6\% des dépenses culturelles de l'ensemble des régions métropolitaines). Depuis 2006, les crédits consacrés à ce secteur en métropole ont baissé : en fonctionnement, ils ont baissé de $1 \%$ par an, et les investissements sont quasiment deux fois plus faibles qu'en 2006.

Parmi les dépenses identifiées par les régions comme relevant de la culture, sans avoir été enregistrées dans les rubriques correspondantes de la nomenclature, certaines, pour un montant total de 9 millions d'euros, n'ont pas pu être ventilées au sein de l'un des trois secteurs d'intervention de la nomenclature.

Tableau 12 - Dépenses culturelles des régions par nature comptable et secteur d'intervention, 2010 (France métropolitaine)

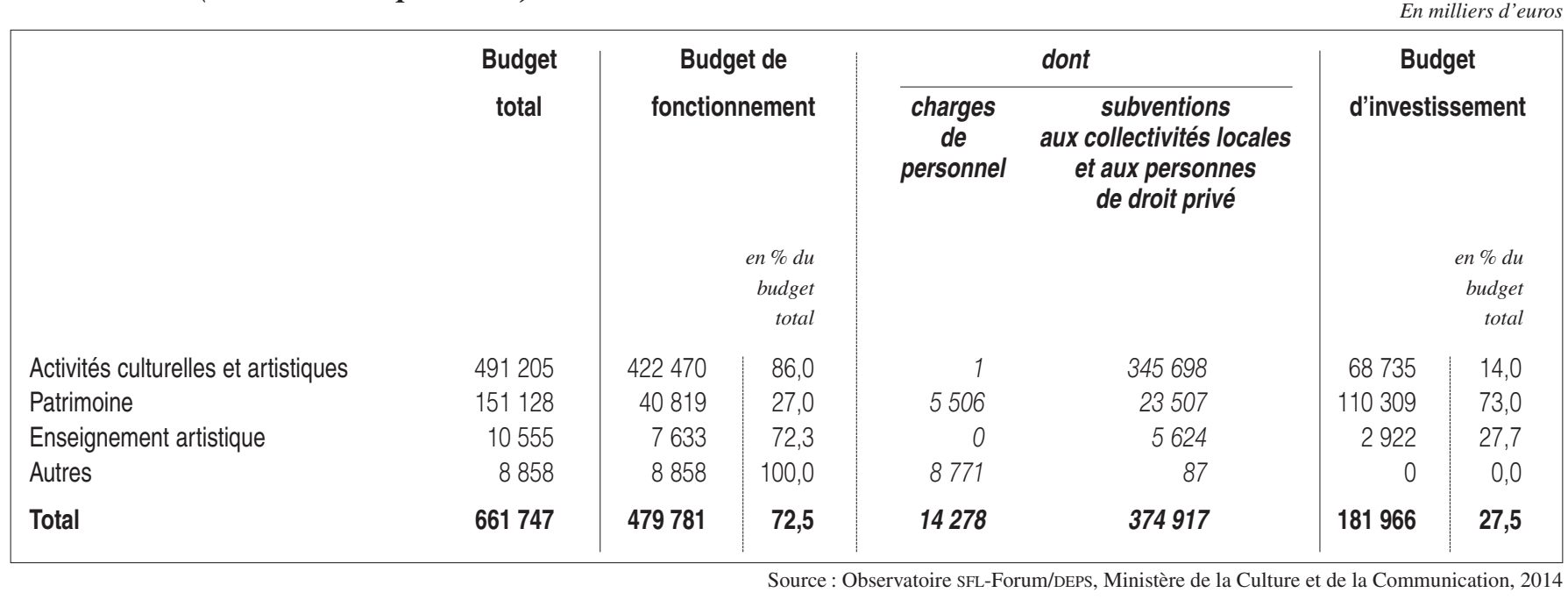

\section{Encadré 7 - Les dépenses culturelles des régions d'outre-mer}

Totalisant un peu plus de 34 millions d'euros pour la culture en 2010, les quatre régions d'outre-mer présentent certaines caractéristiques qui les différencient des régions métropolitaines, sans être homogènes entre elles.

Ainsi, la Guyane et La Réunion affichent un effort culturel de fonctionnement parmi les plus élevés (plus de $5 \%$ des dépenses totales sont des dépenses culturelles) et réalisent un montant de dépenses culturelles supérieur à 15 euros par habitant en fonctionnement (contre 7,6 euros en moyenne pour les régions métropolitaines). Les deux autres régions d'outre-mer ont des dépenses de fonctionnement par habitant plus proches de la moyenne mais tout de même au-dessus de la métropole (entre 8 et 10 euros par habitant).

Les dépenses culturelles totales de La Réunion sont supérieures à la somme des dépenses des trois autres régions d'outre-mer, alors que sa population représente $44 \%$ de la population d'outre-mer.

Les régions Guadeloupe, Martinique et Guyane engagent chacune entre 4 et 6,5 millions d'euros au titre de la culture. Elles présentent une répartition entre fonctionnement et investissement de leurs dépenses culturelles atypique, avec des dépenses culturelles d'investissement ne représentant que 10 à $13 \%$ des dépenses culturelles totales pour la Martinique et la Guyane, et au contraire $45 \%$ de ses dépenses culturelles totales pour la région de la Guadeloupe (contre $27 \%$ en métropole).

Les régions d'outre-mer se distinguent des régions métropolitaines par la prépondérance de l'enseignement artistique, qui représente entre $44 \%$ et $65 \%$ des dépenses de fonctionnement dans trois des quatre régions (sachant que la moitié seulement des régions de métropole affichent des dépenses sur ce secteur). Les activités culturelles et artistiques bénéficient logiquement d'une part plus réduite des dépenses culturelles à l'exception de la Guadeloupe : $77 \%$. En investissement, elles y surpassent en effet les dépenses orientées vers le patrimoine, qui fait plus l'objet d'interventions directes, y compris en fonctionnement, que de subventions. 


\section{Annexe : sources et méthodes}

1 - L'enquête sur les dépenses et les recettes des collectivités territoriales a été menée auprès de l'ensemble des régions et des départements de France, de tous les établissements de coopération intercommunale (EPCI) à fiscalité propre comportant en leur sein au moins une commune de plus de 10000 habitants et ayant déclaré la compétence culturelle, de l'intégralité des syndicats d'agglomération nouvelle (SAN) compétents, et auprès d'un échantillon de 207 communes représentatif des 930 communes de plus de 10000 habitants (selon le recensement de la population de 2007, le plus récent disponible lors du tirage de l'échantillon). Elle a été réalisée par le DEPS, qui s'est appuyé sur le pôle «Statistiques et finances locales » (SFL) du Forum pour la gestion des villes et des collectivités territoriales.

Elle repose dans un premier temps sur la saisie, au niveau le plus fin possible des nomenclatures comptables, des données sur les dépenses exécutées, récapitulées dans les comptes administratifs des collectivités enquêtées. Les collectivités reçoivent ensuite un questionnaire visant à valider, corriger ou à préciser l'affectation des dépenses déclarées. Sur la base de ces enquêtes, les traitements statistiques d'imputation de valeurs manquantes ou de redressement des réponses permettent d'estimer au niveau national les dépenses de chaque groupe de collectivités.

2 - Les dépenses analysées correspondent aux seules dépenses inscrites dans le budget principal des collectivités. Les budgets annexes, qui enregistrent les opérations liées à certaines activités ou équipements culturels spécifiques, ne font pas partie du champ de l'étude. À titre informatif, en 2006, les montants enregistrés dans les budgets annexes culturels des départements de métropole représentaient seulement $0,7 \%$ des montants inscrits dans les budgets principaux; pour les villes, $4,4 \%$. La pratique des budgets annexes est assez stable dans le temps.

Les comptes peuvent inclure des mouvements d'ordre, c'est-à-dire des opérations comptables qui ne se traduisent pas par un encaissement ou un décaissement et qui s'équilibrent en dépenses et en recettes. Ces opérations gonflent les budgets des collectivités et doivent donc être neutralisées pour connaître l'intervention effective des collectivités. Certains mouvements d'ordre étaient directement identifiables dans le compte. Sollicitées grâce au questionnaire, les collectivités ont pu soit confirmer que la fonction culture ne comprenait pas de mouvements d'ordre soit signaler de tels montants.

Les opérations liées à la gestion active de la dette consistent en deux types d'opérations : le réaménagement de la dette (un emprunt est soldé grâce à un nouvel emprunt à un taux d'intérêt inférieur au précédent) et l'option de tirage sur ligne de trésorerie, dont peut être assorti un emprunt de la collectivité (lorsqu'elle dispose d'un volant de trésorerie, la collectivité rembourse par anticipation et momentanément tout ou partie de l'emprunt, évitant les intérêts sur la période). Dans les deux cas, la dette contractée est inchangée, seuls les intérêts dus varient: ces opérations se traduisent budgétairement par une recette et une dépense du même montant, parfois plusieurs fois sur l'année; si elles sont donc neutres sur l'équilibre financier de la collectivité, elles viennent gonfler « artificiellement » et dans des proportions importantes, les volumes de dépenses et de recettes. C'est pourquoi elles sont, dans l'analyse, systématiquement neutralisées des dépenses d'investissement. Ces traitements n'étaient pas faits dans les publications antérieures et l'effort budgétaire correctement calculé et publié ici pour 2010 ne peut pas être comparé directement avec ceux des publications antérieures. Les comparaisons faites dans la présente publication se font à partir de ratios recalculés.

3 - Les traitements des réponses à l'enquête, ainsi que les nomenclatures utilisées pour ventiler les domaines culturels d'affectation des dépenses, sont différents pour chaque type de collectivités. Chaque type de collectivités possède par ailleurs des compétences culturelles qui lui sont propres.

\section{Les communes}

L'enquête a porté sur un échantillon de 207 communes de plus de 10000 habitants, incluant la totalité des communes de plus de 100000 habitants. Compte tenu de la taille des communes du champ de l'enquête, on les appelle parfois "villes » dans le texte de l'étude.

\begin{tabular}{|c|c|c|c|}
\hline $\begin{array}{l}\text { Nombre de communes } \\
\text { (population 2010, millésime 2007) }\end{array}$ & $\begin{array}{c}\text { France } \\
\text { métropolitaine }\end{array}$ & DOM $^{*}$ & $\begin{array}{l}\text { France } \\
\text { entière }\end{array}$ \\
\hline $\begin{array}{l}\text { De } 10000 \text { à moins de } 100000 \text { habitants } \\
100000 \text { habitants ou plus }\end{array}$ & $\begin{array}{r}843 \\
39\end{array}$ & $\begin{array}{r}46 \\
2\end{array}$ & $\begin{array}{r}889 \\
41\end{array}$ \\
\hline Total & 882 & 48 & 930 \\
\hline
\end{tabular}

Source : Observatoire SFL-Forum/DEPS, Ministère de la Culture et de la Communication, 2014

La nomenclature budgétaire et comptable M14 des communes distingue neuf secteurs d'intervention culturelle regroupés en trois grandes fonctions (au sein de la fonction 3): 
A - « L'expression artistique » regroupe les actions en faveur de la création et de la diffusion des œuvres artistiques et en faveur de la formation à la pratique artistique :

- rubrique 311 : expression musicale, lyrique et chorégraphique;

- rubrique 312 : arts plastiques et autres activités artistiques;

- rubrique 313 : théâtres ;

- rubrique 314 : cinémas et autres salles de spectacle.

B - La « conservation et diffusion des patrimoines » correspond aux actions d'entretien, de protection et d'ouverture au public du patrimoine culturel au sens large (monuments, archives, bibliothèques, musées) :

- rubrique 321 : bibliothèques et médiathèques;

- rubrique 322 : musées;

- rubrique 323 : archives;

- rubrique 324 : entretien du patrimoine culturel.

C - « L'action culturelle» (rubrique 33) comprend les activités d'animation culturelle dans lesquelles la production ou l'enseignement artistique est secondaire et qui sont souvent transversales aux autres secteurs (maison de la culture, centre d'animation culturelle, organisation de festivals...).

Une dixième rubrique permet d'enregistrer les opérations communes à l'ensemble de ces secteurs d'intervention (services communs : rubrique 30$)$.

Par ailleurs, l'enquête vise à retracer les dépenses et les recettes culturelles selon leur nature détaillée.

A - Dépenses de fonctionnement:

- chapitre D011 : charges à caractère général (articles 60, 61, 62 sauf 621,63 sauf 631 et 633 ) ;

- chapitre D012 : charges de personnel (articles 621, 631, 633 et 64);

- articles D60225 et D6065 : achats stockés ou non stockés de livres, disques ;

- chapitre D65 : autres charges d'activité, avec le détail des subventions (D657), dont celles de fonctionnement aux organismes publics (D6573);

- chapitre D66: charges financières ;

- chapitre D67 : charges exceptionnelles.

B - Dépenses d'investissement:

- chapitre D16: emprunts et dettes;

- chapitres D20, D21 et D23 : dépenses d'équipement, dont D216 : collections d'œuvres d'art et D204 : subventions d'équipement versées.

C - Recettes de fonctionnement:

- chapitre R70 : produits des services, du domaine et ventes diverses ;

- chapitre R74 : dotations, subventions et participations;

- chapitre R75 : autres produits d'activité;

- chapitre R76 : produits financiers ;

- chapitre R77 : produits exceptionnels.

D - Recettes d'investissement :

- chapitre R13 : subventions d'investissement reçues (par type de collectivités territoriales);

- chapitre R16 : emprunts et dettes.

L'estimation des montants au niveau national est faite à partir des réponses des communes répondantes et des traitements opérés pour les réponses manquantes de quelques communes de l'échantillon, et pour redresser certaines réponses ou nonréponses, concernant par exemple les déclarations de dépenses culturelles affectées à tort dans une fonction non culturelle ou les dépenses regroupées abusivement dans certaines catégories générales. Ces traitements se font par strate de communes, regroupées selon leur taille et leur nature (ville centre, isolée, périphérique, etc.). Les communes des Dom sont traitées séparément de celles de la métropole.

Une fois les traitements appliqués aux réponses des communes, une extrapolation est faite pour obtenir le montant national, en fonction du taux de sondage de chacune des six strates de communes, par nature des dépenses et recettes et par fonction culturelle. Par rapport aux comptes administratifs, les estimations redressent légèrement à la hausse les dépenses de fonctionnement $(+3,8 \%)$ et légèrement à la baisse celles d'investissement $(-1,8 \%)$.

\section{Les groupements de communes}

Les groupements de communes sont la traduction de la coopération intercommunale par laquelle des communes « s'associent » pour la mise en œuvre conjointe de services publics locaux ou, plus largement, de politiques territoriales. Pour cela, la structure juridique utilisée est l'établissement public de coopération intercommunale (EPCI), dont il existe différents types, auxquels des communes se rattachent et qu'elles dotent de compétences et de moyens pour la mise en œuvre de ces politiques: communauté urbaine (CU), communauté d'agglomération ( $\mathrm{CA}$ ), communauté de communes (CC) et syndicat d'agglomération nouvelle (SAN). Permettant les économies d'échelle et la mutualisation de coûts, d'équipements ou de services, la plupart des EPCI se voient dotés de ressources dites propres, c'est-à-dire qu'ils bénéficient directement de certains produits de la fiscalité locale et pas exclusivement de dotations (contributions) des communes membres. Dans ce cas, les EPCI sont qualifiés d'EPCI à fiscalité propre. 
Au $1^{\mathrm{er}}$ janvier 2010, la Direction générale des collectivités locales comptait $2611 \mathrm{EPCl}$ à fiscalité propre, répartis en 16 communautés urbaines, 181 communautés d'agglomération, 5 syndicats d'agglomération nouvelle et 2409 communautés de communes. Seule une partie de ces groupements sont effectivement compétents dans le domaine culturel. La compétence " culture " (développement et aménagement culturels, gestion des équipements culturels) a pu être repérée à partir de la base de données "Banatic " (BAse NATionale d'informations sur l'InterCommunalité en France) du ministère de l'Intérieur, pour les groupements dont la culture n'est pas une compétence obligatoire : CA, CC et SAN. Parmi ces groupements, seuls ceux qui comportaient au moins une commune membre de plus de 10000 habitants ont été enquêtés, en cohérence avec le champ des communes enquêtées. La compétence juridique n'entraîne pas nécessairement une intervention dans le domaine concerné : seuls les $\mathrm{EPCl}$ « actifs » vont effectivement engager des dépenses dans le domaine de compétence en question. En 2010, $245 \mathrm{EPCl}$, composés de 13 communautés urbaines (CU), 127 communautés d'agglomération (CA), 3 syndicats d'agglomération nouvelle (SAN) et 102 communautés de communes (CC), ont effectivement engagé des dépenses au titre de la culture. Ces 245 EPCI regroupaient 4368 communes (y compris de moins de 10000 habitants) et 24465259 habitants en 2010, soit 38 \% de la population française (tableau).

Les données de base de l'analyse ont été extraites de la fonction 3 des comptes administratifs de ces 245 groupements de communes, fonction qui enregistre les dépenses et les recettes culturelles. Dans certains cas, le niveau de détail des comptes n'ayant pas permis d'identifier l'ensemble des informations souhaitées, les données des comptes administratifs ont pu être complétées à partir de celles des comptes de gestion. Suite au traitement des comptes, les EPCI ont été sollicités par questionnaire afin de compléter les données d'éventuelles opérations qui n'auraient pas été enregistrées dans la fonction appropriée ou pour ventiler plus finement les données entre les différentes sous-fonctions de la fonction 3 . Sur les 245 enquêtés, 132 groupements ont répondu au questionnaire. Des traitements du même type que pour les communes ont ensuite permis de redresser les nonréponses. Le travail ainsi réalisé a permis d'ajuster les dépenses culturelles enregistrées dans les comptes administratifs de $+0,5 \%$ en fonctionnement et de $-0,8 \%$ en investissement. De manière plus évidente encore que pour les autres niveaux de collectivités, outre le repérage des groupements du champ, actifs en matière culturelle, l'apport de l'enquête est donc surtout visible dans l'analyse des sommes détaillées par secteurs d'intervention (avec le même niveau de détail que pour les communes, la nomenclature utilisée étant identique) ou par nature des dépenses et des recettes.

Certains groupements non compétents pour la culture peuvent quand même engager des dépenses culturelles pour des actions qui sont à la frontière de leurs autres domaines d'intervention (volet culturel dans un plan de développement touristique par exemple). La limitation de l'étude aux EPCI de villes de plus de 10000 habitants compétents dans le domaine culturel ne prend donc pas en compte ces dépenses.

\section{Tableau - Les établissements publics de coopération intercommunale (EPCI) de métropole et d'outre-mer au $1^{\text {er }}$ janvier 2010}

\begin{tabular}{|c|c|c|c|c|c|c|}
\hline EPCI (à fiscalité propre) & $\begin{array}{c}\text { Nombre } \\
\text { d'EPCI }\end{array}$ & $\begin{array}{c}\text { dont } \\
\text { comportant } \\
\text { au moins une } \\
\text { commune de } \\
+ \text { de } 10000 \text { hab. }\end{array}$ & $\begin{array}{l}\text { dont } \\
\text { dotés de la } \\
\text { compétence } \\
\text { culturelle }\end{array}$ & $\begin{array}{c}\text { dont } \\
\text { effectivement } \\
\text { actifs en } \\
\text { matière culturelle }\end{array}$ & $\begin{array}{c}\text { Nombre } \\
\text { de } \\
\text { communes }\end{array}$ & $\begin{array}{c}\text { Population } \\
\text { (millions) }\end{array}$ \\
\hline Communautés de communes (cc) & 2409 & 217 & 129 & 102 & 1603 & 3,4 \\
\hline Communautés d'agglomération (CA) & 181 & 181 & 148 & 127 & 2399 & 15,6 \\
\hline Communautés urbaines (CU) & 16 & 16 & 16 & 13 & 346 & 5,2 \\
\hline Syndicats d'agglomération nouvelle (SAN) & 5 & 3 & 3 & 3 & 20 & 0,3 \\
\hline Total & 2611 & 417 & 297 & 245 & 4368 & 24,5 \\
\hline
\end{tabular}

En 2010, les reversements de fiscalité ont été identifiés, et ont pu être déduits des dépenses globales, en vue de calculer l'effort culturel budgétaire. Ce n'était pas le cas en 2006. Les dépenses totales utilisées pour calculer l'effort budgétaire étaient donc plus élevées en 2006 et l'effort budgétaire a priori plus faible qu'en 2010. Ces reversements de fiscalité sont des attributions de compensation et des dotations de solidarité communautaire : les groupements à fiscalité professionnelle unique reversent, en règle générale, une partie de la fiscalité économique qu'ils perçoivent à leurs communes membres, via l'attribution de compensation et la dotation de solidarité communautaire. On ne peut donc pas directement comparer l'effort culturel tel qu'il est correctement calculé en 2010 et celui publié en 2006. À titre indicatif donc, l'effort culturel en fonctionnement calculé, au numérateur et au dénominateur, sur les dépenses de personnel, les charges à caractère général et les autres charges de gestion courante, est resté stable : il est passé de 9,3\% en 2006 à $9 \%$ en 2010.

\section{Les départements}

Les données de base ont été extraites des comptes administratifs des 100 départements de métropole et d'outre-mer en 2010 (donc hors Mayotte), et particulièrement de la sous-fonction 31 qui enregistre les opérations liées à la culture. Interrogés par questionnaire, les départements ont, dans un second temps, validé et complété ces données en identifiant les dépenses et les 
recettes culturelles qui ne figuraient pas dans la sous-fonction 31 des comptes. Seulement 77 départements de métropole et d'outre-mer ont répondu au questionnaire. Les non-réponses totales (des 23 départements) ou partielles (à l'intérieur des questionnaires des 77 départements répondants) et les réponses visiblement insuffisantes ont ensuite été traitées par des méthodes similaires à celles utilisées pour les communes. L'estimation des dépenses des départements est alors réalisée. Les traitements statistiques ont conduit à la prise en compte d'un volume de dépenses représentant $37,6 \%$ des dépenses culturelles de fonctionnement et $9,6 \%$ en investissement. Ces redressements étaient d'ampleur comparable en 2006 : respectivement $37,9 \%$ et $4,1 \%$.

Le détail de la nature des dépenses et des recettes (fonctionnement, investissement) est semblable à celui des communes. En revanche, la ventilation par secteur d'intervention est moins détaillée. À partir de la nomenclature M52 appliquée par les départements, on distingue deux grandes fonctions, dont une seule est détaillée par secteur, et comme pour les communes une troisième rubrique, transversale :

A - Activités artistiques et action culturelle.

B - Conservation et diffusion des patrimoines :

- patrimoine;

- bibliothèques et médiathèques ;

- musées;

- archives.

C - Autres.

Dans le domaine culturel, les départements ont la charge particulière des bibliothèques départementales de prêt et des archives départementales, ils se sont vus confier la conservation du patrimoine rural non protégé par la loi Libertés et responsabilités locales du 13 août 2004. L'importance financière de ce transfert pour les départements de métropole est cependant assez limitée, puisque l'État consacrait 5,1 millions d'euros à ce titre avant 2005. La même loi permettait, à défaut des régions, aux départements qui le souhaitaient d'engager une expérimentation, pour quatre ans, concernant la gestion des crédits d'entretien et de restauration du patrimoine classé ou inscrit, n'appartenant pas à l'État ou à ses établissements publics. Le conseil général du Lot a été la seule collectivité départementale en France à expérimenter la gestion déléguée de ces crédits : la convention d'expérimentation (2007-2010) a arrêté la contribution annuelle de l'État (Drac) à 550000 euros et celle du département à 300000 euros. De même, depuis 2004 toujours, les départements peuvent aussi, s'ils en font la demande et comme pour toute collectivité territoriale ou groupement, se voir transférer la propriété de monuments classés ou inscrits, et des objets qu'ils renferment, appartenant à l'État ou au Centre des monuments nationaux et figurant sur une liste établie par décret en Conseil d'État. Sur les 176 monuments et sites transférables, le transfert de 65 monuments a été engagé. Sur les 65 monuments, 16 transferts ont été effectués au bénéfice des départements (43 à celui des communes et 6 à celui des régions).

\section{Les régions}

L'ensemble des vingt-six régions de métropole et d'outre-mer a été interrogé, en vue de valider ou de compléter les données des comptes administratifs. Vingt et une régions ont répondu au questionnaire. Les traitements statistiques des non-réponses ou des réponses partielles ou erronées ont ensuite conduit à redresser à la hausse les dépenses de fonctionnement de 2,4\%, et de $2,9 \%$ les dépenses d'investissement par rapport aux comptes administratifs.

Le chiffrage de certaines dépenses continue cependant de buter sur certains obstacles. Ainsi, la grande majorité des régions n'est pas en mesure d'identifier avec précision les dépenses relatives au personnel régional intervenant dans le domaine culturel. Une telle identification nécessiterait en effet souvent un travail trop important du service ressources humaines des régions afin de connaître la masse salariale des agents intervenant dans le champ culturel. Parmi les 22 régions de métropole, l'identification de ces dépenses a été possible pour 10 régions, soit 8 de plus qu'en 2006 , ces charges totalisant $5 \%$ de leurs dépenses culturelles totales et $6 \%$ des seules dépenses de fonctionnement. Ces éléments ne permettent cependant pas d'envisager une estimation des dépenses de personnel pour les régions n'ayant pas pu réaliser ce travail d'identification.

À partir de la nomenclature M71 appliquée aux régions, le détail par fonction culturelle est différent de celui des départements comme des communes:

A - Activités artistiques et action culturelle

- enseignement artistique ;

- activités culturelles et artistiques.

$B$ - Patrimoine.

C-Autres.

Dans le domaine culturel, les régions ont une responsabilité en matière de développement culturel et se sont vues transférer l'inventaire général du patrimoine culturel par la loi Libertés et responsabilités locales du 13 août 2004. L'importance financière de ce transfert, réalisé en 2005 et 2006, effectif en 2007 en matière de personnel, est cependant assez limitée, les régions ayant reçu 2,2 millions d'euros en 2006. Concernant le volet enseignement artistique de la loi du 13 août 2004, aucun transfert de crédit n'est intervenu jusqu'à l'année enquêtée. 
Tableau A - Dépenses et recettes culturelles redressées et extrapolées

à l'ensemble des communes de plus de 10000 habitants, 2010 (France entière*)

\begin{tabular}{|c|c|c|c|c|c|c|c|c|c|c|c|}
\hline Fonction & $\begin{array}{c}30 \\
\text { Services } \\
\text { communs }\end{array}$ & $\begin{array}{c}311 \\
\text { Expression } \\
\text { musicale, } \\
\text { lyrique et } \\
\text { chorégraphique }\end{array}$ & $\begin{array}{l}312 \\
\text { Arts } \\
\text { plastiques } \\
\text { et autres } \\
\text { activités } \\
\text { artistiques }\end{array}$ & $\begin{array}{c}313 \\
\text { Théâtres }\end{array}$ & $\begin{array}{c}314 \\
\text { Cinémas } \\
\text { et autres } \\
\text { salles } \\
\text { de } \\
\text { spectacle }\end{array}$ & $\begin{array}{c}321 \\
\text { Bibliothèques } \\
\text { et } \\
\text { médiathèques }\end{array}$ & $\begin{array}{c}322 \\
\text { Musées }\end{array}$ & $\begin{array}{c}323 \\
\text { Archives }\end{array}$ & $\begin{array}{c}324 \\
\text { Entretien } \\
d u \\
\text { patrimoine } \\
\text { culturel }\end{array}$ & $\begin{array}{c}33 \\
\text { Action } \\
\text { culturelle }\end{array}$ & Total \\
\hline Dépenses totales & 158285 & 840787 & 203986 & 491829 & 171969 & 871050 & 515769 & 83158 & 239796 & 1133820 & 4710448 \\
\hline Dépenses de fonctionnement & 132340 & 788243 & 177852 & 369487 & 138842 & 759320 & 376801 & 67805 & 63343 & 903882 & 3777914 \\
\hline $\begin{array}{l}\text { Charges à caractère général } \\
\text { dont achat de livres, disques }\end{array}$ & $\begin{array}{r}29454 \\
6\end{array}$ & $\begin{array}{r}55028 \\
316\end{array}$ & $\begin{array}{r}16114 \\
52\end{array}$ & $\begin{array}{r}64850 \\
0\end{array}$ & $\begin{array}{r}52382 \\
1\end{array}$ & $\begin{array}{r}145491 \\
55741\end{array}$ & $\begin{array}{r}86902 \\
927\end{array}$ & $\begin{array}{r}6546 \\
28\end{array}$ & $\begin{array}{r}27460 \\
1113\end{array}$ & $\begin{array}{r}277860 \\
141\end{array}$ & $\begin{array}{r}762085 \\
58325\end{array}$ \\
\hline Charges de personnel & 73645 & 539284 & 115825 & 85379 & 48991 & 609411 & 260566 & 59823 & 26149 & 236482 & 2055554 \\
\hline $\begin{array}{l}\text { Autres charges d'activité } \\
\text { dont subventions de fonctionnement }\end{array}$ & 24832 & 180708 & 42424 & 212187 & 27581 & 2309 & 22793 & 1113 & 7886 & 351321 & 873154 \\
\hline aux organismes publics & 182 & 47432 & 1355 & 59121 & 3290 & 0 & 339 & 30 & 78 & 37690 & 149518 \\
\hline dont versées aux régions & 0 & 0 & 0 & 0 & 0 & 0 & 0 & 0 & 0 & 0 & 0 \\
\hline dont versées aux départements & 0 & 0 & 0 & 0 & 0 & 0 & 0 & 0 & 0 & 16 & 16 \\
\hline $\begin{array}{l}\text { dont versées aux communes et EPCI } \\
\text { dont subventions de fonctionnement }\end{array}$ & 8 & 7235 & 106 & 25472 & 0 & 0 & 0 & 0 & 0 & 92 & 32913 \\
\hline aux organismes de droit privé & 16964 & 87071 & 42205 & 133797 & 21558 & 1839 & 13213 & 1068 & 7625 & 307271 & 632610 \\
\hline Charges financières & 0 & 0 & 0 & 0 & 0 & 23 & 4 & 0 & 1 & 5 & 34 \\
\hline Charges exceptionnelles & 4355 & 12902 & 3467 & 7043 & 9886 & 1583 & 5869 & 6 & 1856 & 38211 & 85179 \\
\hline Dépenses d'investissement & 25945 & 52544 & 26134 & 122342 & 33127 & 111730 & 138968 & 15353 & 176452 & 229939 & 932535 \\
\hline Emprunts et dettes & 0 & 76 & 0 & 0 & 2 & 237 & 0 & 0 & 160 & 2 & 477 \\
\hline $\begin{array}{l}\text { Dépenses d'équipement } \\
\text { dont collections et ceuvres d'art }\end{array}$ & $\begin{array}{r}19696 \\
2015\end{array}$ & $\begin{array}{r}50953 \\
1\end{array}$ & $\begin{array}{r}25186 \\
391\end{array}$ & $\begin{array}{r}119665 \\
56\end{array}$ & $\begin{array}{r}28710 \\
90\end{array}$ & $\begin{array}{r}111256 \\
4723\end{array}$ & $\begin{array}{r}132506 \\
12327\end{array}$ & $\begin{array}{r}15353 \\
478\end{array}$ & $\begin{array}{r}172299 \\
2039\end{array}$ & $\begin{array}{r}212573 \\
1085\end{array}$ & $\begin{array}{r}888197 \\
23204\end{array}$ \\
\hline $\begin{array}{l}\text { Total subventions versées } \\
\text { dont versées }\end{array}$ & 3801 & 1494 & 949 & 2670 & 3049 & 211 & 6162 & 0 & 3981 & 9393 & 31710 \\
\hline $\begin{array}{l}\text { aux régions } \\
\text { dont versées }\end{array}$ & 0 & 0 & 225 & 0 & 1025 & 0 & 0 & 0 & 0 & 1115 & 2365 \\
\hline $\begin{array}{l}\text { aux départements } \\
\text { dont versées }\end{array}$ & 0 & 0 & 0 & 0 & 0 & 0 & 0 & 0 & 0 & 0 & 0 \\
\hline $\begin{array}{l}\text { aux communes et EPCI } \\
\text { dont versées }\end{array}$ & 3391 & 800 & 0 & 0 & 444 & 211 & 0 & 0 & 0 & 0 & 4846 \\
\hline aux personnes de droit privé & 322 & 518 & 724 & 2558 & 1416 & 0 & 242 & 0 & 3477 & 6553 & 15809 \\
\hline Recettes totales & 14117 & 135347 & 26461 & 66734 & 33096 & 70159 & 63667 & 5630 & 74345 & 174619 & 664174 \\
\hline Recettes de fonctionnement & 13412 & 127497 & 23504 & 46543 & 28257 & 27029 & 40782 & 1443 & 11916 & 96914 & 417299 \\
\hline $\begin{array}{l}\text { Produits des services du domaine, } \\
\text { ventes diverses }\end{array}$ & 2931 & 81856 & 12577 & 22178 & 16564 & 15669 & 25643 & 1139 & 5200 & 32557 & 216314 \\
\hline Dotations, subventions et participations & 6197 & 39158 & 6806 & 9218 & 1945 & 8777 & 10810 & 207 & 2483 & 28138 & 113738 \\
\hline Régions & 249 & 3843 & 266 & 1074 & 103 & 124 & 1159 & 8 & 341 & 3028 & 10196 \\
\hline Départements & 2317 & 13450 & 600 & 1966 & 768 & 2436 & 3041 & 40 & 162 & 5609 & 30389 \\
\hline Communes et EPCl & 1888 & 3149 & 96 & 1366 & 0 & 3120 & 1262 & 0 & 0 & 5444 & 16326 \\
\hline Autres produits d'activités & 1741 & 4958 & 2212 & 9293 & 7442 & 752 & 2493 & 27 & 1411 & 13702 & 44031 \\
\hline Produits financiers & 0 & 0 & 0 & 0 & 13 & 0 & 57 & 0 & 80 & 45 & 195 \\
\hline Produits exceptionnels & 16 & 402 & 1243 & 5306 & 408 & 982 & 966 & 0 & 2380 & 18572 & 30276 \\
\hline Recettes d'investissement & 705 & 7849 & 2957 & 20191 & 4838 & 43130 & 22885 & 4187 & 62429 & 77705 & 246875 \\
\hline Emprunts et dettes & 17 & 83 & 0 & 0 & 2 & 1 & 421 & 0 & 320 & 4 & 848 \\
\hline Subventions d'investissement & 653 & 7725 & 2957 & 19881 & 4727 & 41234 & 21852 & 4187 & 59493 & 67962 & 230671 \\
\hline dont reçues des régions & 11 & 3469 & 784 & 1994 & 2312 & 5986 & 8420 & 2119 & 8074 & 19248 & 52417 \\
\hline dont reçues des départements & 57 & 1097 & 806 & 6262 & 1603 & 2806 & 1484 & 114 & 15230 & 5930 & 35388 \\
\hline dont reçues des communes et EPCI & 226 & 8 & 0 & 4560 & 19 & 163 & 864 & 79 & 911 & 716 & 7545 \\
\hline
\end{tabular}

* Le tableau relatif à la France métropolitaine est disponible à l'adresse www.culturecommunication.gouv.fr/Etudes-et-statistiques/Lespublications 
Tableau B - Dépenses et recettes culturelles des groupements de communes (EPCI à fiscalité propre comportant au moins une commune de plus de 10000 habitants, compétents et actifs dans le domaine culturel), 2010 (France entière*)

\begin{tabular}{|c|c|c|c|c|c|c|c|c|c|c|c|}
\hline Fonction & $\begin{array}{c}30 \\
\text { Services } \\
\text { communs }\end{array}$ & $\begin{array}{c}311 \\
\text { Expression } \\
\text { musicale, } \\
\text { lyrique et } \\
\text { chorégraphique }\end{array}$ & $\begin{array}{c}312 \\
\text { Arts } \\
\text { plastiques } \\
\text { et autres } \\
\text { activités } \\
\text { artistiques }\end{array}$ & $\begin{array}{c}313 \\
\text { Théâtres }\end{array}$ & $\begin{array}{c}314 \\
\text { Cinémas } \\
\text { et autres } \\
\text { salles } \\
\text { de } \\
\text { spectacle }\end{array}$ & $\begin{array}{c}321 \\
\text { Bibliothèques } \\
\text { et } \\
\text { médiathèques }\end{array}$ & $\begin{array}{c}322 \\
\text { Musées }\end{array}$ & $\begin{array}{c}323 \\
\text { Archives }\end{array}$ & $\begin{array}{c}324 \\
\text { Entretien } \\
\text { du } \\
\text { patrimoine } \\
\text { culturel }\end{array}$ & $\begin{array}{c}33 \\
\text { Action } \\
\text { culturelle }\end{array}$ & Total \\
\hline Dépenses totales & 22619 & 308803 & 44934 & 93890 & 57459 & 245975 & 130534 & 6548 & 21059 & 134176 & 1065997 \\
\hline Dépenses de fonctionnement & 17627 & 260521 & 38804 & 64050 & 25645 & 176507 & 60963 & 3604 & 7874 & 104389 & 759983 \\
\hline $\begin{array}{l}\text { Charges à caractère général } \\
\text { dont achat de livres, disques }\end{array}$ & $\begin{array}{r}2047 \\
40\end{array}$ & $\begin{array}{r}27751 \\
219\end{array}$ & $\begin{array}{r}5922 \\
60\end{array}$ & $\begin{array}{r}9486 \\
0\end{array}$ & $\begin{array}{r}5573 \\
1\end{array}$ & $\begin{array}{l}42800 \\
12557\end{array}$ & $\begin{array}{r}18590 \\
82\end{array}$ & $\begin{array}{r}504 \\
4\end{array}$ & $\begin{array}{r}3205 \\
3\end{array}$ & $\begin{array}{r}24929 \\
42\end{array}$ & $\begin{array}{r}140806 \\
13007\end{array}$ \\
\hline Charges de personnel & 10649 & 208881 & 21880 & 13086 & 3499 & 129750 & 26765 & 3025 & 3590 & 25919 & 447045 \\
\hline $\begin{array}{l}\text { Autres charges d'activité } \\
\text { dont subventions de fonctionnement }\end{array}$ & 4932 & 19160 & 10781 & 41384 & 15996 & 3070 & 15361 & 75 & 1015 & 51988 & 163762 \\
\hline aux organismes publics & 1450 & 9897 & 20 & 10948 & 2971 & 1449 & 4825 & 0 & 187 & 10155 & 41901 \\
\hline dont versées aux régions & 0 & 0 & 0 & 0 & 0 & 0 & 0 & 0 & 0 & 0 & 0 \\
\hline dont versées aux départements & 0 & 0 & 0 & 0 & 0 & 0 & 0 & 0 & 0 & 0 & 0 \\
\hline $\begin{array}{l}\text { dont versées aux communes et EPCl } \\
\text { dont subventions de fonctionnement }\end{array}$ & 474 & 6077 & 3 & 446 & 25 & 1438 & 200 & 0 & 5 & 2610 & 11278 \\
\hline aux organismes de droit privé & 2221 & 8291 & 3699 & 28424 & 11832 & 263 & 9216 & 75 & 829 & 40468 & 105318 \\
\hline Charges financières & 0 & 144 & 0 & 4 & 72 & 616 & 45 & 0 & 0 & 10 & 890 \\
\hline Charges exceptionnelles & 0 & 4508 & 195 & 23 & 504 & 175 & 199 & 0 & 6 & 1542 & 7152 \\
\hline Dépenses d'investissement & 4992 & 48282 & 6130 & 29840 & 31814 & 69468 & 69571 & 2944 & 13185 & 29787 & 306013 \\
\hline Emprunts et dettes & 0 & 479 & 6 & 1 & 41 & 1220 & 16 & 0 & 2 & 5 & 1771 \\
\hline $\begin{array}{l}\text { Dépenses d'équipement } \\
\text { dont collections et ceuvres d'art }\end{array}$ & $\begin{array}{r}4983 \\
0\end{array}$ & $\begin{array}{r}45611 \\
5\end{array}$ & $\begin{array}{r}5958 \\
29\end{array}$ & $\begin{array}{r}28755 \\
0\end{array}$ & $\begin{array}{r}30698 \\
0\end{array}$ & $\begin{array}{r}67813 \\
1389\end{array}$ & $\begin{array}{r}66510 \\
2340\end{array}$ & $\begin{array}{r}2944 \\
7\end{array}$ & $\begin{array}{r}11077 \\
13\end{array}$ & $\begin{array}{r}27892 \\
98\end{array}$ & $\begin{array}{r}292240 \\
3881\end{array}$ \\
\hline $\begin{array}{l}\text { Subventions d'équipement versées } \\
\text { dont versées }\end{array}$ & 9 & 72 & 118 & 572 & 976 & 435 & 3042 & 0 & 929 & 1889 & 8043 \\
\hline $\begin{array}{l}\text { aux régions } \\
\text { dont versées }\end{array}$ & 0 & 0 & 0 & 0 & 0 & 0 & 0 & 0 & 0 & 0 & 0 \\
\hline $\begin{array}{l}\text { aux départements } \\
\text { dont versées }\end{array}$ & 0 & 0 & 0 & 0 & 0 & 0 & 0 & 0 & 0 & 0 & 0 \\
\hline $\begin{array}{l}\text { aux communes et EPCl } \\
\text { dont versées }\end{array}$ & 10 & 21 & 0 & 61 & 711 & 435 & 594 & 0 & 945 & 865 & 3641 \\
\hline aux personnes de droit privé & 0 & 28 & 18 & 258 & 158 & 0 & 2448 & 0 & 7 & 824 & 3740 \\
\hline Recettes totales & 3359 & 63172 & 6339 & 18492 & 11398 & 36414 & 42585 & 1128 & 10500 & 16450 & 209836 \\
\hline Recettes de fonctionnement & 1077 & 45263 & 5661 & 4967 & 6120 & 9899 & 7229 & 448 & 1141 & 8372 & 90177 \\
\hline $\begin{array}{l}\text { Produits des services du domaine, } \\
\text { ventes diverses }\end{array}$ & 435 & 25044 & 2098 & 2993 & 1960 & 3925 & 3513 & 429 & 697 & 4621 & 45715 \\
\hline Dotations, subventions et participations & 549 & 18346 & 3043 & 704 & 525 & 3766 & 2262 & 12 & 319 & 2080 & 31604 \\
\hline Régions & 254 & 1386 & 685 & 151 & 18 & 262 & 233 & 0 & 46 & 386 & 3420 \\
\hline Départements & 204 & 7926 & 497 & 187 & 51 & 658 & 280 & 2 & 17 & 521 & 10344 \\
\hline Communes et EPCl & 0 & 532 & 33 & 28 & 148 & 624 & 27 & 0 & 0 & 301 & 1694 \\
\hline Autres produits d'activités & 13 & 558 & 115 & 120 & 3166 & 603 & 456 & 0 & 18 & 867 & 5915 \\
\hline Produits financiers & 0 & 0 & 0 & 643 & 0 & 0 & 0 & 0 & 0 & 0 & 643 \\
\hline Produits exceptionnels & 1 & 185 & 71 & 232 & 243 & 926 & 189 & 0 & 66 & 729 & 2642 \\
\hline Recettes d'investissement & 2282 & 17909 & 678 & 13525 & 5278 & 26514 & 35356 & 680 & 9358 & 8078 & 119659 \\
\hline Emprunts et dettes & 750 & 22 & 11 & 235 & 471 & 4550 & 0 & 0 & 0 & 131 & 6169 \\
\hline $\begin{array}{l}\text { Subventions d'investissement } \\
\text { dont recues des régions }\end{array}$ & $\begin{array}{r}1499 \\
0\end{array}$ & $\begin{array}{r}16407 \\
7778\end{array}$ & $\begin{array}{l}637 \\
261\end{array}$ & $\begin{array}{r}13007 \\
5129\end{array}$ & $\begin{array}{l}3743 \\
1449\end{array}$ & $\begin{array}{r}21256 \\
6431\end{array}$ & $\begin{array}{r}12621 \\
6052\end{array}$ & $\begin{array}{r}680 \\
0\end{array}$ & $\begin{array}{l}8655 \\
3374\end{array}$ & $\begin{array}{l}6938 \\
1212\end{array}$ & $\begin{array}{l}85445 \\
31686\end{array}$ \\
\hline dont reçues des départements & 1348 & 5283 & 0 & 3917 & 82 & 5525 & 3061 & 0 & 2736 & 1455 & 23406 \\
\hline dont reçues des communes et EPCI & 45 & 202 & 0 & 71 & 537 & 3484 & 256 & 0 & 285 & 521 & 5401 \\
\hline
\end{tabular}


Tableau C - Dépenses et recettes culturelles de l'ensemble des départements, 2010 (France entière*)

\begin{tabular}{|c|c|c|c|c|c|c|c|}
\hline \multirow[b]{3}{*}{ Fonction } & & & & & & & \\
\hline & \multirow{2}{*}{$\begin{array}{c}311 \\
\text { Activités } \\
\text { artistiques et } \\
\text { action culturelle }\end{array}$} & \multirow{2}{*}{$\begin{array}{c}312 \\
\text { Patrimoine }\end{array}$} & \multirow{2}{*}{$\begin{array}{c}313 \\
\text { Bibliothèques } \\
\text { et médiathèques }\end{array}$} & \multirow{2}{*}{$\begin{array}{c}314 \\
\text { Musées }\end{array}$} & 315 & \multirow[b]{2}{*}{ Non ventilé } & \multirow[b]{2}{*}{ Total } \\
\hline & & & & & $\begin{array}{c}\text { Services } \\
\text { d'archives }\end{array}$ & & \\
\hline Dépenses totales & 543465 & 265357 & 201615 & 195782 & 179767 & 42433 & 1428420 \\
\hline Dépenses de fonctionnement & 493090 & 108375 & 171958 & 85371 & 126891 & 3381 & 989066 \\
\hline $\begin{array}{l}\text { Charges à caractère général } \\
\text { dont achats stockés }\end{array}$ & 34667 & 24757 & 37022 & 28182 & 24239 & 37 & 148903 \\
\hline $\begin{array}{l}\text { de livres, disques } \\
\text { dont achats non stockés }\end{array}$ & 0 & 0 & 0 & 0 & 0 & 0 & 0 \\
\hline de livres, disques & 114 & 47 & 20623 & 144 & 207 & 0 & 21135 \\
\hline Charges de personnel & 52690 & 49747 & 121182 & 34110 & 101882 & 3339 & 362950 \\
\hline Autres charges d'activité & 401683 & 31674 & 13634 & 20861 & 754 & 0 & 468607 \\
\hline dont subventions versées aux régions & 27 & 88 & 0 & 0 & 0 & 0 & 114 \\
\hline dont subventions versées aux départements & 0 & 0 & 0 & 0 & 0 & 0 & 0 \\
\hline $\begin{array}{l}\text { dont subventions versées aux communes } \\
\text { et structures intercommunales } \\
\text { dont subventions versées }\end{array}$ & 69242 & 3119 & 5266 & 1201 & 77 & 0 & 78905 \\
\hline aux organismes de droit privé & 262885 & 12338 & 7126 & 4418 & 277 & 0 & 287044 \\
\hline Charges financières & 1 & 0 & 0 & 1 & 0 & 0 & 2 \\
\hline Charges exceptionnelles & 4048 & 2197 & 119 & 2216 & 16 & 5 & 8602 \\
\hline Autres dépenses de fonctionnement & 1 & 0 & 0 & 0 & 0 & 0 & 2 \\
\hline Dépenses d'investissement & 50374 & 156982 & 29657 & 110411 & 52876 & 39052 & 439353 \\
\hline Emprunts et dettes & 0 & 0 & 0 & 0 & 0 & 0 & 0 \\
\hline $\begin{array}{l}\text { Dépenses d'équipement } \\
\text { dont collections et cuuvres d'art }\end{array}$ & $\begin{array}{r}8655 \\
271\end{array}$ & $\begin{array}{r}55539 \\
1467\end{array}$ & $\begin{array}{r}14589 \\
1793\end{array}$ & $\begin{array}{r}93054 \\
3872\end{array}$ & $\begin{array}{r}47794 \\
2211\end{array}$ & $\begin{array}{r}39052 \\
0\end{array}$ & $\begin{array}{r}258684 \\
9615\end{array}$ \\
\hline $\begin{array}{l}\text { Subventions d'équipement versées } \\
\text { dont versées }\end{array}$ & 41720 & 98870 & 15067 & 17238 & 1872 & 0 & 174767 \\
\hline $\begin{array}{l}\text { aux régions } \\
\text { dont versées }\end{array}$ & 0 & 228 & 0 & 0 & 0 & 0 & 228 \\
\hline $\begin{array}{l}\text { aux départements } \\
\text { dont versées }\end{array}$ & 23 & 33 & 0 & 375 & 50 & 0 & 481 \\
\hline $\begin{array}{l}\text { aux communes et structures } \\
\text { intercommunales } \\
\text { dont versées }\end{array}$ & 35411 & 78711 & 14880 & 4784 & 1808 & 0 & 135593 \\
\hline aux personnes de droit privé & 5945 & 15213 & 55 & 244 & 10 & 0 & 21468 \\
\hline Autres dépenses d'investissement & 0 & 2574 & 1 & 118 & 3210 & 0 & 5903 \\
\hline Recettes totales & 12416 & 27602 & 1645 & 16831 & 11084 & 0 & 69579 \\
\hline Recettes de fonctionnement & 10341 & 10907 & 1423 & 7388 & 1961 & 0 & 32021 \\
\hline $\begin{array}{l}\text { Produits des services du domaine, } \\
\text { ventes diverses }\end{array}$ & 6044 & 7392 & 229 & 5785 & 603 & 0 & 20052 \\
\hline Dotations, subventions et participations & 2772 & 1583 & 1014 & 782 & 941 & 0 & 7092 \\
\hline Régions & 514 & 610 & 72 & 93 & 103 & 0 & 1391 \\
\hline Départements & 15 & 56 & 0 & 0 & 0 & 0 & 71 \\
\hline Communes et structures & & & & & & & \\
\hline intercommunales & 1047 & 75 & 584 & 79 & 19 & 0 & 1804 \\
\hline Autres produits d'activités & 172 & 1317 & 88 & 352 & 91 & 0 & 2021 \\
\hline Produits financiers & 0 & 0 & 0 & 0 & 0 & 0 & 0 \\
\hline Produits exceptionnels & 459 & 457 & 77 & 266 & 142 & 0 & 1401 \\
\hline Autres recettes de fonctionnement & 1353 & 109 & 16 & 202 & 185 & 0 & 1865 \\
\hline Recettes d'investissement & 2075 & 16695 & 222 & 9443 & 9123 & 0 & 37558 \\
\hline Emprunts et dettes & 0 & 0 & 0 & 1 & 0 & 0 & 1 \\
\hline Subventions d'investissement & 2068 & 14867 & 140 & 5904 & 9099 & 0 & 32078 \\
\hline Régions & 1578 & 4691 & 29 & 3138 & 2053 & 0 & 11489 \\
\hline Départements & 0 & 0 & 0 & 0 & 0 & 0 & 0 \\
\hline Communes et structures intercommunales & 0 & 131 & 0 & 267 & 0 & 0 & 398 \\
\hline Autres recettes d'investissement & 7 & 1828 & 82 & 3539 & 24 & 0 & 5479 \\
\hline
\end{tabular}




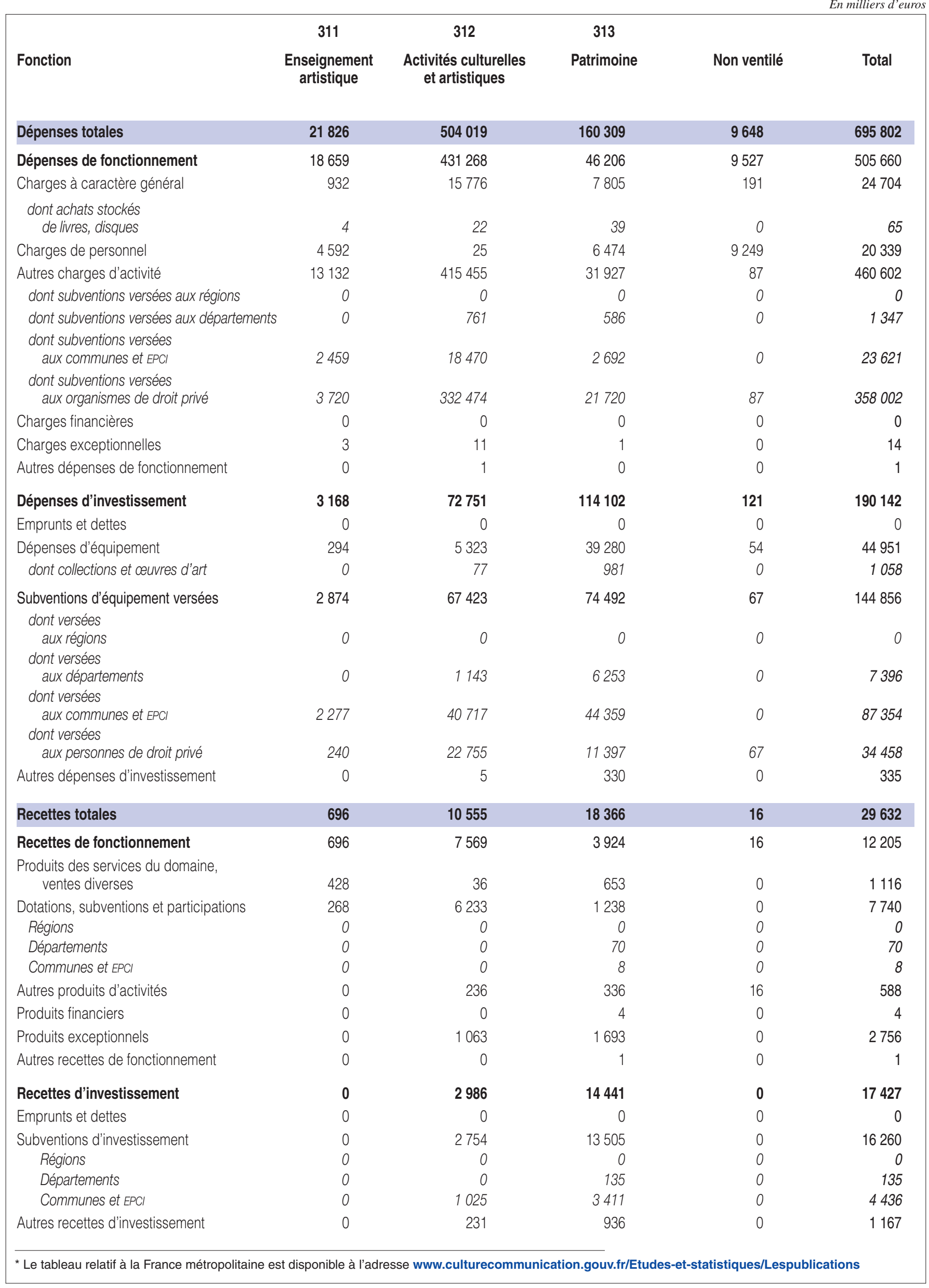




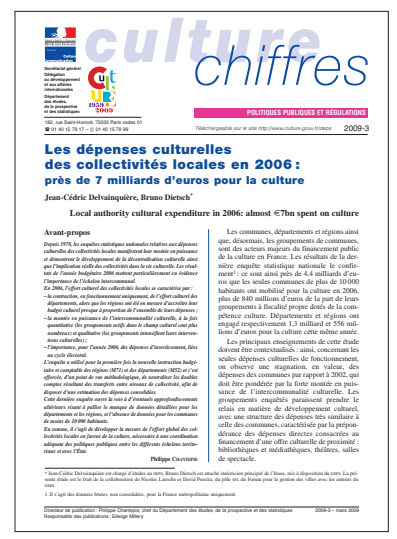

CC-2009-3

\section{Les dépenses culturelles}

des collectivités locales en 2006 : près de 7 milliards d'euros pour la culture

\section{Jean-Cédric Delvainquière, Bruno Dietsch}

Mars 2009, 32 p.

Les résultats de l'enquête sur les dépenses culturelles des collectivités territoriales, dont les données n'avaient pas été actualisées depuis 2002, confirment que les communes, départements et régions ainsi que, désormais, les groupements de communes, sont des acteurs majeurs du financement public de la culture en France. Ce sont ainsi près de 4,4 milliards d'euros que les seules communes de plus de 10000 habitants ont mobilisés pour la culture en 2006, tandis que leurs groupements à fiscalité propre dotés de la compétence culturelle y ont consacré plus de 840 millions d'euros. Départements et régions ont engagé respectivement 1,3 milliard et 556 millions d'euros pour la culture cette même année.

Au-delà des domaines réservés d'intervention découlant de la première vague de transfert de compétences comme la lecture publique pour les départements par exemple, on observe que les communes et groupements de communes consacrent leurs dépenses culturelles de fonctionnement et d'investissement aux équipements de proximité (écoles de musique et de danse, bibliothèques et médiathèques, musées municipaux ou départementaux), tandis que les départements et particulièrement les régions attribuent plus massivement des subventions aux équipements et acteurs culturels.

\section{À paraître en avril 2014 :}

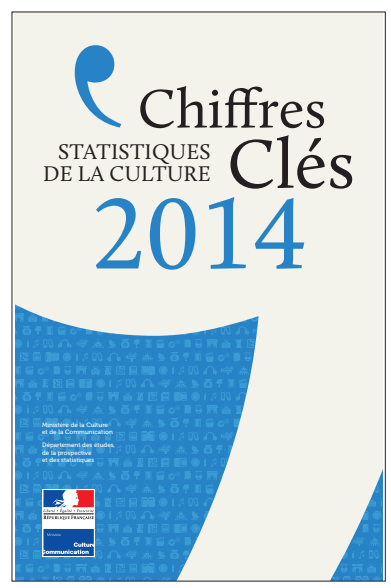

\section{Chiffres Clés}

\section{Statistiques de la Culture 2014}

144 p., $12 €$

ISBN : 978-2-11-128154-7

Diffusion : La documentation française

Décliner la culture en chiffres permet de prendre la mesure de la richesse foisonnante de la création, de l'offre artistique et de la diversité des pratiques artistiques et culturelles en France.

62 millions de visiteurs dans les 1200 musées de France, 2,8 millions de visiteurs dans les 23 fonds régionaux d'art contemporain et les 49 centres d'art contemporain. 14000 monuments classés au titre des monuments historiques, un millier de chantiers de fouilles archéologiques en 2012, ou encore plus de 2 millions de documents communiqués dans les services d'archives communaux, départementaux, régionaux et nationaux.

Plus de 1000 représentations lyriques qui attirent plus d'1,4 million de spectateurs par saison. Cinq théâtres nationaux, 70 scènes nationales, 17 zéniths, 39 centres dramatiques nationaux, plus d'une centaine de scènes conventionnées et plusieurs centaines de scènes et lieux de diffusion du spectacle privés... et des milliers de festivals chaque année en France.

Plus de 2000 cinémas, près de 16000 lieux de lecture publique et 500 conservatoires de musique et de danse où enfants et adultes peuvent se former à la musique, à la danse et au théâtre.

La France est riche d'une offre culturelle multiple et variée.

Chiffres clés 2014 en propose une approche objective et constitue ainsi un outil essentiel à la connaissance du champ culturel. 


\section{ABSTRACT}

In 2010, local and regional expenditure (regions, départements, municipalities with populations over 10,000 and their local authority associations, including French overseas territories) rose to $€ 7.6 \mathrm{bn}$, i.e. $€ 118$ per head of population. The municipalities and their associations of local authorities are responsible for three quarters (73\%) of this expenditure (€4.6bn and $€ 1$ bn respectively), départements $18 \%$ (i.e. $€ 1.4$ billion) and the regions $9 \%$ ( $€ 0.7$ billion). This expenditure represents on average a higher proportion of the total expenditure of the municipalities and their associations of local authorities (8\% and $7 \%$ ) than that for the regions $(2.7 \%)$ and départements $(2.1 \%)$.

Compared with 2006 (the date the last survey was published), territorial cultural expenditure has increased by almost $10 \%$, i.e. an annual increase of $2.3 \%$ in mainland France. More or less keeping pace with inflation (+1.4\% per annum), the volume of the municipalities'cultural expenditure has remained fairly static, whereas the number of associations of local authorities active in the cultural sphere has increased and their cultural expenditure has increased by $6 \%$ per annum. Cultural expenditure for the départements and the regions has continued slightly above inflation for the départements ( $+1.8 \%$ per annum) and more significantly so for the regions $(+4.5 \%$ per annum) which is mostly down to strong growth at the start of the period. The drive to promote culture within départements and regions then diminished due to a strong increase in total expenditure, linked to transfers of competency.

Support for artistic expression and cultural activities accounts for around $60 \%$ of the expenditure of the municipalities and their associations of local authorities ( $€ 4.32 \mathrm{bn})$, largely accounted for by running costs (85\%). Départements and regions have increasingly invested in cultural heritage, which represented 59\% of the départements'cultural expenditure and $23 \%$ of regional expenditure in 2010.

More involved in the often direct management of local cultural services and facilities (libraries, conservatoires and art schools, museums, etc.), municipalities and their local authority associations saw over half of their cultural running costs go on wages, to the tune of almost $€ 2.5 \mathrm{bn}$. However it is cultural subsidies for running costs which have seen the greatest increase (+ 5\% per annum for mainland municipalities between 2006 and 2010), which particularly benefited theatres and the visual arts.

Conversely, subsidies represent over $80 \%$ of regional cultural expenditure. They are supporting the running costs of beneficiaries in the private sector, (mostly non-profit organisations), as well as cultural promotion in the municipalities and their local authority associations.

\section{Tous les documents publiés par le DEPS sont téléchargeables sur http://www.culturecommunication.gouv.fr/Etudes-et-statistiques et sur http://www.cairn.info}

Le DEPS n'assurant pas de diffusion physique de ses collections, nous vous proposons de vous informer régulièrement des parutions par message électronique. Pour ce faire, merci de bien vouloir nous communiquer votre courriel à l'adresse contact.deps@culture.gouv.fr 